\title{
The effects of regulatory and financial policy instruments on innovative behavior. Experimental evidence
}

\author{
Dissertation \\ zur Erlangung des Doktorgrades \\ der Wirtschaftswissenschaftlichen Fakultät \\ der Georg-August-Universität Göttingen
}

vorgelegt von

Julia Brüggemann

geboren in Georgsmarienhütte

Göttingen, 2016 
Erstgutachter:

Zweitgutachter:

Weiteres Mitglied der Prüfungskommission:
Prof. Dr. Kilian Bizer

Prof. Dr. Markus Spiwoks

Prof. Dr. Margarete Boos 


\section{Contents}

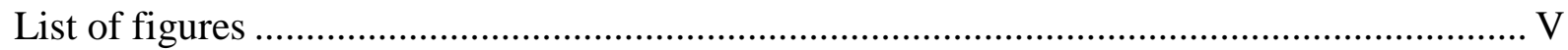

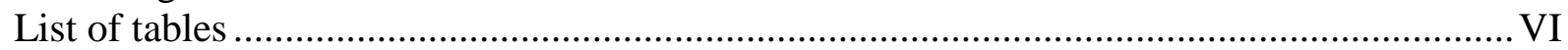

1. Introduction $\quad 1$

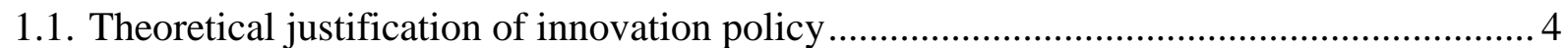

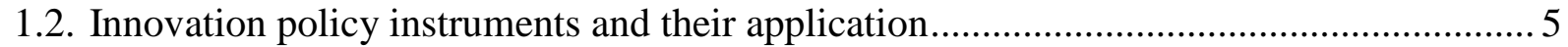

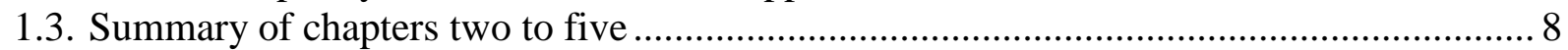

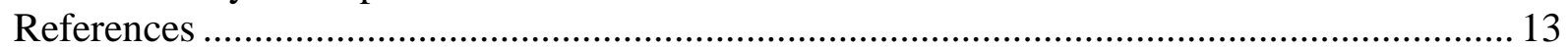

2. Intellectual property rights hinder sequential innovation 15

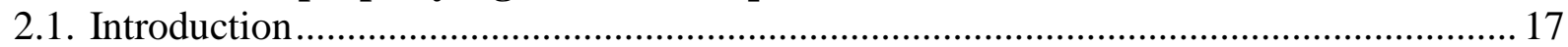

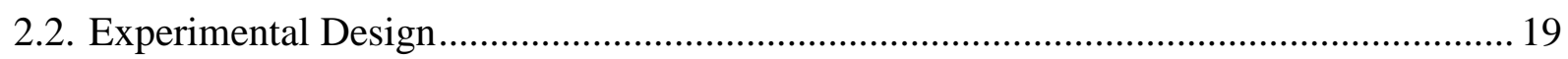

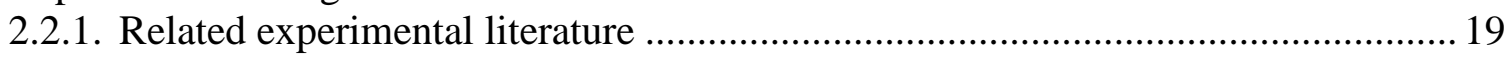

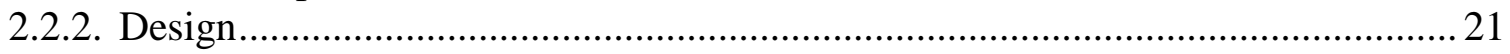

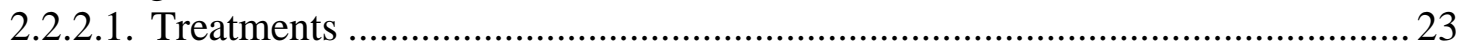

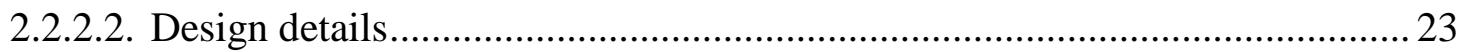

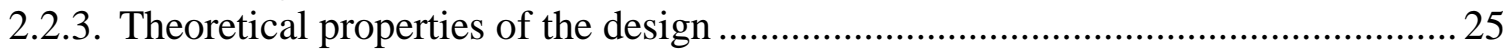

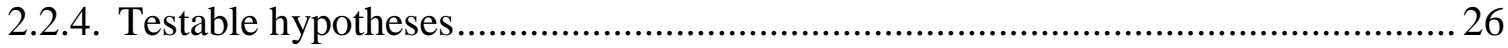

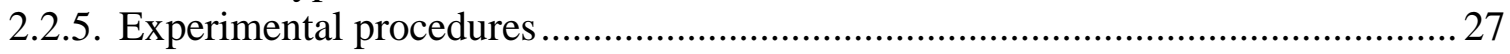

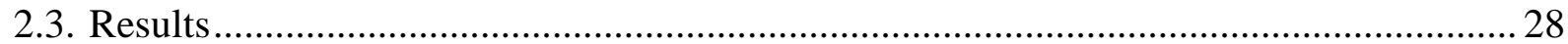

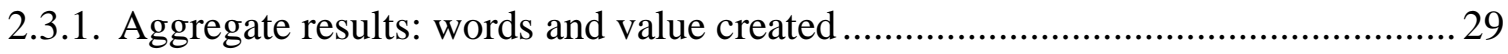

2.3.1.1. The effect of intellectual property rights ..................................................... 29

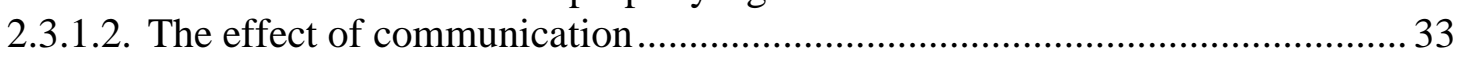

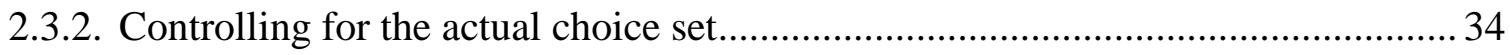

2.3.3. Results and behavior determinants at the individual and group level .................... 37

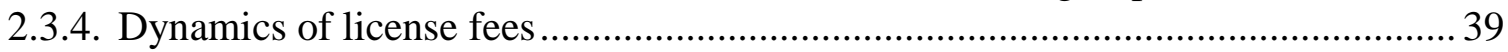

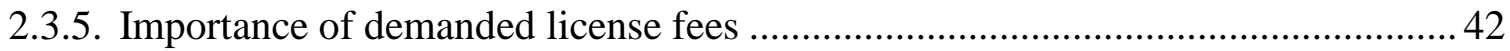

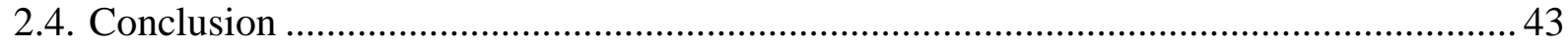

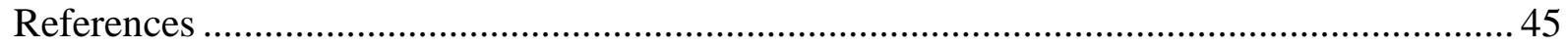

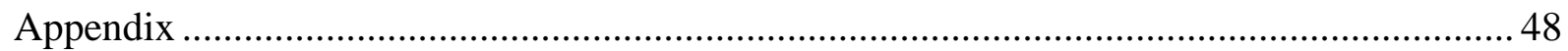

3. Experimental evidence on the effects of innovation contests 54

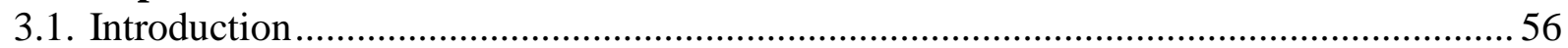

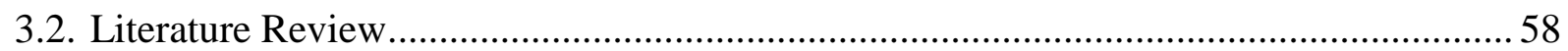

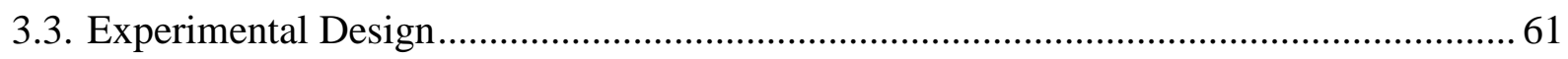

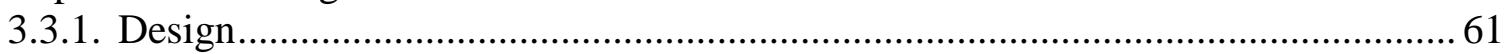

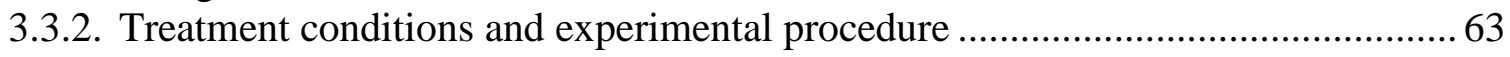

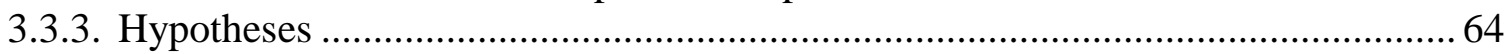

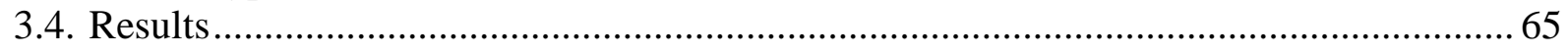

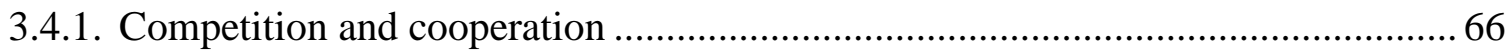

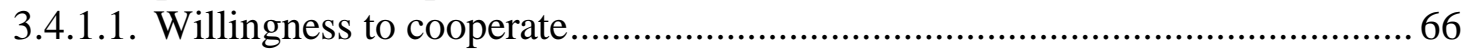

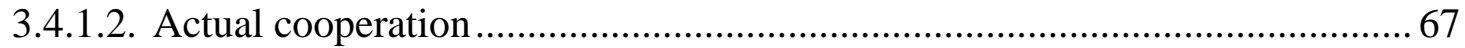

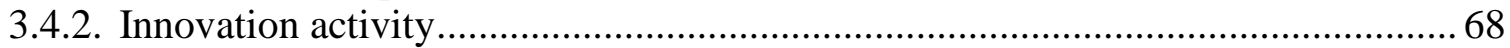

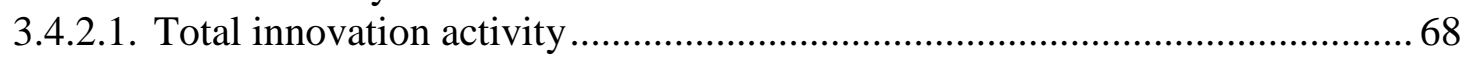

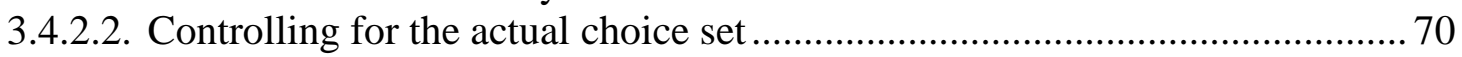

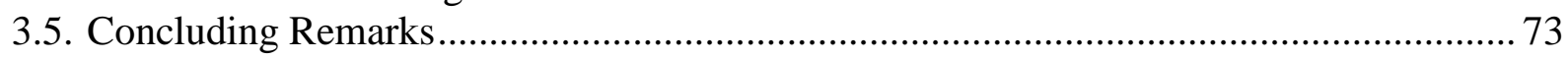

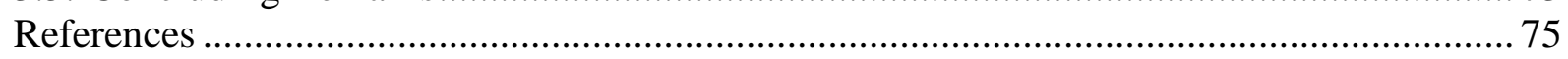

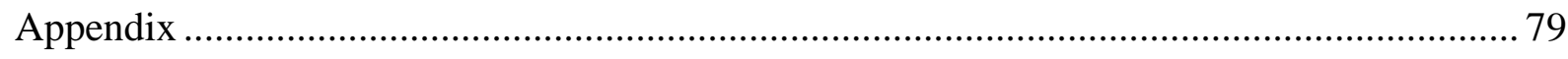




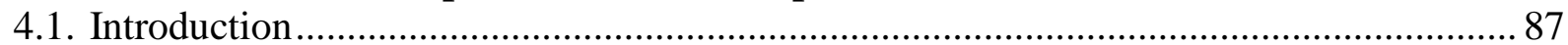

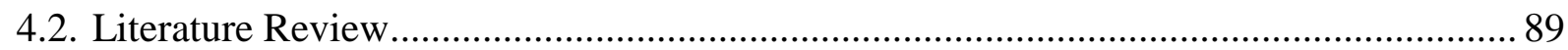

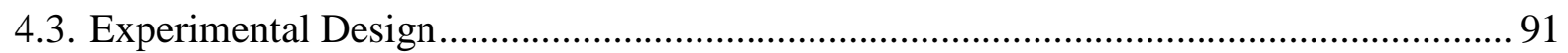

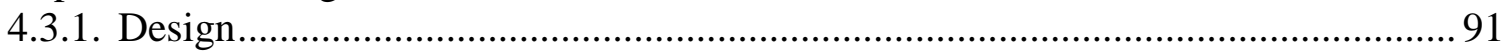

4.3.2. Treatment conditions and experimental procedure ......................................... 94

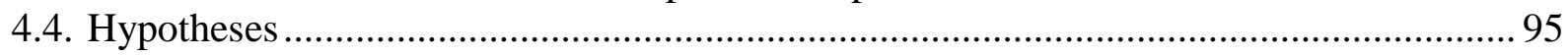

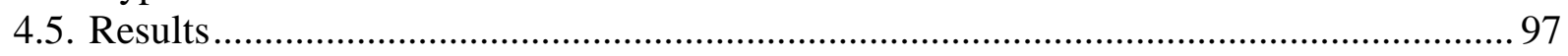

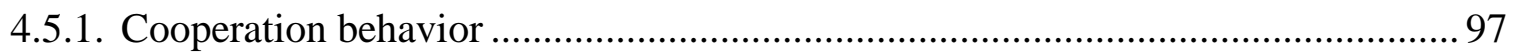

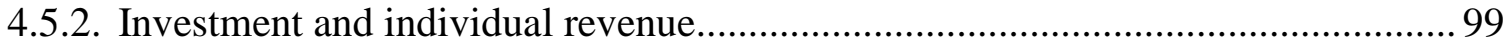

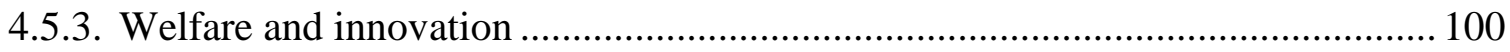

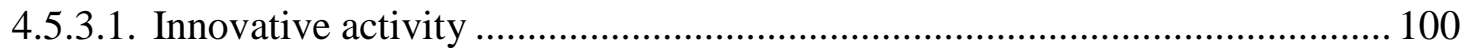

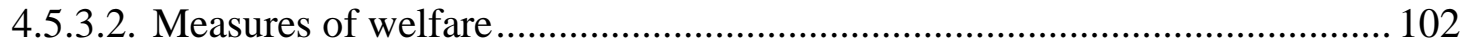

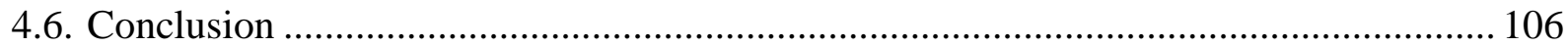

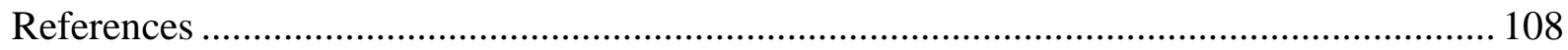

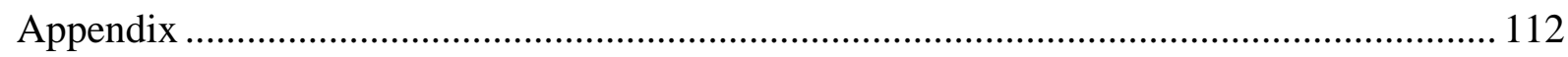

5. Experimental approaches to innovation research 119

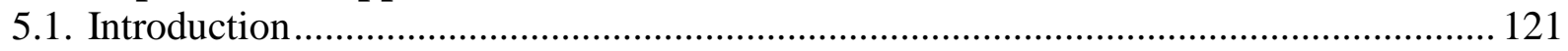

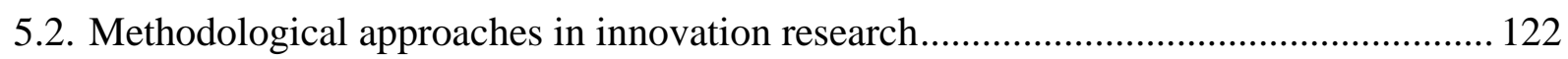

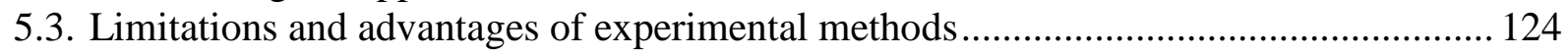

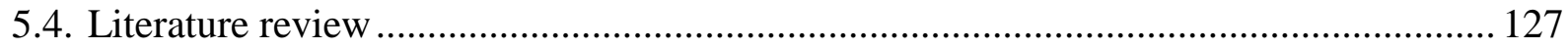

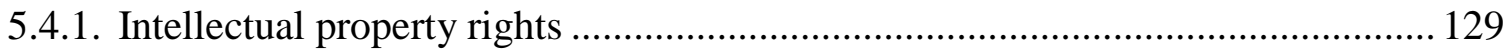

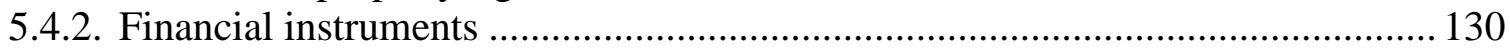

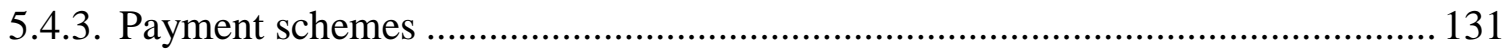

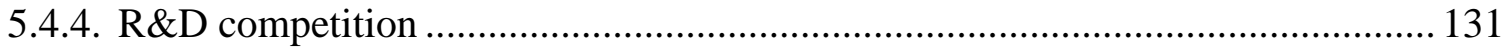

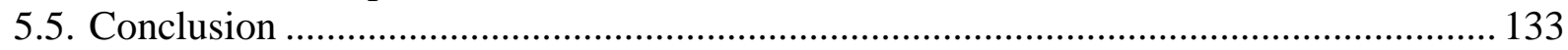

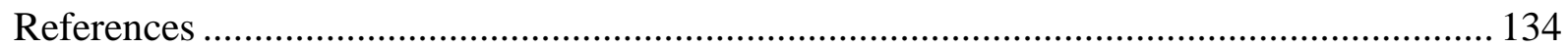




\section{List of figures}

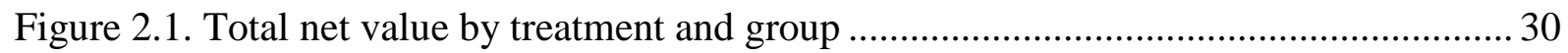

Figure 2.2. Number of roots and extensions created, by treatment........................................ 31

Figure 2.3. Share of extensions of self-originated words by treatments ................................. 33

Figure 2.4. Evolution of minimum, maximum and actual payoffs by period and treatment ... 36

Figure 2.5. Average license fees over periods by treatment and within chat/IP .................... 40

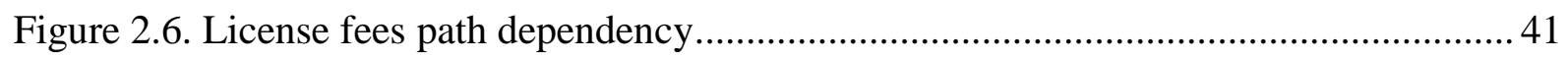

Figure 2.7. Average license fees and total net value RNV .............................................. 42

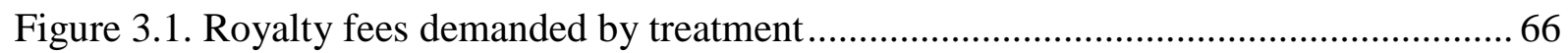

Figure 3.2. Share of extensions of others' roots and royalty fees by group............................ 68

Figure 3.3. Value of words produced within ranked groups by treatment.............................. 70

Figure 3.4. Average values for the RNV's determinants over periods by treatment ............... 72

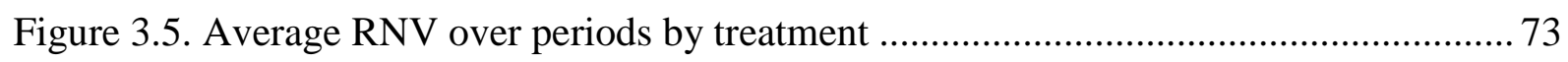

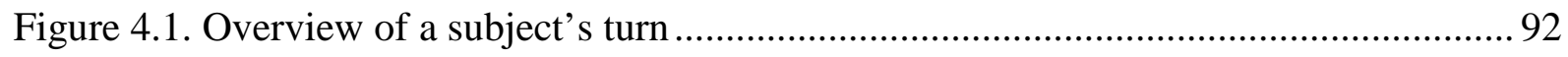

Figure 4.2. Average license fees over periods by treatment and experiment.......................... 98

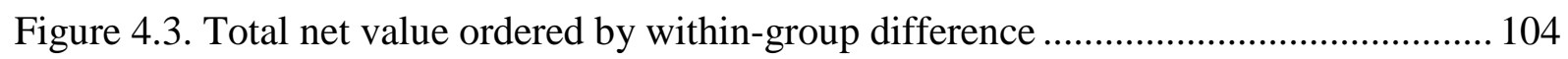

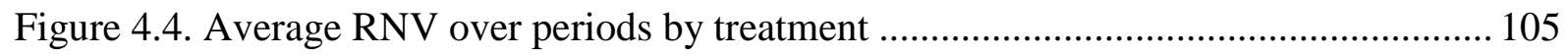

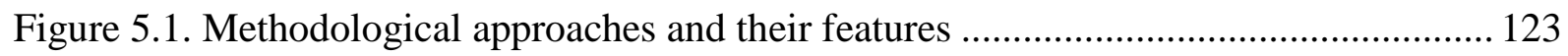




\section{List of tables}

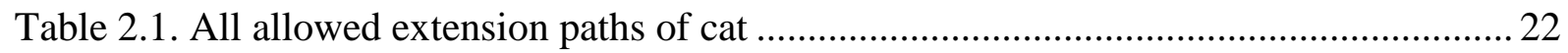

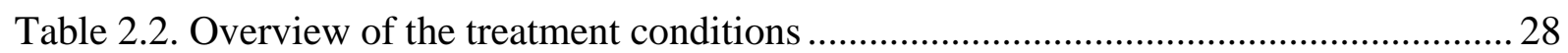

Table 2.3. Overview of words and value created by treatment........................................... 29

Table 2.4. Summary statistics of the Relative Net Value by treatments ................................. 35

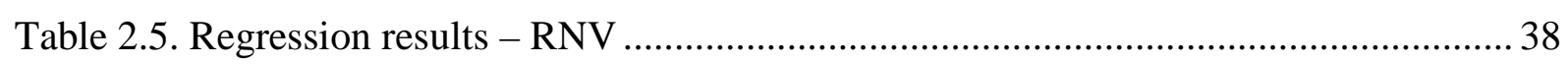

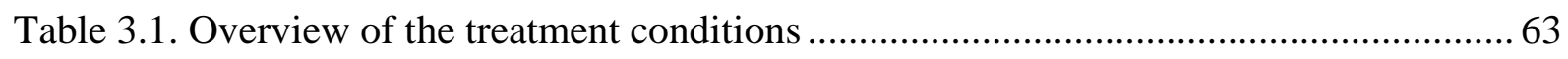

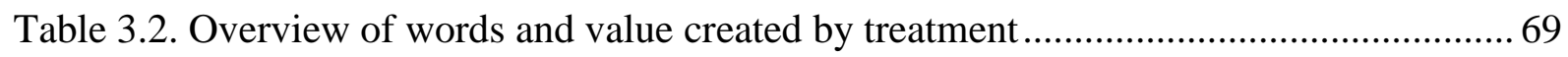

Table 3.3. Relative Net Value across treatments. Summary statistics ................................... 71

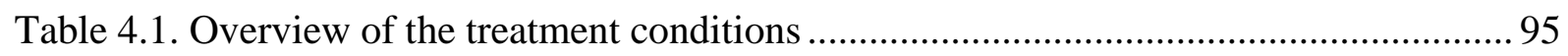

Table 4.2. Overview of investment and revenue by treatment and player............................. 99

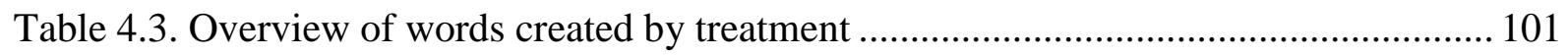

Table 4.4. Different welfare measures by treatment and group .......................................... 103

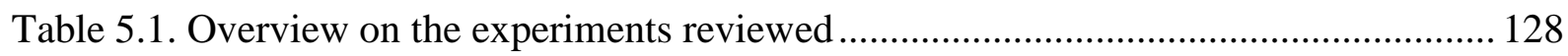


1. Introduction 
Innovations through research and development $(\mathrm{R} \& \mathrm{D})$ driving technological change are considered the key determinants of the long-standing competitiveness and economic welfare of national economies. ${ }^{1}$ Fostering innovation is thus broadly acknowledged as a core requirement of successful economic policy. Naturally, technological and institutional innovations are not considered as a means in itself; rather, the specific aims connected to innovation policy are determined in the political process and might be economic growth, high levels of employment, international competitiveness or goals related to environmental, social, public health or defense objectives. Therefore, each nation follows distinct patterns of innovation policy, which are shaped in the respective national policy discourses. Innovation policy thus builds upon historically established institutional patterns and traditions but similarly integrates the results acknowledged in the field of innovation research (Audretsch 2002; Fagerberg et al. 2010; Borrás and Edquist 2013).

Following this focus on innovativeness in the political discussion, economic research has contributed theoretical and empirical evidence for decades in terms of determining how to foster economies' innovativeness. Therefore, it analyzes the effects of incentives for creativity and innovation and the distribution of knowledge, as well as the socio-economic framework conditions such as institutions, law and policy processes. Among this, researchers discuss the impact of legal regulations on entrepreneurial decisions, which includes the use of specific policy instruments and their effective combination (Flanagan et al. 2011; Guerzoni and Raiteri 2015).

This dissertation contributes to this field by investigating the effects of regulatory and financial policy instruments on individuals' propensity to engage in innovative activities and the extent to which specific instruments can enhance the welfare created through fostering innovation. Thus, it addresses the questions which policy instruments should be employed and how to best shape the respective institutional frameworks to achieve an optimal development of innovative activity. In particular, it explores the extent to which specific policy instruments can positively influence the individual innovation activity and whether specific institutional factors affect an individual's innovation output as well as their cooperation behavior. Both aspects are among the central factors determining the overall success of long-term innovation policies, whereby the innovation output can be considered the core parameter to determine the overall welfare effect of a specific instrument (Grossman and Helpman 1990; Verspagen 2005). Similarly, innovators' willingness to engage in cooperation is considered an essential

\footnotetext{
${ }^{1}$ In a broad sense, innovation is defined as "the implementation of a new or significantly improved product (good or service), or process, a new marketing method, or a new organizational method inbusiness [sic] practices, workplace organization or external relations” $\operatorname{OECD}(2005,46)$.
} 
feature of all successful and sustained innovative processes which involve the sharing, dissemination and further development of knowledge (Lundvall and Borrás 2005; Faria et al. 2010). If one of these two parameters were to decrease due to the introduction of a specific policy instrument, its further implementation should be questioned.

While a large number of theoretical and empirical methods have been developed and significantly improved to assess the effectiveness of specific policy tools, ambiguity remains in innovation research regarding the optimal use and combination of policy instruments. Overall, the established methods in theoretical and empirical innovation research continue to yield mixed evidence; further, there is a lack of data providing clear counterfactual evidence on the effects of introducing or altering specific instruments (Cohen 2010; Zúñiga-Vicente et al. 2014). The methodology of laboratory experiments is employed in this dissertation due to its distinct advantage of being able to provide this particular kind of empirical evidence, i.e. for counterfactual situations. Specifically, three examples from the field of innovation research are analyzed in chapters two to four using laboratory experiments to provide evidence on the effects of specific policy instruments in the three domains of intellectual property rights, innovation contests and subsidies. In all three cases, the experimental method is a fruitful addition to the existing studies, as a situation without the specific instrument can be compared to a counterfactual setting implementing the instrument in question.

While the approach of using experiments in innovation research has already yielded interesting insights, there is valid criticism concerning its application. Specifically, it is argued that transferring innovation processes in the laboratory entails a trade-off between simulating a complex process precisely and maintaining the game's feasibility for the participants of the experiment (Levitt and List 2007). Acknowledging the methodological discussion on the appropriate application of laboratory evidence, this dissertation considers the advantages and limitations of the experimental approach in simulating innovation activities in its final chapter five. Furthermore, the final chapter highlights the contributions of laboratory experiments to innovation research to date and derives suggestions for future lines of research.

Before summarizing the different chapters of this dissertation, the introduction provides insights into the theoretical background of public innovation support and the policy instruments that have been developed and used to foster innovation. Since the core chapters of this dissertation pursue an experimental approach, it is refrained from explicating the general understanding of innovation policy in each chapter. Thus, the basic understanding and definitions of innovation policy and its implications underlying this dissertation are described in the following. 


\subsection{Theoretical justification of innovation policy}

From a micro level perspective, firms by definition aim to increase profits and protect or enhance their position on the market by initiating innovative activities to develop new products or processes. Baumol summarizes this need strikingly by stating: "Under capitalism, innovative activity [...] becomes mandatory, a life-and-death matter for the firm” (Baumol 2002, 1), which is indicated for example in the study by Banbury and Mitchell (1995) by showing a positive relationship between a firm's long-term success and their innovation rate (Hong et al. 2012). Consequently, firms are assumed to have an intrinsic motivation to further drive innovations.

By contrast, from the government's perspective, the goal of innovation policy - which in a wider understanding also includes technology and industrial policy - is to change the outcomes of ordinary market competition, to improve social welfare and to influence the rate and direction of technological change. In a broader sense, innovation policy also includes the intervention for the development of sectors with high prospects of economic growth (Pack and Saggi 2006).

The rationale behind supporting publicly innovation activity is the existence of market failures, as initially suggested by Arrow (1962) and Nelson (1959) for the case of underinvestment and underproduction in scientific research. Arrow argues that knowledge can be considered an important production factor that generates positive spill-overs as it can be adopted and used easily from other private actors; nonetheless, from the originator's perspective, the private rate of return from knowledge is lower than its social return. This gap between the private rate of return and the cost of producing knowledge leads to an underinvestment in $\mathrm{R} \& \mathrm{D}$ as the market does not provide adequate incentives to invest in research. Therefore, knowledge is a public good as it is non-rivalrous and non-excludable and thus leads to free-riding on the innovators' investments. The difference between the innovators' costs - which includes the investment risks - and the socially desirable production of knowledge can be understood as the opportunity costs of relying on the market mechanisms. These opportunity costs need to be weighed against the costs of government intervention which aim at increasing the production of knowledge. This line of reasoning can partly be transferred to technological knowledge, which can be distinguished from scientific knowledge by the institution responsible for its generation. The latter produces knowledge under open disclosure with the innovators' aim of receiving recognition by the scientific community, while innovators of technological knowledge aim to acquire exclusive rights for the commercial exploitation of the innovation in the form of intellectual property rights or the 
possibility of secrecy. Therefore, up to a certain degree, the argumentation of scientific knowledge also comprehends technological knowledge. Nonetheless, technological knowledge can only partly be characterized as a public good, since the system of intellectual property rights enables the exclusion of others (Audretsch 2002; Hall 2002; Steinmueller 2010).

The existence of market failures such as knowledge externalities or financial market imperfections due to information asymmetries are often necessary yet not sufficient conditions to justify state intervention. Optimally, before governments decide to intervene, the costs and benefits of the intervention are taken into account and it is only decided in favor of an intervention when the benefits are very likely to outperform the costs (Audretsch 2002). Obviously, this fundamental reasoning of market failure in favor of innovation policy has been expanded during recent decades in numerous different ways such as Schumpeterian growth theory, Neo-Marshallian, systemic institutional and evolutionary approaches. These theories have added several potential rationales for government interventions such as system and institutional failures, support to the accumulation of endogenous $R \& D$ and learning failures (Laranja et al. 2008). Nevertheless, Arrow's approach of market failure in knowledge production can be considered a theoretical basis for the development of governmental interventions in the field of innovation. On this basis, a broad set of policy instruments has been developed, which are explained in the following.

\subsection{Innovation policy instruments and their application}

Public policy instruments can be defined as a collection of methods to foster economic change by stimulating innovation (Vedung 1998, 21). To classify the choice and design of different policy instruments, they can be divided into three categories: (1) regulatory instruments, (2) economic and financial instruments and (3) soft instruments, whereby the combination of the three instruments has been referred to as 'carrots, sticks and sermons'. ${ }^{2}$ In the following, these central instruments outlined by Vedung (1998) and Borrás and Edquist (2013, 1515-18) are briefly explained to provide the context in which the experiments in this dissertation have been conducted.

(1) Legal tools constitute the first category, in which the institutional frameworks for the interactions between economic actors are defined through the normative authority of governments. Therefore, regulatory instruments are used to determine the overarching market

\footnotetext{
2 There are other classifications of policy instruments, as discussed for instance by Steinmueller (2010); however, the classification used in this dissertation is broadly accepted in both the scientific literature and practical contexts, see Borrás and Edquist (2013) and Vedung (1998).
} 
conditions in which innovative activity takes place. An important characteristic of regulatory instruments is their mandatory nature and the implied sanctioning of violators. Depending on the legal tool - for example, laws, rules or directives - the sanction can differ between fines, other economic penalties or a temporary retraction of specific rights. Furthermore, this category comprises instruments such as intellectual property rights as part of patent law, the regulation of research and higher education, competition law with a focus on $R \& D$, ethical regulations as well as regulations of the industrial sector affecting innovative activities. Beside these immediate influences of regulatory instruments, they also can function indirectly - for example, by prohibiting a specific chemical process - which subsequently forces the respective firms to develop alternative processes or products to remain in the market.

(2) Economic and financial instruments support innovators with specific monetary and non-monetary incentives or disincentives, which makes innovating more attractive in terms of money, time and effort. In contrast to regulatory instruments, these instruments are not compulsory, which means that they neither impose nor prohibit a specific action. Therefore, innovators can decide for themselves whether to take the respective action or not. Incentives used to encourage and promote innovative activities include cash transfers and grants, subsidies, reduced interest loans, loan guarantees and competitive research funding for applied industrial as well as basic research. Among the disincentives available to regulators are taxes, charges, fees, customs duties and tariffs on particular goods and services. Moreover, financial instruments might foster technology transfer or incentivize the investment of venture and seed capital. Beside this direct support for private actors, a substantial part of public economic support is often invested directly in state-owned universities and public research organizations. Consequently, research infrastructures can be considered as an indirect financial instrument to support innovative activity.

(3) Soft instruments can be understood as a form of moral suasion by the state. They are based on the transfer of knowledge, the communication of information, persuasive reasoning and a resulting voluntary adherence of the economic actors. Soft instruments can provide advice, normative requests or ask for voluntary approval to specific policy measures, whereby examples include promoting scientific knowledge on 'research days', publicly accessible documentations, codes of conduct for firms and public research organizations, voluntary technical standards or stipulations. Institutional means to implement soft instruments can include technology transfer offices or cooperation in public-private partnerships sharing costs, benefits and risks for knowledge infrastructure. By using these instruments, the function of the government changes "from being a provider and regulator to being a coordinator and 
facilitator” (Borrás and Edquist 2013, 1516). The application of soft instruments - and thus a different understanding of the state's role - has developed during the past two decades.

When considering the application of these three instruments, it can be stated that the current strong role of these instruments and the prevalence of innovation and industrial policy have increased in recent years. Since the 1980s, the field of industrial policy - and thus innovation policy - had been disregarded for two distinct reasons. First, there were concerns that direct innovation policy would necessarily induce government failures due to a lack of information on the part of the government. This was assumed to lead governments to take counterproductive regulatory choices. Second, concerns about the effects of lobbying were weighed more heavily. It was assumed that strong government interventions in industrial policy would lead to rent-seeking behavior by firms and thus induce corruption, which would ultimately hamper innovation and economic growth. Therefore, it was implied that industrial policy would allocate resources worse than the market; nevertheless, instruments such as grants and tax exemptions were still used broadly (Landesmann 2015).

However, it is argued that there has been a revival of industrial policy in Europe following the international financial and economic crisis of 2008, partly due to the need to restore growth after the crisis itself and partly due to the increasing pressure of being competitive on globalized markets (Landesmann 2015). For example, the German federal government has pledged to establish a high-tech strategy, building upon the European Commission's Horizon 2020 strategy declared in 2010, within which the European Commission determined the aim that each member state should spent three percent of its gross domestic product (GDP) for research and development (COM (2010) 2020; BMBF 2014). Germany only narrowly failed to reach this goal in 2013, for which the most current set of data is available: the share of internal expenditures for R\&D was 2.85 percent of the GDP in 2013, which corresponds to about 80 billion Euros (Statistisches Bundesamt 2015, 11).

Traditionally, innovation policy in Germany is based on project funding and thus it primarily uses economic and financial instruments. They can be distinguished into specific programs such as fostering Nano-technology and programs promoting innovative activities more broadly with a less specified range. These broader programs can include almost every kind of economic instrument, with the exception of tax credits, which are not practiced in Germany. Building on this institutional tradition, of the 80 billion Euros, about 67 percent were given to the private sector, 18 percent to universities and about 15 percent was invested in state-owned or non-profit organizations (Statistisches Bundesamt 2015, 10). For firms involved in innovative processes, the relevance of public financing has grown substantially: 
before the crisis, subsidies were the fifth most important source of R\&D funding for German firms and were used by only eight percent of the firms between 2004 and 2006. After the crisis, public support has increased to become the second important source of funding for 2011 to 2013, being used by 21 percent of German firms (Rammer and Peters 2015, 32).

This brief overview of innovation policy, its instruments and application underlines the increased priority of governmental action in fostering innovative activity. This implicates the purpose for innovation research to analyze the different instruments in detail. As outlined before, laboratory experiments can add to the existing literature of analyzing innovation policy instruments building on their ability to create counterfactual situations in which innovators' reactions with and without the policy instrument are tested. Therefore, this dissertation presents three laboratory experiments, in which one regulatory and two economic instruments are investigated. Furthermore, the final chapter discusses the approach of using laboratory experiments in innovation research. Before presenting the four studies in chapters two to four, they are summarized in the following.

\subsection{Summary of chapters two to five}

The second chapter - named "Intellectual property rights hinder sequential innovation. Experimental evidence" - deals with the regulatory instrument of intellectual property rights and their effects on individual innovativeness and welfare. The aim of this chapter is to add insights to the discussion concerning the feasibility of intellectual property rights. Therefore, evidence from a counterfactual situation in an economic experiment is used, enabling the comparison of innovative settings with and without intellectual property rights. In the experiment, a sequential innovation process is simulated by building upon a creativity task introduced by Crosetto (2010), which transfers the board game Scrabble into an economic experiment. Within the experiment, subjects are rewarded for creating words and extending existing words with letters, which are bought from the experimenter. In the baseline treatment, all innovations can be used for free by all subjects. In a treatment implementing intellectual property rights, subjects are allowed to license their innovations for the use of others. In a further treatment, communication is introduced with a chat window to analyze cooperation effects during the innovative process. Therefore, a 2x2 between subjects design is implemented to check the effects of intellectual property (IP) rights and communication in comparison to a non-IP rights setting without inter-subject communication.

The results show that welfare - as measured by the number and complexity of innovations created - decreases by 20-30 percent when license fees on innovations can be set. This follows from individual behavior in the intellectual property treatments, where subjects tend 
to use their own innovations more often to avoid paying license fees to others. Moreover, there is a shift from more sophisticated and more valuable innovations to less valuable, simpler innovations, which further reduces overall welfare. Regarding the effects of communication among participants in this setting, previous findings in repeated public good games lead to the expectation that altruistic, cooperative behavior would increase (Fischbacher and Gächter 2010), thus translating into lower license fees in this experimental setting. However, communication does not have a positive influence on welfare in both respective treatments. Moreover, similar to the behavioral patterns observed in public good games, there is a strong path dependency of the level of license fees within a group, which is determined by the level of license fees chosen in the first periods. Furthermore, the level of license fees increases during the course of the game, which corresponds to a decrease in cooperation, comparable to declining contributions in public good games. The chapter concludes with the policy implication that IP rights might slow down - rather than fostering the rate of innovation and the resulting welfare in domains of strictly sequential innovation such as software or bioengineering.

The third chapter - entitled "Experimental evidence on the effects of innovation contests" investigates innovation contests as a financial instrument for fostering innovation which is easily available to policy makers. This chapter adds to the discussion in economics and innovation management dealing with the impact and optimal design of innovation contests. Similar to chapter two, the Scrabble-like word creation task is used to simulate the innovation process and test for the effects that innovation contests might have on overall welfare and the willingness of innovators to cooperate. In the experiment, subjects are compensated for their innovations and - similar to chapter two - they have the possibility to license their innovations, which allows measuring their willingness to cooperate. Furthermore, two different kinds of innovation contests - a prize for the aggregate innovativeness and a prize for the best innovation - are compared to a benchmark treatment without a contest. The first contest is implemented by a relative payoff-scheme compensating the most innovative subject, whereby the prize for the aggregate innovativeness is implemented by awarding the most valuable innovation with a bonus. In the benchmark treatment, subjects are compensated for the number and quality of their innovations.

The results demonstrate that the willingness to cooperate decreases in both types of contests in comparison to the benchmark treatment as royalty fees substantially increase. Nevertheless, the actual cooperation does not change, as subjects continue to use others' innovations as often as in the benchmark treatment - presumably because they are eager to 
win the contest - thus ignoring higher royalty fees. From a welfare perspective, there is no positive effect of contests, since the total innovation activity does not change across treatments. However, the welfare analysis does not include the costs for implementing the innovation contests: assuming that states bear substantial costs for organizing and financing the contests, the overall welfare effects might become substantially negative. With respect to policy implications, the results can be interpreted as questioning the positive effects of innovation contests, since they lead to a diminishing willingness to cooperate among innovators while fostering no positive effects on the individuals' innovativeness and thus potentially incurring negative overall welfare effects. Furthermore, as royalty fees are increasing due to a contest structure, this instrument might have a further counterproductive effect when it is used as an additional tool to the existing structure of IP rights: since the effects of these instruments might overlap, the resulting incentive structure might be highly undesirable from a policy perspective.

The fourth chapter - "The effectiveness of public subsidies for private innovations. An experimental approach" - examines another financial instrument used quite frequently to stimulate innovation, namely subsidies provided to firms to foster the development of innovative products and services. Previous discussions in different disciplines of innovation research have yielded highly ambiguous results regarding the effects of subsidies on innovativeness and welfare. Therefore, the evidence reported in this chapter adds to the discussion of the effectiveness of public subsidies in fostering private innovation activity with a laboratory experiment, again based on the Scrabble-like word creation task.

Once again, the subjects' goal in this experiment is to generate income by creating and extending words with the possibility to set a license fee on created words over multiple periods, thus simulating a sequential innovation process. This experiment and its distinct treatments allow testing whether innovators behave differently in a setting with a subsidy compared to a setting without a subsidy. The treatments are organized in a within-subjects design to capture the effects of changes in subsidization. In particular, a benchmark treatment without subsidies is tested against a treatment with additional material resources allocated in the form of a free letter in each period in a first experiment. In a second experiment, the benchmark is compared to a treatment with direct monetary resources allocated in the form of additional money amounting to the cost of one letter in each period.

Overall, the results show that subsidies do not yield positive outcomes in welfare and innovativeness. While additional material resources induce no change in welfare, additional monetary resources even have negative welfare effects. Moreover, a crowding-out of private 
investment occurs following the introduction of subsidies. Consequently, subjects’ individual average incomes increase due to the additional resources, although the innovation activity and overall welfare remain unchanged. Furthermore, with subsidies, producing more basic innovations is encouraged, while the creation of more sophisticated innovations is discouraged. Subsidies do not have an influence on the cooperation behavior among subjects measured by the level of license fees. From a policy perspective, the results indicate that the use of subsidies as a tool to foster innovativeness and welfare might be questionable. This would apply all the more when including the cost for the subsidy itself into the welfare analysis, which would show a negative overall effect of innovation subsidies.

While chapters two to four present novel empirical evidence on the design of optimal innovation policy instruments, chapter five adopts a broader, methodological perspective. Entitled "Experimental approaches to innovation research", the chapter discusses the advantages of conducting laboratory experiments as an additional method in the "toolbox" of innovation research. As policy makers aim to foster private innovation activity, a large number of methods have been suggested to measure the effects of the specific instruments. However, the established methods in innovation research have been criticized for being unable to provide counterfactual evidence, leading to the establishment of a new field of laboratory experiments covering questions of innovation research. The final contribution highlights this discussion and its methodological foundations.

To gain a deeper understanding of the methodological development, the features of the different established approaches in innovation research are outlined, namely neoclassical models, 'traditional' empirical research, natural experiments, randomized field experiments and laboratory experiments. Explicating the advantages and limitations of lab experiments, it is suggested that lab experiments can provide new insights in the domains of analyzing existing and developing new policy instruments, as well as measuring their welfare implications by creating and comparing individual behavioral patterns in counterfactual situations. Furthermore, to highlight the recent progress in experimental innovation research, a literature review of 18 laboratory studies is conducted, encompassing the topics of IP rights, financial instruments, payment schemes as well as R\&D competition. Based on the placement of laboratory experiments in the broader methodological context of innovation research, the discussion of advantages and limitations of experiments, the recent contributions of behavioral evidence to innovation research and the overall applicability of experiments is discussed. Following Chetty (2015), a pragmatic use of laboratory experiments is suggested, emphasizing that whenever experiments can contribute additional insights and their 
methodological advantages outweigh the limitations, behavioral evidence can be considered a valuable extension to innovation research and provide vital policy recommendations.

Overall, this dissertation provides new insights into the effects of the policy instruments intellectual property rights, contests and subsidies by providing counterfactual evidence based on laboratory experiments as well as a discussion of the experimental methodology in innovation research. However, the four studies presented of course only constitute a starting point for further research in the emerging field of innovation research. Future research should therefore extend the use of experimental methods for deriving counterfactual evidence on other policy instruments to measure their effectiveness and efficiency and thus enrich the current mix of methods in innovation research. 


\section{References}

Arrow, Kenneth J. 1962. "Economic welfare and the allocation of resources for invention." In The rate and direction of inventive activity. Economic and social factors, ed. Richard R. Nelson. Princeton, NJ: Princeton University Press, 609-26.

Audretsch, David B. 2002. "The economics of science and technology." The Journal of Technology Transfer, 27(2): 155-204.

Banbury, Catherine M. and Will Mitchell. 1995. "The effect of introducing important incremental innovations on market share and business survival.” Strategic Management Journal, 16: 161-82.

Baumol, William J. 2002. The free-market innovation machine. Analyzing the growth miracle of capitalism. Princeton, NJ: Princeton University Press.

Borrás, Susana and Charles Edquist. 2013. “The choice of innovation policy instruments.” Technological Forecasting and Social Change, 80(8): 1513-22.

Bundesministerium für Bildung und Forschung (BMBF). 2014. "Die neue HightechStrategie. Innovationen für Deutschland.”

Chetty, Raj. 2015. "Behavioral economics and public policy. A pragmatic perspective." American Economic Review: Papers and Proceedings, 105(5): 1-33.

Cohen, Wesley M. 2010. "Fifty years of empirical studies of innovative activity and performance." In Handbook of the economics of innovation. Volume 1, ed. Bronwyn H. Hall and Nathan Rosenberg. Amsterdam: Elsevier, 129-213.

COM (2010) 2020. "Europe 2020. A strategy for smart, sustainable and inclusive growth.” (http://eur-lex.europa.eu/LexUriServ/LexUriServ.do?uri=COM:2010:2020:FIN:EN:PDF) last accessed on $14^{\text {th }}$ Dec. 2015.

Crosetto, Paolo. 2010. "To patent or not to patent. A pilot experiment on incentives to copyright in a sequential innovation setting." In IFIP advances in information and communication technology, Open source software. New horizons. $6^{\text {th }}$ International IFIP WG 2.13 Conference on Open Source Systems, ed. Pär J. Ågerfalk, Cornelia Boldyreff, Jesús M. González-Barahona, Gregory R. Madey, and John Noll. Berlin, New York: Springer, 53-72.

Fagerberg, Jan, Martin Srholec, and Bart Verspagen. 2010. "Innovation and economic development." In Handbook of the economics of innovation. Volume 2, ed. Bronwyn H. Hall and Nathan Rosenberg. Amsterdam: Elsevier, 833-72.

Faria, Pedro de, Francisco Lima, and Rui Santos. 2010. "Cooperation in innovation activities. The importance of partners.” Research Policy, 39(8): 1082-92.

Fischbacher, Urs and Simon Gächter. 2010. "Social preferences, beliefs, and the dynamics of free riding in public goods experiments." The American Economic Review, 100(1): 541-56.

Flanagan, Kieron, Elvira Uyarra, and Manuel Laranja. 2011. "Reconceptualising the 'policy mix' for innovation.” Research Policy, 40(5): 702-13.

Grossman, Gene M. and Elhanan Helpman. 1990. “Trade, innovation, and growth.” The American Economic Review, 80(2): 86-91.

Guerzoni, Marco and Emilio Raiteri. 2015. "Demand-side vs. supply-side technology policies. Hidden treatment and new empirical evidence on the policy mix." Research Policy, 44(3): 726-47. 
Hall, Bronwyn H. 2002. "The financing of research and development." Oxford Review of Economic Policy, 18(1): 35-51.

Hong, Shangqin, Les Oxley, and Philip McCann. 2012. "A survey of the innovation surveys.” Journal of Economic Surveys, 26(3): 420-44.

Landesmann, Michael A. 2015. "Industrial policy. Its role in the European economy." Intereconomics, 50(3): 133-128.

Laranja, Manuel, Elvira Uyarra, and Kieron Flanagan. 2008. "Policies for science, technology and innovation. Translating rationales into regional policies in a multi-level setting.” Research Policy, 37(5): 823-35.

Levitt, Steven D. and John A. List. 2007. "What do laboratory experiments measuring social preferences reveal about the real world?” Journal of Economic Perspectives, 21(2): 153-74.

Lundvall, Bengt-Åke and Susana Borrás. 2005. "Science, technology, and innovation policy.” In The Oxford handbook of innovation, ed. Jan Fagerberg, David C. Mowery, and Richard R. Nelson. Oxford: Oxford Univ. Press, 599-631.

Nelson, Richard R. 1959. "The simple economics of basic scientific research.” The Journal of Political Economy, 67(3): 97-306.

Organisation for Economic Co-operation and Development (OECD). 2005. "Oslo manual. Guidelines for collecting and interpreting innovation data. Third edition.”

Pack, Howard and Kamal Saggi. 2006. "The case for industrial policy. A critical survey.” World Bank Research Observer, 21(2): 267-97.

Rammer, Christian and Bettina Peters. 2015. "Dokumentation zur Innovationserhebung 2014. Innovationen mit Bezug zur Energiewende, Finanzierung von Innovationen.” ZEW Dokumentation 15-02.

Statistisches Bundesamt. 2015. "Finanzen und Steuern. Ausgaben, Einnahmen und Personal der öffentlichen und öffentlich geförderten Einrichtungen für Wissenschaft, Forschung und Entwicklung.” Fachserie 14 Reihe 3.6.

Steinmueller, W. E. 2010. "Economics of technology policy." In Handbook of the economics of innovation. Volume 2, ed. Bronwyn H. Hall and Nathan Rosenberg. Amsterdam: Elsevier, 1182-218.

Vedung, Evert. 1998. "Policy instruments. Typologies and theories.” In Carrots, sticks \& sermons. Policy instruments \& their evaluation, ed. Marie-Louise Bemelmans-Videc, Ray C. Rist, and Evert Vedung. New Brunswick, NJ: Transaction Publishers, 21-58.

Verspagen, Bart. 2005. "Innovation and economic growth.” In The Oxford handbook of innovation, ed. Jan Fagerberg, David C. Mowery, and Richard R. Nelson. Oxford: Oxford Univ. Press, 487-513.

Zúñiga-Vicente, José Á., César Alonso-Borrego, Francisco J. Forcadell, and José I. Galán. 2014. "Assessing the effect of public subsidies on firm R\&D investment. A survey.” Journal of Economic Surveys, 28(1): 36-67. 


\section{Intellectual property rights hinder sequential innovation. Experimental evidence}

with Paolo Crosetto, Lukas Meub \& Kilian Bizer

cege Discussion Paper 227, Georg-August-Universität Göttingen, January 2015. Download: http://wwwuser.gwdg.de/ cege/Diskussionspapiere/DP227 


\begin{abstract}
In this paper we contribute to the discussion on whether intellectual property rights foster or hinder innovation by means of a laboratory experiment. We introduce a novel Scrabble-like creativity task that captures most essentialities of a sequential innovation process. We use this task to investigate the effects of intellectual property allowing subjects to assign license fees to their innovations. We find intellectual property to have an adversely effect on welfare as innovations become less frequent and less sophisticated. Communication among innovators is not able to prevent this detrimental effect. Introducing intellectual property results in more basic innovations and subjects fail to exploit the most valuable sequential innovation paths. Subjects act more self-reliant and non-optimally in order to avoid paying license fees. Our results suggest that granting intellectual property rights hinders innovations, especially for sectors characterized by a strong sequentiality in innovation processes.
\end{abstract}

\title{
Keywords
}

creativity, innovation, intellectual property, laboratory experiment, real effort task

\section{JEL-Classification}

C91, D89, P14 


\subsection{Introduction}

The question whether to grant intellectual property (IP) rights to innovators has been discussed widely in economics, law and politics. Proponents of IP rights argue that temporary monopoly rights granted through patents or copyright provide incentives by protecting innovators from imitation and allotting to them a part of the social surplus generated by subsequent innovators (Arrow 1962; Nordhaus 1969; Scherer 1972). Further, patents are assumed to induce disclosure of new technologies and therefore foster a swift and comprehensive diffusion of knowledge (Machlup 1958). These traditional arguments have been increasingly put to question. Opponents of IP rights argue that the creation of monopolies on innovations increases prices, which distorts resource allocations, causes inefficiencies and leads to welfare losses (Stiglitz 2008; Boldrin and Levine 2013). Moreover, too broad, too long, or too fragmented IP rights can give rise to gridlock and anticommons issues in downstream innovations (Heller and Eisenberg 1998).

In this paper we contribute to the debate by means of a controlled real-effort laboratory experiment involving creativity. We introduce a novel design that allows us to create counterfactual situations and test directly the effects of IP rights on the innovation rate and welfare of a laboratory economy.

The issues of what are the optimal extent and nature of IP rights have been long debated, but neither theoretical nor empirical research has provided a final answer. Theoretical results cut both ways. Conventional wisdom is largely derived from static models, and does not robustly survive in dynamic, sequential innovation models that best describe sectors characterized by cumulative research (Scotchmer 1991). Dynamic models offer a less positive view of the effect of IP on the rate of innovations and thus aggregate welfare. Green and Scotchmer (1995) study the division of profits between sequential innovators and suggest that it is desirable to minimize patent life. Moschini and Yerokhin (2008) analyze IP regimes with and without research exemptions. They find ambiguous effects and show that firms ex ante always prefer a full patent protection regime. In contrast, Bessen and Maskin (2009) implement a model with sequential and complementary innovations, finding that IP rights are welfare-reducing, and, in some cases, are not even preferred by the inventor, who favors instead to publicly disclose her innovations. Going a step further, Boldrin and Levine (2008) theoretically and empirically show that innovators can earn competitive rents even in complete absence of monopoly power. Hunt (2004) investigates the role of the patentability standard in a sequential innovation model in which profitability of inventions is eroded by 
new inventions. He finds an inverse U-shaped relationship between patentability standards and the rate of innovation. Using an asymmetric-ability multistage $R \& D$ race model, Fershtman and Markovich (2010) find that the opportunity of licensing in a patent system might be superior to a system with strong patent rights. Summing up, the dynamic models focus on the trade-off between securing sufficient incentives to current and future inventors. The overall result of the theoretical analyses, though, seems to crucially depend on the assumptions of the respective model.

Empirical research also yields mixed evidence. Results on the impact of IP rights on innovativeness range from a positive influence (Ernst 2001), an "inverted U” shaped relation (Aghion et al. 2002; Furukawa 2007; Hashmi 2013), a negligible impact (Dosi et al. 2006; Lerner 2009) to a negative influence (Qian 2007; Williams 2013).

Methodologically, both theoretical and empirical analyses are second-best with respect to the observation of a clean counterfactual situation. The absence of conclusive evidence might be due to the lack of natural experiments that could allow us to observe a counterfactual, nonexistent patent-free world (Sørensen et al. 2010; Hall and Harhoff 2012).

In this paper we exploit the unique characteristic of laboratory experiments of allowing to easily build counterfactual situations while retaining control over several confounding factors. We recreate a sequential innovation setting similar to Bessen and Maskin (2009), which fits best to copyrighted non-rivalrous goods and the respective industries such as software and semiconductors. In the spirit of Scotchmer (2004) we use this setting to explore the effects of IP rights on innovativeness and welfare.

The advantages of the laboratory in terms of control come at a cost. The laboratory creates an artificial environment that might lack external validity. In bringing IP rights to the lab we hence face a trade-off between replicating the complex interactions of creative, sequential innovation industries and making the task manageable for an experimental session characterized by time and monetary restrictions. This basic trade-off has been tackled in various ways in the still sparse experimental literature in the economics of innovation and IP rights. A laboratory task adapted to analyze innovation should include the use of both financial and creative resources, and should recreate both the incentive structure and the uncertainty of actual innovation settings. Moreover, it should provide an innovation space that is countable, in order to allow the researchers to analyze the data quantitatively. These constraints have been usually met by developing search tasks over some large, multidimensional space unknown to the subjects but controlled by the experimenter (see, for instance, Cantner et al. 2009; Meloso et al. 2009; Buccafusco and Sprigman 2010; Ederer and 
Manso 2013; Buchanan and Wilson 2014). Another set of papers, has instead forfeited control over the results of the creation process to focus on creativity only (see, for instance, Buccafusco and Sprigman 2010, who let the subjects write poems). Toubia (2006) is, to the best of our knowledge, the only paper implementing a sequential 'ideation' task that requires creativity and provides some sort of countable space in which different incentive schemes for creativity can be studied.

To achieve a reasonable balance, and include both dynamics and creativity, we employ the design of Crosetto (2010) and develop a Scrabble-like word-creation task. The task involves creative use of scarce resources (letters) over a known but vast space (all the existing words), thus at the same time implementing creative effort and granting complete control of the results. We implement (strict) sequentiality by allowing only three-letter words to be created from individual letters, while longer words have to be built extending shorter ones, one letter at a time. Subjects are rewarded for creating words. Additionally, subjects can license, for a fee, their words and extensions to other subjects to serve as base for extensions in further periods.

Within this artificial but rich setting we implement two treatments, across subjects. First, we directly test the effects of IP rights on innovativeness and welfare by imposing two alternative IP regimes: a no-IP regime, where all license fees are exogenously set to zero, and an IP regime in which license fees are determined endogenously by subjects for each newlycreated word. Second, we test the robustness of individual licensing behavior in the case of stronger social interaction, by enabling or not chat communication. We thus investigate whether communication among innovators builds up altruistic norms that foster cooperation and decrease overall license fees for innovations.

We find that the presence of IP rights results in less frequent and less sophisticated innovations and significantly reduces total welfare by 20 to 30 percent. This is due to IP rights causing a shift in behavior from more valuable, longer words towards less valuable, shorter ones. At the same time subjects, in their quest to avoid paying license fees, forego innovation opportunities that are instead seized in absence of IP rights. The detrimental effect of introducing IP rights holds both with and without communication.

\subsection{Experimental Design}

\subsubsection{Related experimental literature}

Experimenters trying to deal with intellectual property issues face two sets of problems when designing their tasks. First, they need to translate the idea of innovation in the lab. This means 
allowing the subjects to use both financial and creative resources, but within a task in which it is possible to accurately assess quality and quantity of the goods produced. Introducing creativity and skills is crucial to obtain external validity of the results; control is crucial to allow for treatment comparisons and to derive robust results. Second, they must recreate a multi-period dynamic landscape in a relatively short-lived experimental session.

In order to deal with these basic design problems a first group of experiments chooses to model the creative process using search over complex spaces. Subject explore the search space looking for some optimal solution that yields higher payoffs, and that the experimenter knows and controls. Often this optimal solution is randomly chosen by the experimenter over the space. Meloso et al. (2009) use a combinatorial task, with an optimal non-obvious solution, and find that participants disseminate intellectual discoveries better in a market than in a patent system. Cantner et al. (2009) model R\&D as a multidimensional search process with uncertainty, in which the best option is randomly determined. They investigate competition for innovation in a patent race scenario to classify investor types, finding that most subjects use objective investment criteria. Dimmig and Erlei (2013) use a similar task and show that the introduction of patenting has only a minor impact on R\&D behavior. Ederer and Manso (2013) use a search task in a multi-dimensional space. They find that a combination of tolerance for early failure and rewards for long-term success are most effective in fostering innovation. Buchanan and Wilson (2014) implement a search task that consists of creating colors with the aim of finding the 'color of the day', randomly set by the experimenter, and introduce trade. In their IP treatment the creation of non-rivalrous knowledge goods is highest; however, prices increase as substantial monopoly profits are acquired by the innovators. In the absence of IP, Buchanan and Wilson still identify the incentive to create non-rivalrous knowledge goods, but IP theft as well. They also implement chat communication among subjects to enable bargaining and cooperation.

By choosing to implement search tasks, the aforementioned experiments abstract away from the crucial features of creativity and individual skills. In some of the designs, finding the 'right' combination is just a matter of luck and enough trials. Innovations are usually not created through such a process. A smaller set of papers choose instead to implement outright “creative” tasks, i.e. tasks involving creative skills rather than the search of an often randomly chosen optimal solution. Buccafusco and Sprigman (2010) ask their subjects to write poems and subsequently implement a market for them. They find that the preferences of IP creators, owners, and purchasers are unstable and dependent on the initial distribution of IP rights, and that there is a substantial valuation asymmetry between creators and purchasers of IP, similar 
to the well-known endowment effect. Such designs capture the creativity core of innovations better, but forfeit control - it is impossible to accurately assess which poem is 'better' or 'more creative' in the set.

In this paper we develop a task that integrates both creativity and control of the outcome. We employ a Scrabble-like real effort word creation game originally introduced by Crosetto (2010). In this task subjects innovate over a familiar space (their language), using both economic (experimental money) and cognitive (creative effort) resources. The production process requires creativity and skill, but its results are countable and can be used to create precise statistics and comparisons across conditions. By allowing subjects to extend already created words, we induce sequentiality and dynamics in an intuitive way. Our approach is similar to Toubia (2006). In his 'ideation game' subjects are faced with complex problems (i.e., "How can the impact of the U.N. Security Council be increased”) and must come up with ideas. Ideas can be 'new' or build on an existing idea, thus introducing sequentiality. The value of ideas is a function of the incentive scheme introduced. The game implements different incentive schemes, including a flat condition, in which subjects are paid for participation but ideas are worthless in themselves, a piece-rate condition in which each idea was worth one token, and a citation condition, in which ideas that are more built upon and extended are more valuable. Differently from Toubia (2006), our experiment allows for an evaluation of the output of the innovation process (in our case, words) that is independent of the incentive scheme adopted; words are valued according to an objective Scrabble-like rule assigning value to each letter, thus allowing to assess the total production of the economy by an objective standard known to all participants.

\subsubsection{Design}

Our experimental design, originally proposed by Crosetto (2010), is inspired by the board game Scrabble with the addition of a price on letters, strict sequentiality in word creation and IP rights on created words. Buying letters is a risky investment and sequentiality and IP rights add a strategic dimension to the game.

The task of the subjects is to create words. They do so by using letters, which they buy from the experimenters. Each word produced generates an immediate payoff that corresponds to the sum of the values of the letters used in the respective word. This value is the same as in Scrabble, roughly determined by the inverse of a letter's absolute number in the set. For example, an $a$ is worth 1 , a $b 3$, an $x 8 .^{3}$

\footnotetext{
${ }^{3}$ The details of the letterset used are given in appendix B, together with the English translation of the original experimental instructions.
} 
There are two types of words in the experiment. With the letters they own, subjects can either form a three-letter word (we call it a root), or extend existing words (an extension). Roots can be produced with any three letters, as long as the word exists. For example, with $t, r$ and $a$, a subject can produce art or rat. Extensions are generated by adding one letter in any position of a word: for instance, cat can be extended into cart, or cats, or chat. ${ }^{4}$ Extensions can be further extended as long as the language allows: for instance, cart can be further extended into chart. Roots can be used to generate alternative extension paths and the amount of possible extensions stemming from each word is usually long and branched. We hence implement in our experiment a required inventive step of three letters for new inventions and one letter for marginal innovations. Table 2.1 shows all the extension paths of cat, along with their value.

Table 2.1. All allowed extension paths of cat

\begin{tabular}{|c|c|c|c|c|c|}
\hline \multirow{2}{*}{ root } & \multicolumn{5}{|c|}{ extensions } \\
\hline & +1 & +2 & +3 & +4 & +5 \\
\hline \multirow{21}{*}{ cat (5) } & & canst (7) & canton (8) & \multirow{3}{*}{$\begin{array}{l}\text { cantons (9) } \\
\text { cantors (9) }\end{array}$} & \\
\hline & cant (6) & canto (7) & cantor (8) & & \\
\hline & & cants (7) & cantons (8) & & \\
\hline & capt (8) & & & & \\
\hline & & & carats (8) & \multirow{4}{*}{$\begin{array}{c}\text { carpets (11) } \\
\text { clarets (9) }\end{array}$} & \\
\hline & cart (6) & carat (1) & carets (8) & & \\
\hline & Cart (0) & carts (7) & carpet (10) & & \\
\hline & & & claret (8) & & \\
\hline & & & caster (8) & casters (9) & \multirow{4}{*}{ coasters (10) } \\
\hline & cast (6) & caste (7) & $\begin{array}{l}\text { caster (8) } \\
\text { castes (8) }\end{array}$ & castled (10) & \\
\hline & cats (6) & casts (7) & castle (8) & castles (9) & \\
\hline & & & & coaster (9) & \\
\hline & \multirow{4}{*}{ chat (9) } & chant (10) & chants (11) & \multirow{4}{*}{$\begin{array}{l}\text { chasten (12) } \\
\text { chastes (12) }\end{array}$} & \multirow{4}{*}{ chastens (13) } \\
\hline & & chart (10) & charts (11) & & \\
\hline & & chats (10) & chaste (11) & & \\
\hline & & cheat (10) & cheats (11) & & \\
\hline & coat (6) & coast (7) & \multirow{2}{*}{ coasts (8) } & & \\
\hline & Codt (U) & coats (7) & & & \\
\hline & \multirow{3}{*}{ scat (6) } & & scants (8) & & \multirow{3}{*}{ scantily (13) } \\
\hline & & scant (7) & scanty (11) & scantly (12) & \\
\hline & & scats (7) & secant (8) & secants (9) & \\
\hline
\end{tabular}

\footnotetext{
${ }^{4}$ For the sake of clarity, all examples are reported in English, even if the actual experiment was run in German. While the actual words that can be created vary across languages, the basic rules and the ideas behind the examples are general.
} 
It is clear from table 2.1 that longer words tend to yield higher payoffs. Extensions are more profitable than roots, rewarding the extender with the full value of the word extended and not just with the value of his marginal contribution. For example, extending cat into cart costs the subject the letter $r$, worth 1 token, and yields a payoff of 6 tokens. To keep the experiment simple and manageable we rule out technological obsolescence: the full value of the extended word is transferred to the extension, with no discounting.

This structure allows us to introduce intellectual property rights in a simple and intuitive way by allowing the subjects to impose a license fee on the use of their created word for extensions. Through this fee subjects can secure part of the surplus created in extending for themselves. The surplus is generated by reusing the same resources, i.e. letters. We let subjects choose the level of the fee as a percentage, from 0 to $100 \%$, of the value of the licensed word. In the example, the owner of cat (value 5) can choose to impose a fee that ranges from 0 to 5 tokens to the subject that wishes to extend cat into cart. License fees enable us to address in a simple way the central problem in sequential IP rights, the split of profits between upstream and downstream innovators (Scotchmer 1991).

\subsubsection{Treatments}

We implement two different treatments over this basic structure, in a factorial 2x2 betweensubjects design. First, we manipulate exogenously the presence or absence of intellectual property rights. In the Intellectual Property (IP) treatments, subjects can impose a license fee on the access to their words to others. This is not possible in noIP treatments and all words are publicly available at no extra fee. noIP treatments are equivalent to exogenously setting all license fees to $0 \%$. We can thus directly test the effect of IP rights on the rate of word creation and hence on payoffs at the individual and group levels.

Second, we manipulate the possibility for subjects to communicate with each other. In chat treatments we introduce a chat box in which subjects can communicate with all others in their group. In noChat treatments subjects cannot communicate. These treatments allow us to observe the effect of communication as a means of facilitating cooperation on individual and collective performance.

\subsubsection{Design details}

With this general description in mind, we now move to the details of the task. The game is played by randomly matched groups of 4 subjects. The composition of groups is constant 
during the whole game. Within groups, subjects play sequentially, as in turn-based games. ${ }^{5}$ Subjects start the experiment with an endowment of 75 tokens ( 1 token converts to $€ 0.12$, so that the initial endowment is of €9) and 4 randomly pre-assigned letters. The experiment lasts for 25 periods. In each period, each subject has to make at most three choices: an investment decision, a production choice and, in IP treatments only, an intellectual property decision.

\section{Investment}

Subjects buy a letter at a fixed price of 2 tokens. Letters are randomly drawn from the letter set. The random sequence governing letter draws is predetermined and fixed, though unknown to the subjects, in order to make results from different groups and treatments fully comparable. The average value of a drawn letter is 1.87 , so that the price is slightly above the expected value, which makes buying a letter a risky investment with potentially negative returns. Subjects can skip the investment phase and choose not to buy any letter.

\section{Production}

Subjects are then given the opportunity to produce a word. They can create a new three-letter word (a root), extend an existing word by adding exactly one letter in any position (an extension), or do not produce anything and pass.

All submitted roots or extensions are spellchecked by the system. Moreover, to give stronger incentives to be creative, subjects are not allowed to submit a word previously created by other subjects. All validly created words enter a public word repository that each subject has at the center of its screen at any time. The list of existing words can be sorted alphabetically or by word length, value, and, for IP treatments, word owner and license fee attached to the word.

\section{Intellectual Property}

In IP treatments and in case subjects produced a word (root or extension alike) in the period, they are asked to set a license fee that will apply to their newly-created word. Subjects submit their choice using a line of radio buttons consisting of 11 discrete values, ranging from $0 \%$ to $100 \%$ in steps of $10 \%$, with no default value selected. Subjects can impose license fees only to their marginal contribution to the word created. In the case of a root, license fees are imposed on the whole three-letter word. In the case of an extension, the license fee is imposed only on the added letter.

\footnotetext{
${ }^{5}$ Synchronous decisions have been ruled out both for reasons of software complexity and in order to avoid issues with duplicated words and time pressure.
} 
Let us work out an example. Subject A creates cat, a root of value 5, and imposes a license fee of $60 \%$. Subject B then extends cat into chat. Accordingly, subject B has to pay a license fee of 3 tokens ( 5 times 0.6 ) to subject A for using cat, but can in turn impose a license fee on her marginal contribution to the word, the letter $h$. Her payoff for creating chat is the value of chat (9 tokens) minus the fee paid (3 tokens) and it is hence 6. If subject B sets a license fee $80 \%$ on $h$ (the value of $h$ is 4 ), then a potential extender of chat will have to pay 3 tokens to subject A and 3.2 (80\% of $h$ 's 4 ) to subject B. All these computations are automatically performed by the computer that allocates license fees to the respective marginal contributors.

By imposing license fees on words, subjects can gain additional revenue, when their words are extended by others. However, on the group level, license fees are nothing but a zero-sum mechanism to redistribute wealth as there are no transaction costs.

\section{Idle phase}

When it is not their turn, subjects face the main board of the game. ${ }^{6}$ Here they can keep track of their earnings, follow what other subjects are doing, inspect and sort the list of words created and use an interactive spellchecker for free. ${ }^{7}$

In chat treatments, the main board incorporates a chat box where subjects can communicate with each other. Messages sent to the chat box are instantaneously visualized by all the other 3 subjects in the group.

\subsubsection{Theoretical properties of the design}

Our design aims at recreating in the lab a sequential, cumulative innovation setting inspired by the models of Scotchmer (2004) and most closely Bessen and Maskin (2009). In particular, we induce strict sequentiality, since each extension is created from an existing word by adding one and only one letter.

We translate the concept of innovation in the lab by letting subjects be creative within a familiar space that is vast but intuitively searchable. Moreover, the space is countable, as it resides totally within the chosen dictionary. Every word that can be created according to our rules is fully described by two dimensions: its value that is translated in immediate payoff at the moment of creation and its extendibility. For each root we computed the number and value of all possible extensions. Recursively, we did the same for each extension. We hence have a precise and complete map of the innovation space facing our subjects.

\footnotetext{
${ }^{6}$ A screenshot of the main board can be found in the instructions in appendix B.

${ }^{7}$ The spellchecker has been provided to enable the subjects to explore the space of words and make individual skills less prominent. The spellchecker is based on the system's internal dictionary - in our case, the standard Windows dictionary for German.
} 
Creating extensions requires effort and the presence of roots to be extended, but the reward is higher. This models the effort needed to invent in a natural way: generating complex ideas requires both effort and the ability to stand on the shoulders of giants. Our payoff structure implements constant returns to innovations. That is, an extension is worth exactly its marginal contribution (the added letter) plus the value of the root it is using. Absent any way to transfer the value of the root back to the root creator, in the form of license fees or citations (Hall et al. 2005) (in noIP treatments) then extensions are a much better deal than roots. This payoff structure best describes the situation of basic science - in which the first contributions lay down the foundations, allowing subsequent contributions to carry most of the value - or in the software industry - in which modern software technologies are built on thousands of algorithms, hardware, drivers, etc. that have been accumulated over the years.

Moreover, our experiment includes a key feature of technology markets: the fact that “imitators do not produce direct 'knockoffs,' but rather differentiated products. [... T] The different $R \& D$ paths behind these products permit innovative complementarities. Imitation then increases the 'biodiversity' of the technology [...], improving prospects for future innovation” (Bessen and Maskin 2009, 613). Extensions not only incorporate the existing root, but enlarge it in different directions, increasing the 'biodiversity' and opening up paths for future extensions. Discoveries work through improvement rather than replacement.

Finally, as in Bessen and Maskin (2009, 613) innovations in our experiment are complementary. Each innovator can take a different research line, i.e. produce different words given the same letters, or strike a different deal between value and extension potential, and thus enhance the probability that more sophisticated products are created.

\subsubsection{Testable hypotheses}

\section{What is the effect of IP rights on innovation?}

Our IP treatments are designed to provide an experimental answer to this issue. In our task, overall welfare depends on the relative number of extensions built per each root. Since the expected net value of buying one letter is negative (the expected value of randomly drawing a letter is 1.87 for a cost of 2), a group only producing roots will face a decline in welfare, as compared with the initial endowment. Extensions allow groups to use their resources (letters) several times, producing net welfare gains as investment costs are sunk.

In IP treatments the presence of license fees affects the allocation of the surplus generated by extensions between the upstream and the downstream inventors. IP rights give incentives to innovate, but at the same time impose costs on downstream innovators, and hence act as a brake on the creation of more complex, derivative inventions. As in Scotchmer (1991), the 
effect of IP rights on overall welfare are hence ex-ante ambiguous and we do not posit a specific hypothesis on the matter.

What is the effect of communication on innovation?

We further investigate the individual motivation in contributing to sequential innovation. Based on the findings of the public goods literature, where communication leads to more cooperation (see, among others, Bochet et al. 2006) and the studies pointing to high altruistic contributions in open innovative communities (Lakhani and Hippel 2003), we expect communication to have a positive effect on the innovation rate. We therefore expect communicating subjects to build up group norms of low overall license fees independent of the IP framework. Lower fees would then lead to an increase in the number of extensions for each root, allowing the groups to reach more sophisticated innovations.

Which level of license fee will prevail in the long run?

In IP treatments, in which subjects are free to set their preferred license fee, our task replicates a social dilemma situation. Setting low or no license fees increases the chances of collectively reaching longer, profitable words, providing a public benefit; higher fees, on the other hand, are likely to generate higher private returns. In this context setting low fees can be interpreted as cooperation, since it potentially boosts the group's overall welfare.

Moreover, robust evidence from public good games hint at decreasing levels of cooperation over repetitions of the game and at a strong effect of initial values (see, for instance, Croson 2007; Fischbacher and Gächter 2010). As in public good games, we therefore expect a path dependency following the initial decisions, whereby license fees chosen in the beginning determine the long term average level of license fees within groups. We expect subjects to impose increasing license fees as the game proceeds; we also expect the level and rate of increase to be lower in chat treatments, in which cooperation is facilitated.

\subsubsection{Experimental procedures}

Experiments were conducted in the Laboratory for Behavioral Economics at the University of Göttingen in August and September 2013. The experimental software was written in python and adapted from Crosetto (2010). Participants were recruited with ORSEE Greiner (2004) and were allowed to participate in one session only. We recruited 214 participants. Prior to the experiment, participants were exposed to a language-test to ensure a full working knowledge 
of German. ${ }^{8} 22$ subjects failed the test and had to be excluded from participation. The remaining 192 participants took part in 18 sessions of the experiment.

We implemented a pure between, 2x2 factorial design crossing the dimensions chat/noChat and IP/noIP. Subjects were allocated to 48 groups of 4 players, 12 for each treatment as summarized in table 2.2.

Table 2.2. Overview of the treatment conditions

\begin{tabular}{lcc}
\hline & no communication & communication \\
\hline no IP & noChat/noIP & chat/noIP \\
& $(\mathrm{N}=48)$ & $(\mathrm{N}=48)$ \\
IP - endogenous license fee & noChat/IP & chat $/$ noIP \\
& $(\mathrm{N}=48)$ & $(\mathrm{N}=48)$ \\
\hline
\end{tabular}

Once allowed to participate and before the start of the main task, subjects went through an incentivized word-finding control task. ${ }^{9}$ At the end of the 25 periods of the main task and after being notified their final score and payoff, participants were asked to complete a short not incentivized questionnaire, including demographics, controls for language skills, familiarity with word tasks and risk aversion. Overall participants were 24.1 years old and 53.6\% were female. Sessions lasted around 90 minutes. The 192 participants earned $€ 16.19$ on average, with a minimum payoff of $€ 7.1$ and a maximum of $€ 28.5$.

\subsection{Results}

In this section, we first report treatment effects, analyzing the impact of both the IP and chat manipulations on the total number, quality and value of created words. Since the game is path-dependent, we then test the robustness of our findings by controlling for the actual decision sets faced by each subject at each decision. We then turn to the individual and group level and run regressions to check if results survive when group and individual heterogeneity are taken into account. The focus on individual choices allows us to check to what extent individual choices were consistent with individual, or group payoff maximization. Finally, we analyze the prevailing levels of license fees, their dynamics and whether their level impacts the innovation rate.

\footnotetext{
${ }^{8}$ The test was developed by Kirchkamp and Reiß (2011). The participants had to find the correct words or forms to complete sentences in a German text.

${ }^{9}$ The task was adapted from Eckartz et al. (2012). For details see appendix A.
} 


\subsubsection{Aggregate results: words and value created}

We first test if and to what extent the aggregate output created in our experiment is affected by the presence of IP rights and communication. To measure output we use the total net value created in each group, i.e., the value of all the words created, minus the cost of the letters used to create them.

Table 2.3. Overview of words and value created by treatment

\begin{tabular}{|c|c|c|c|c|c|}
\hline & & noChat/noIP & noChat/IP & chat/noIP & chat/IP \\
\hline letters bought & mean (sd) & $\begin{array}{c}85.5 \\
(7.51)\end{array}$ & $\begin{array}{c}84.3 \\
(8.05)\end{array}$ & $\begin{array}{c}80 \\
(9.16)\end{array}$ & $\begin{array}{l}81.42 \\
(7.43)\end{array}$ \\
\hline \multirow[t]{4}{*}{ total net value } & mean (sd) & $\begin{array}{l}288.25 \\
(44.21)\end{array}$ & $\begin{array}{l}204.92 \\
(46.23)\end{array}$ & $\begin{array}{l}252.42 \\
(76.51)\end{array}$ & $\begin{array}{c}189.17 \\
(56.26)\end{array}$ \\
\hline & median & 295.5 & 210 & 235.5 & 209 \\
\hline & $\min$ & 200 & 103 & 155 & 99 \\
\hline & $\max$ & 350 & 274 & 404 & 280 \\
\hline word length & mean (sd) & $\begin{array}{c}4.97 \\
(0.3756)\end{array}$ & $\begin{array}{c}4.49 \\
(0.3219)\end{array}$ & $\begin{array}{c}4.84 \\
(0.4103)\end{array}$ & $\begin{array}{c}4.37 \\
(0.3573)\end{array}$ \\
\hline word value & mean (sd) & $\begin{array}{c}7.62 \\
(0.5507)\end{array}$ & $\begin{array}{c}6.62 \\
(0.3730)\end{array}$ & $\begin{array}{c}7.31 \\
(0.6985)\end{array}$ & $\begin{array}{c}6.66 \\
(0.6741)\end{array}$ \\
\hline no. extensions & mean (sd) & $\begin{array}{l}49.33 \\
(5.76)\end{array}$ & $\begin{array}{l}43.33 \\
(6.21)\end{array}$ & $\begin{array}{l}45.33 \\
(8.11)\end{array}$ & $\begin{array}{c}38.5 \\
(7.54)\end{array}$ \\
\hline no. roots & mean (sd) & $\begin{array}{l}10.92 \\
(1.98)\end{array}$ & $\begin{array}{c}13 \\
(2.22)\end{array}$ & $\begin{array}{l}10.67 \\
(2.61)\end{array}$ & $\begin{array}{l}14.25 \\
(2.60)\end{array}$ \\
\hline $\begin{array}{l}\text { extensions per } \\
\text { root }\end{array}$ & mean (sd) & $\begin{array}{c}4.69 \\
(1.219)\end{array}$ & $\begin{array}{c}3.41 \\
(.7384)\end{array}$ & $\begin{array}{c}4.58 \\
(1.604)\end{array}$ & $\begin{array}{c}2.81 \\
(.7846)\end{array}$ \\
\hline
\end{tabular}

Table 2.3 summarizes the core results on words and net value created. In the table, the total amount of letters bought represents the level of investment in the group. The average word length, together with the average word value, measure the degree of sophistication reached. The number of roots and extensions measures the share of base and follow-up inventions, respectively. All measures are calculated at the group level.

\subsubsection{The effect of intellectual property rights}

We find that noIP treatments result in significantly higher total net value, with and without chat communication (Mann-Whitney-U (MWU) test for chat/IP and chat/noIP $\mathrm{z}=-1.675$, $\mathrm{p}=.094$; for noChat/IP and noChat/noIP $\mathrm{z}=-3.464, \mathrm{p}=.0005)$. The difference is rather large. In absence of property rights with (without) chat communication the average net value created is 
about 40\% (33\%) higher. The groups performing worst in the noIP treatments achieve a total net value that is $50 \%$ ( $100 \%$ without chat) higher than the worst group of the IP treatments. Figure 2.1 shows that the distribution of total net value across noIP groups dominates the one for the IP groups, both within the chat and the noChat treatments.

Figure 2.1. Total net value by treatment and group
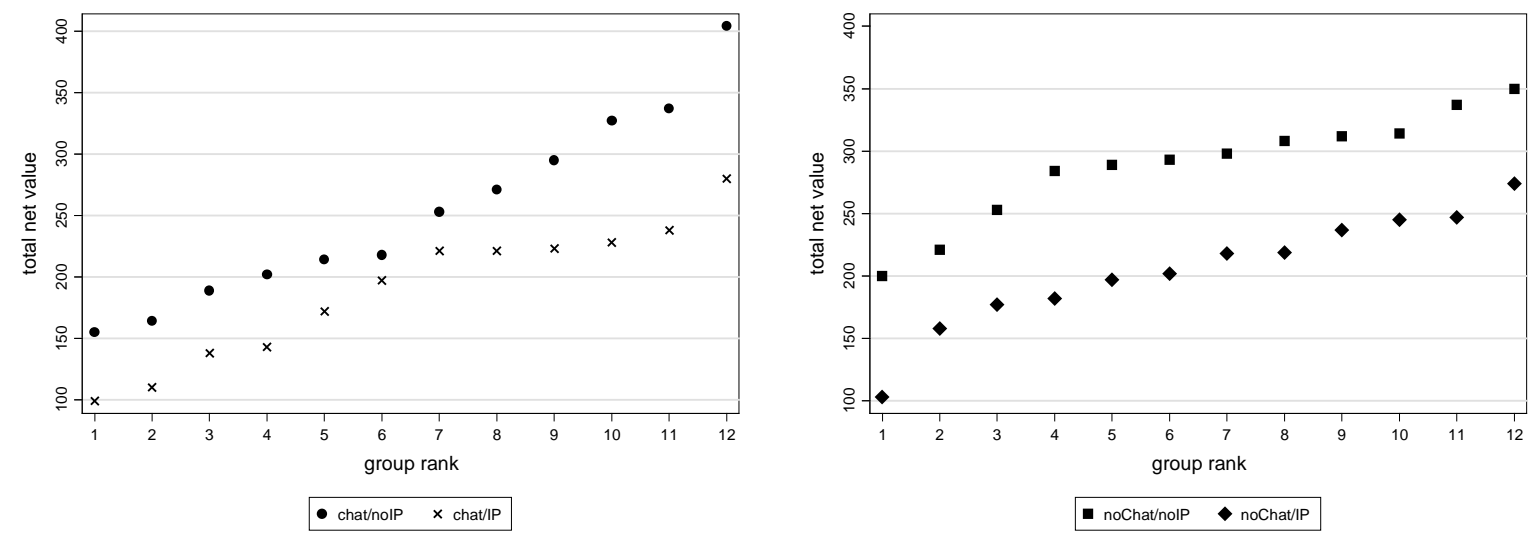

These striking differences are reflected in the characteristics of the words created. Without IP words are longer (MWU-test for chat/IP and chat/noIP $\mathrm{z}=-2.483, \mathrm{p}=.013$; for noChat/IP and noChat/noIP $\mathrm{z}=-2.944, \mathrm{p}=.0032$ ) and tend to be more valuable on average (MWU-test for chat/IP and chat/noIP $\mathrm{z}=-1.559, \mathrm{p}=.119$; for noChat/IP and noChat/noIP $\mathrm{z}=-3.233, \mathrm{p}=.0012$ ). In contrast, the average investment is almost equal across treatments, as measured by the number of letters bought (MWU-test for chat/IP and chat/noIP $\mathrm{z}=0.521, \mathrm{p}=.6024$; for noChat/IP and noChat/noIP z=-0.406, $\mathrm{p}=.6850$ ).

RESULT 1: Introducing IP decreases overall welfare as a comparable level of investment is transformed into less sophisticated and less valuable innovations.

We now analyze what drives these treatment differences. Recall that a group as a whole does not bear any additional costs when building on existing roots or prior extensions, whereby the letters already used generate their inherent payoff again. Letters already bought can be seen as an endowment which was paid for beforehand, i.e. there are only sunk costs but potential gains in creating extensions. As a consequence, overall welfare increases with the relative number of extensions compared to roots. 
Figure 2.2. Number of roots and extensions created, by treatment

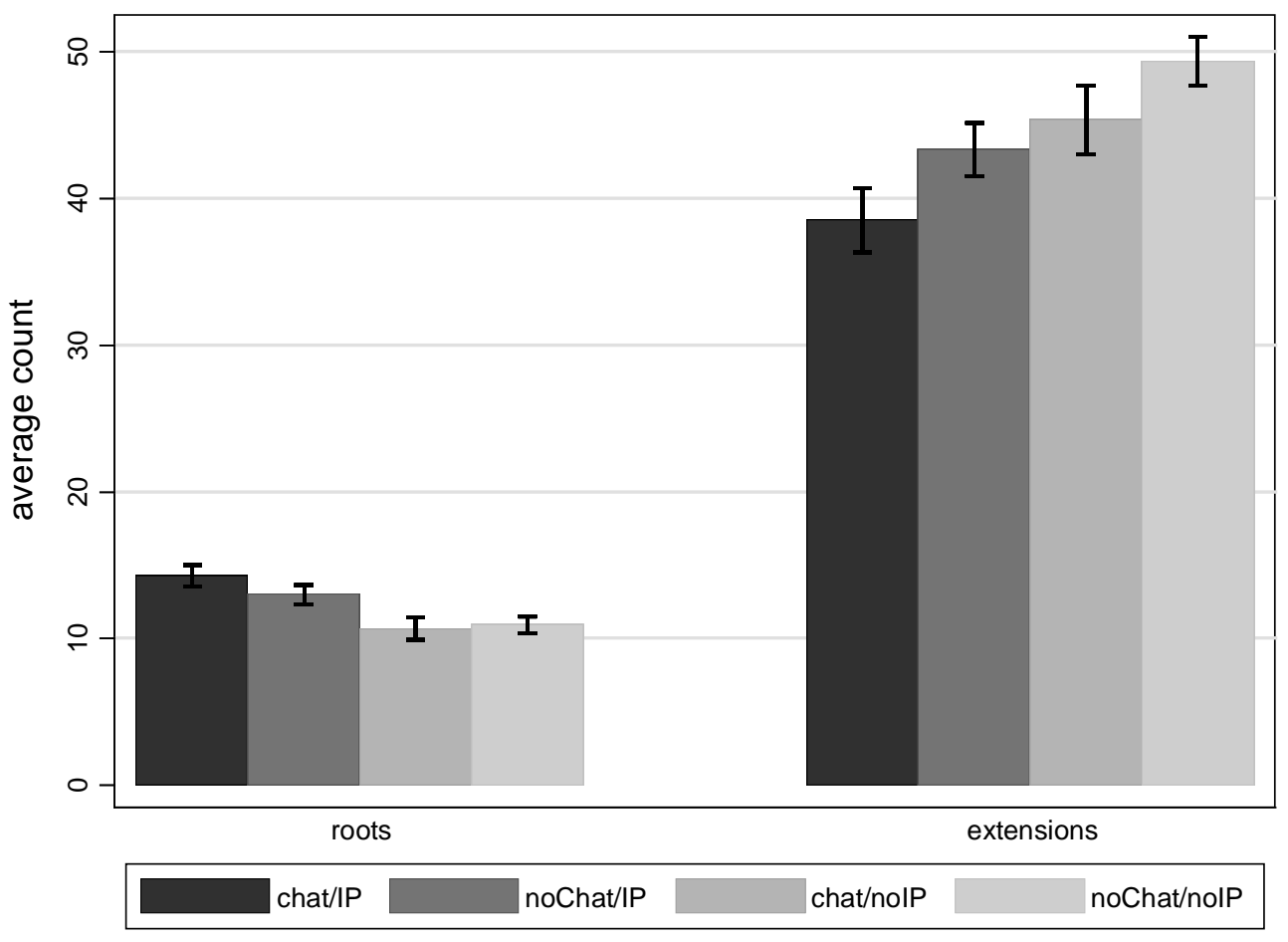

Note: Error bars show st.err. of the mean.

Figure 2.2 shows the average over groups of the number of roots and extensions by treatment. There are substantial differences across treatments. In the IP treatments roots are built significantly more often relative to extensions. In chat/IP (noChat/IP) 71.1\% (71.9\%) of created words are extensions, whereas in chat/noIP (noChat/noIP) the share is $79.3 \%$ (78.5\%). Both differences are statistically significant. Moreover, in the noIP treatments more extensions are created on average from each root (MWU-test for chat/IP and chat/noIP $\mathrm{z}=-$ 2.830, $\mathrm{p}=.0047$; for noChat/IP and noChat/noIP $\mathrm{z}=-2.688, \mathrm{p}=.0072)$. Finally, not only in $I P$ treatments subject created more roots, but these roots had a higher, though not significantly so, extendibility potential, that is, the value of all possible extensions path for each root (2632 for IP vs. 2374 for noIP). This is in line with intuition: in IP treatments subjects had incentives to create more extendible roots since they could expect a higher stream of royalties. Despite this higher potential, in IP treatments there were less extensions per root.

RESULT 2a: The deterioration in welfare due to introducing IP can partially be ascribed to a shift towards more basic innovations relative to the more sophisticated sequential ones. 
We consider another channel through which IP rights could cause detrimental effects on total net value. Subjects might be characterized by a preference for their own creations. That is, they might refrain from extending words created by other players and restrict attention to their own. This might be due to an enhanced familiarity with one's own creations, or, in IP treatments, to avoid license fee payments. If this behavior emerges, profitable opportunities might be missed and the total net value of the group might end up being lower.

This behavior might stem from two different strategies. On the one hand, subjects might be rationally avoiding paying fees and choose to create those words or extensions that give the highest payoff individually but not collectively. In other words, subjects in our IP treatments face collective action problems, while subjects in noIP treatments do not. On the other hand, subjects might show an aversion to license fees even when paying a fee might be the individually optimal choice. In this paragraph, we restrict attention to the preference for own words, irrespective of the reason. We discuss the rationality of this behavior in section 2.3.3 below, where we analyze choices at the individual level.

We investigate the existence of a potential preference for own words by assigning an originator to each word. The originator is the subject who created the root for the respective word. ${ }^{10}$ Assuming an even distribution of letters and skills, if players do not take into account the property status of the word they wish to extend, about one extension in four should originate from the same subject, while three out of four should originate from other subjects. ${ }^{11}$ Higher shares might be expected, however, due to some path dependency causing subjects to find extensions to their own words more easily. Additionally, subjects might think in advance of a stream of extensions when building a root and hence create a word that they are able to extend by themselves as the game proceeds. Nonetheless, for the sake of simplicity we will take a share of $25 \%$ as our benchmark. Figure 2.3 gives the average share of extensions built on self-originated words by treatment.

\footnotetext{
${ }^{10}$ Consider, for instance, a four letter word that was created by subject A and then extended by another subject B: the word is assigned subject A as its originator. This definition strongly simplifies the analysis as we do not have to deal with multiple owners and are still able to make meaningful comparisons based on an appropriate number of observations.

${ }^{11}$ This is the share that should prevail if players do not care about the property of the word they want to extend, and just choose the best option available to them at any time. This is also the expected behavior in the noIP treatments, since in those treatments all words have the same property status - they belong to everyone, and noone.
} 
Figure 2.3. Share of extensions of self-originated words by treatments

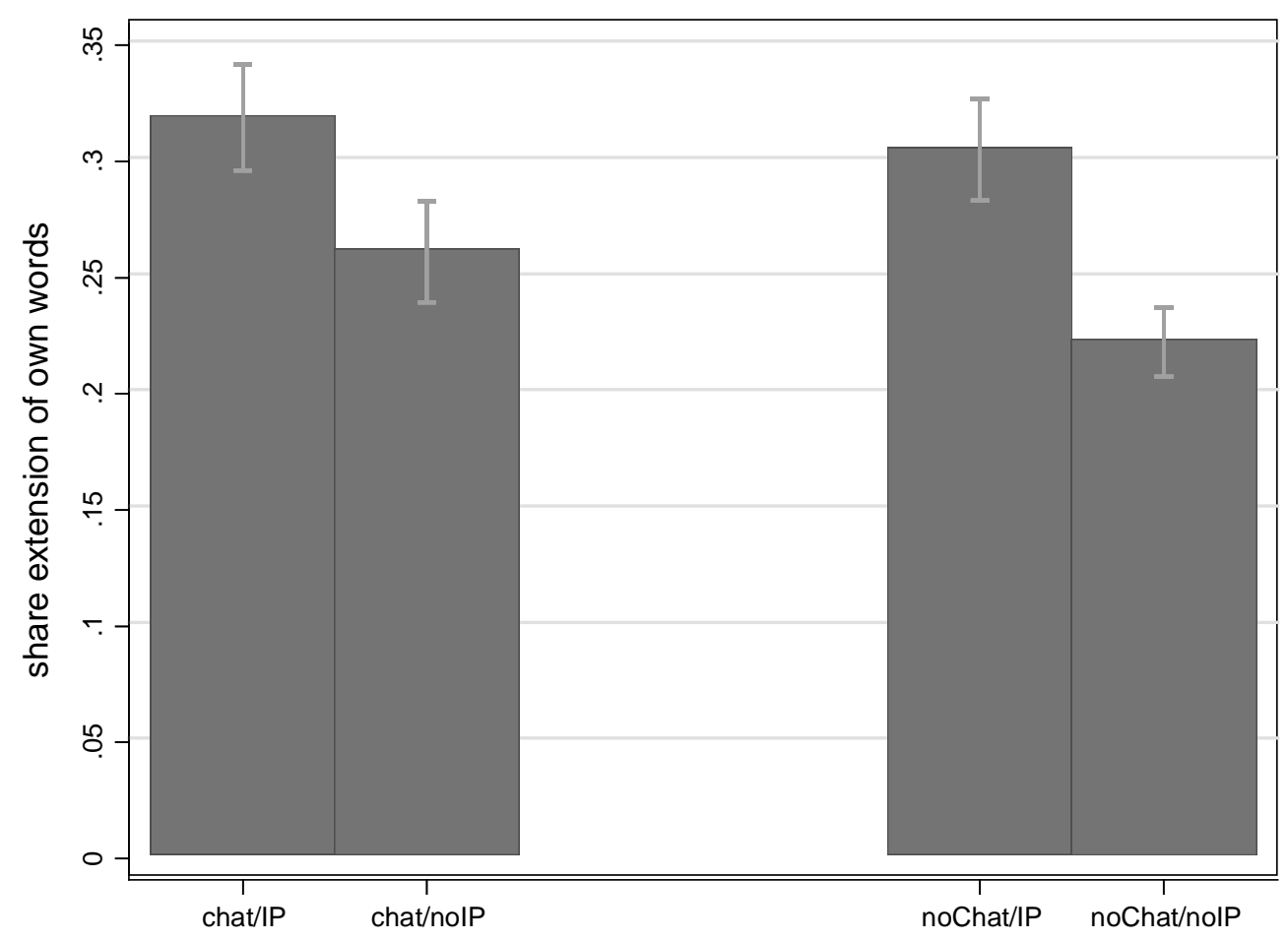

Note: Error bars show st.err. of the mean.

The figure shows that in the noIP treatments the share of self-originated words is near to the $25 \%$ benchmark that we assumed for the case of no preference for own words. In IP treatments, on the other hand, the share is higher than $30 \%$, significantly so with respect to noIP treatments (MWU-test for chat/IP and chat/noIP $\mathrm{z}=1.877, \mathrm{p}=.0605$; for noChat/IP and noChat/noIP z=2.543, $\mathrm{p}=.011$ ).

RESULT 2b: The deterioration in welfare due to introducing IP can partially be ascribed to a shift towards favoring self-originated innovations to avoid paying license fees.

\subsubsection{The effect of communication}

When comparing the communication treatments conditional on the IP regime, we find no significant differences in total net value (MWU-test for chat/IP and noChat/IP $\mathrm{z}=-0.549$, $\mathrm{p}=.5832$; for chat/noIP and noChat/noIP $\mathrm{z}=-1.444, \mathrm{p}=.1487$ ).

The number of letters bought is significantly higher when there is no chat communication for the noIP treatment (MWU-test for chat/IP and noChat/IP $\mathrm{z}=-0.668, \mathrm{p}=.5043$; for chat/noIP and noChat/noIP $\mathrm{z}=-1.852, \mathrm{p}=.0640$ ). The difference for noIP is quite relevant and amounts to 5.5 letters (85.5-80). Without chat communication created words are of the same 
length (MWU-test for chat/noIP and noChat/noIP $\mathrm{z}=-0.808, \mathrm{p}=.4189$; for chat/IP and noChat/IP $\mathrm{z}=-0.751, \mathrm{p}=.4529)$. The effect of communication on word length is not significant in the IP treatments, while in the noIP case the groups allowed to communicate produce slightly shorter words than the groups that were not (MWU-test for chat/noIP and noChat/noIP z=-1.877, $\mathrm{p}=.0605$; for chat/IP and noChat/IP $\mathrm{z}=-0.866, \mathrm{p}=.3864$ ).

These results might be somewhat misleading since not all groups that were offered chat communication actually used it. In chat/IP (chat/noIP) only 58\% (75\%) of groups sent at least one message. We can further define a criterion that identifies groups that actually used the chat communication in a meaningful way, i.e., to discuss the game or possible strategies. ${ }^{12}$ Only 42\% (66\%) of the groups in chat/IP (chat/noIP) did so. However, these groups achieved a higher total net value - 219 (263) on average against 167.86 (231.25) on average - than groups that did not use the chat. These differences are only weakly to not significant (MWUtest for IP $\mathrm{z}=-1.627, \mathrm{p}=.1038$; for $n o I P \mathrm{z}=-1.189, \mathrm{p}=.2345)$. Recall that in noChat/IP the average created net value amounts to 204.92 and in noChat/noIP to 288.25. Accordingly, groups using chat communication in a meaningful way are still incapable of substantially outperforming the average noChat group. We are further not able to identify whether groups offered communication and using it perform better because of the communication itself or because of a self-selection process, whereby more cooperative or more capable group members communicate more often. We conclude that introducing communication by no means precludes the detrimental effects of introducing property rights identified in our experiment.

RESULT 3: Allowing for communication has no effect on overall welfare, regardless of the established IP regime.

\subsubsection{Controlling for the actual choice set}

The results reported above are strong, but are crucially dependent on the path that was taken by the different groups in terms of extendibility of the words created. Each choice by each subject not only gives an immediate payoff, but also shapes the current and future choice sets

\footnotetext{
${ }^{12}$ We define this criterion as being true if players communicate to discuss game related topics and not just greet each other. Communication is defined as game related if they talk about something meaningful with respect to license fees (player 2: “Shall we keep the license fees down?”, player 1: „20 percent is fair :-)”, player 3: ,agreed :)", player 4: “Sounds good”), the words produced (player 1: "did you built miste out of mist or out of mit? @player 2”, player 2: “mist”), looking for help to find words (player 2: “do you have an idea for j?”, player 1: "hmm, no, that's difficult"), making sure the rules of the experiment (player 3: "How many rounds are there? Till there are no letters left?”, [...] player 1: „25 rounds, I think!“, player 4: „yes“) or discussing possible strategies (player 1: "does it make sense to buy a letter in each round? And we maybe always wait to press enter till the time is over to have more time for thinking?”, player 2: “ok”).
} 
of all subjects. In this section, we take care of this problem by introducing an indicator of the value of a word relative to the actual choice set facing a subject at the moment of choice.

Consider the actual choice set $C_{i t}$ given for each subject $i$ in period $t$. This choice set is a function of the letters owned by player $i$ and the existing words at time $t$. For each choice $c_{i t} \epsilon C_{i t}$ we computed the immediate net payoff as $\pi\left(c_{i t}\right)$, subtracting from the raw payoffs the license fee paid and the cost of the letter(s) used. We then compute, alongside the actual payoff $\pi_{i t}$ the maximum $M_{i t}=\max \left\{\pi\left(c_{i t}\right), c_{i t} \epsilon C_{i t}\right\}$ and minimum $m_{i t}=\left\{\pi\left(c_{i t}\right), c_{i t} \epsilon C_{i t}\right\}$ payoffs obtainable from $C_{i t}$.

The actual payoff $\pi_{i t}$ is by definition smaller than or equal to the maximum $M_{i t}$ and greater than or equal to the minimum $m_{i t}$ payoff obtainable. We then can calculate the relative net value of the actual choice by subject $i$ at time $t$, henceforth $R N V_{i t}$, as:

$$
R N V_{i t}=\left(\pi_{i t}-m_{i t}\right) /\left(M_{i t}-m_{i t}\right)
$$

Note that $R N V_{i t} \epsilon[0,1], m \leq 0, M \geq 0$ and $m \leq c \leq M$ for all subjects, periods and treatments. This measure allows us to control for path dependency: higher values of the RNV imply better performance in the specific situation conditional on the actual choice set faced by the subject. Subjects clearly should aim to maximize the RNV as it maximizes payoffs. ${ }^{13}$ Table 2.4 shows the RNV for all treatments pooled over groups and periods.

Table 2.4. Summary statistics of the Relative Net Value by treatments

\begin{tabular}{|c|c|c|c|c|}
\hline & \multicolumn{4}{|c|}{ RNV } \\
\hline & average (sd) & median & $\min$ & $\max$ \\
\hline noChat/noIP & $\begin{array}{c}0.392 \\
(0.0313)\end{array}$ & 0.387 & 0.356 & 0.450 \\
\hline noChat/IP & $\begin{array}{c}0.317 \\
(0.0309)\end{array}$ & 0.311 & 0.274 & 0.378 \\
\hline chat/noIP & $\begin{array}{c}0.366 \\
(0.0569)\end{array}$ & 0.358 & 0.272 & 0.461 \\
\hline chat/IP & $\begin{array}{c}0.3233 \\
(0.0399)\end{array}$ & 0.333 & 0.253 & 0.389 \\
\hline
\end{tabular}

\footnotetext{
${ }^{13}$ Note that, however, using the RNV does not allow for checking if a decision was optimal for the group as a whole. To be capable of defining a decision as being optimal from a group's perspective, we would have to account for all possible paths and future outcomes a root or extension opens up. It is technically possible to do so, but we argue that these calculations are way above the cognitive capabilities of subjects and therefore cannot be considered to measure the optimality of a given choice. Consequently, we build on this rather myopic maximization problem of an individual player.
} 
RESULT 1, 2 and 3 are robust to the introduction of RNV rather than total net value. The Null that all RNVs are equal across treatments can be rejected (Kruskal-Wallis test $\chi^{2}=19.913$ with $\mathrm{df}=3, \mathrm{p}=.0002)$. We find significant differences between IP treatments conditional on the communication regime (MWU-test for chat/IP and chat/noIP $\mathrm{z}=-2.136, \mathrm{p}=.0327$; for noChat/IP and noChat/noIP $\mathrm{z}=-3.811, \mathrm{p}=.0001)$, but no significant differences between communication treatments conditional on the IP regime (MWU-test for chat/IP and noChat/IP $\mathrm{z}=0.520, \mathrm{p}=.6033$; for chat/noIP and noChat/noIP $\mathrm{z}=-1.501, \mathrm{p}=.1333$ ).

While the total value created is always weakly increasing over periods, the RNV can in principle increase or decrease. It increases if subjects learn to better exploit the opportunities they face. It decreases if subjects cannot keep up with the increasing amount of possibilities open to them. The maximum obtainable payoff is an indicator of the opportunities that a group is able to build; the RNV measures to what extent these opportunities are seized by the subjects.

Figure 2.4 shows the development of the maximum, minimum obtainable and actual payoffs over time by treatment.

Figure 2.4. Evolution of minimum, maximum and actual payoffs by period and treatment

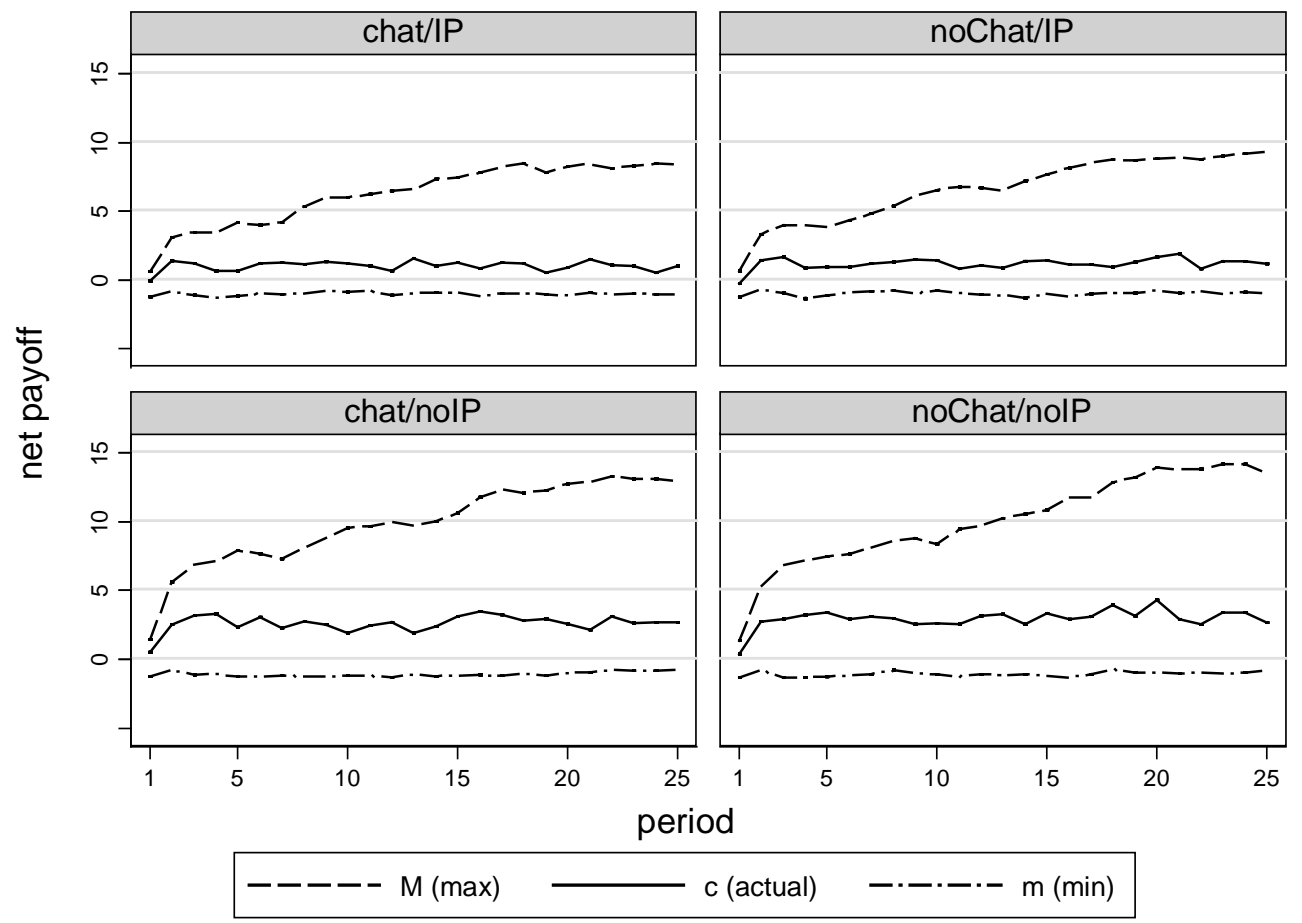

Three remarkable facts are evident from the figure. First, as already noted in table 2.4 above, the average value of subjects' choices is higher in absence of IP. Second, the RNV is decreasing for all treatments as a consequence of the fact that the increase in $\mathrm{M}-$ as more 
words are created opening up more opportunities for subjects - is not matched by a similar increase in actual payoffs. Third, noIP treatments generate way more opportunities than IP treatments - as can be seen from the trajectory of the maximum achievable value (M) shooting off. The slope of $\mathrm{M}$ by period is significantly higher for noIP vs. IP treatments (the slope is 0.4165 for pooled noIP treatments, 0.3069 for pooled IP treatments, differently significant in an interacted regression, $\mathrm{p}<.000$ ). This different success at creating opportunities is due to the fact that in noIP treatments more extensions are built, allowing the subjects to reach longer words and opening up a greater set of choices.

In our experiment, in presence of IP some sequential innovations with a very high value for the whole group are not attainable at all or only with considerable delay. For instance, the most valuable attainable word reaches in treatment noChat/noIP a payoff of 10 by period 13, moving then to reach a maximum over 14 . In the corresponding noChat/IP treatment, $\mathrm{M}$ is at 6.4 by period 13 and it never reaches the value of 10 .

RESULT 4: In presence of IP very valuable sequential innovations are out of reach or achieved with delay only. Absence of IP pushes further the frontier of achievable innovations.

\subsubsection{Results and behavior determinants at the individual and group level}

We now turn to the individual and group level in order to test the robustness of our results and to identify the determinants of performance.

Therefore, we run a simple OLS regression of the RNV on treatment conditions and a set of control variables. We introduce dummy variables for chat and IP treatments; their interaction identifies the chat/IP treatment. The baseline treatment for the regression is noChat/noIP. In order to control for unobserved heterogeneity in subjects' abilities in word creation, we include in the regression their performance in a control task that we designed for the purpose and was run before the experiment. Details of the task and its results can be found in appendix A. We include dummy variables for subjects in the upper and lower 25 percentile of the earned points distribution in the task, denoted as wordtask_high and wordtask_low. Furthermore age, female, proficiency in German (on a scale from 1 to 5) and period are included as explanatory variables. We interact period with the respective treatment condition, as we expect the RNV to decrease more strongly in absence of property rights (see figure 2.4).

Individuals’ performance might crucially depend on the capabilities of the other group members. We therefore run the regression on the group level as well. In this case the most capable member of the group might determine the others' performance as she might open up promising paths by building favorable roots and extensions. The exact opposite might be true 
if there is a member with very low task-specific skills. This aspect is accounted for by redefining the dummy variables wordtask_high and wordtask_low, which in this case refer to the presence of at least one group member showing high or low performance in the control task. Results are summarized in table 2.5.

Table 2.5. Regression results - RNV

\begin{tabular}{|c|c|c|}
\hline & (individual level) & (group level) \\
\hline chat & $\begin{array}{l}\mathbf{- 0 . 0 3 2 5} \\
(0.0321)\end{array}$ & $\begin{array}{l}\mathbf{- 0 . 0 4 1 9} \\
(0.0297)\end{array}$ \\
\hline IP & $\begin{array}{c}-\mathbf{0 . 0 8 3 9} * * \\
(0.0346)\end{array}$ & $\begin{array}{c}-\mathbf{0 . 0 8 7 1} \\
(0.0297 *)\end{array}$ \\
\hline chat_IP & $\begin{array}{c}\mathbf{0 . 0 6 5 3} \\
(0.0534)\end{array}$ & $\begin{array}{c}\text { 0.0794* } \\
(0.0420)\end{array}$ \\
\hline period & $\begin{array}{c}-\mathbf{0 . 0 1 1 2} * * * \\
(0.00145)\end{array}$ & $\begin{array}{c}-\mathbf{0 . 0 1 1 8} * * * \\
(0.00141)\end{array}$ \\
\hline period_chat/IP & $\begin{array}{l}\mathbf{- 0 . 0 0 1 3 5} \\
(0.00265)\end{array}$ & $\begin{array}{l}\mathbf{- 0 . 0 0 1 7 9} \\
(0.00199)\end{array}$ \\
\hline period_noChat/IP & $\begin{array}{l}\mathbf{0 . 0 0 0 2 8 1} \\
(0.00208)\end{array}$ & $\begin{array}{l}\mathbf{0 . 0 0 0 6 0 1} \\
(0.00199)\end{array}$ \\
\hline period_chat/noIP & $\begin{array}{l}\mathbf{0 . 0 0 0 6 4 9} \\
(0.00234)\end{array}$ & $\begin{array}{r}\mathbf{0 . 0 0 0 8 6 2} \\
(0.00199)\end{array}$ \\
\hline high in control task & $\begin{array}{c}\mathbf{0 . 0 1 7 1} \\
(0.0170)\end{array}$ & $\begin{array}{c}\mathbf{0 . 0 1 4 5} \\
(0.0110)\end{array}$ \\
\hline low in control task & $\begin{array}{c}\mathbf{- 0 . 0 5 7 0} * * * \\
(0.0163)\end{array}$ & $\begin{array}{l}\mathbf{- 0 . 0 1 0 2} \\
(0.0115)\end{array}$ \\
\hline female & $\begin{array}{c}-\mathbf{0 . 0 2 5 9} * * \\
(0.0123)\end{array}$ & \\
\hline age & $\begin{array}{c}\mathbf{- 0 . 0 0 4 9 1} * * \\
(0.00233)\end{array}$ & \\
\hline proficiency & $\begin{array}{c}\mathbf{0 . 0 0 2 3 8} \\
(0.00408)\end{array}$ & \\
\hline Constant & $\begin{array}{c}\mathbf{0 . 6 7 3} * * * \\
(0.0608)\end{array}$ & $\begin{array}{c}\text { 0.552*** } \\
(0.0246)\end{array}$ \\
\hline Observations & 4603 & 1200 \\
\hline R-squared & 0.070 & 0.216 \\
\hline
\end{tabular}

Note: Standard errors in parentheses and ${ }^{* * *} \mathrm{p}<0.01,{ }^{* *} \mathrm{p}<0.05,{ }^{*} \mathrm{p}<0.1$. Standard errors are clustered on the group level for the individual level regression.

Estimated coefficients confirm our findings. Introducing IP decreases the created relative net value. A joint significance test for chat and chat_IP does not reject the Null of no influence (on the individual level $\mathrm{F}=0.81, \mathrm{p}=.4502$; on the group level $\mathrm{F}=1.8, \mathrm{p}=.1662$ ). Thus chat communication cannot prevent the negative effect of introducing intellectual property rights. As the game proceeds, created relative net value deteriorates as the marginal effect for period is significant, negative and quite strong. Recall that 25 periods were played, i.e. the 
average RNV is estimated to almost halve from the first to very last period. This result confirms the developments shown in figure 2.4, although the interaction of period and IP is not significant, indicating that there is no significant difference in the downward trend between treatments. The indicator variables for the performance in the control task show the expected signs. On the individual level we find a significantly worse performance of subjects performing weakly in our control task. Females and older participants tend to perform worse, while the self-reported level of proficiency in German shows no significant influence.

All in all, our results prove robust when controlling for the dynamics of the game, the actual choice set and participants characteristics at the individual and group level.

The results of the RNV regressions shed light on another reason why IP leads to comparatively worse performance: in IP treatments subjects restrict attention to selforiginated words more than what optimal behavior would grant. In presence of license fees, optimality for the individual and for the group diverge. Roots and extensions of own words are more favorable as no license fee payments are induced. Thus, the observed systematic shift in behavior towards more roots and more self-originated words could reflect a rational, payoff-maximizing adjustment at the individual level. The RNV regressions show that this is not the case. In IP treatments subjects not only create less opportunities (lower maximum available payoff, see figure 2.4), but they also perform worse relative to these reduced opportunities, as clearly indicated by the strong and significant negative sign for IP in the RNV regressions. In IP treatments subjects overreact to the introduction of IP and forego substantial gains by trying to avoid license fee payments. As a consequence the total value created decreases even more than it could be expected when assuming fully rational behavior.

RESULT 5: IP causes behavior to change even more drastically than it could be expected by assuming rational behavior. Subjects opt for lower net payments to avoid license fees.

\subsubsection{Dynamics of license fees}

In IP treatments subjects were able to choose the license fee between 0 and $100 \%$ of the value of their marginal contribution to the word. Figure 2.5 shows the average license fees chosen over periods for the IP treatments. Average fees tend to increase as the game proceeds. ${ }^{14}$ Since the chosen fee can be interpreted as a measure of the level of cooperation within a group (cooperation increases as the fee demanded goes down), this finding resembles the

\footnotetext{
${ }^{14}$ Although the result of increasing license fees is not generalizable as subjects knew the finite horizon of 25 periods, it is an interesting finding which well connects to the findings in public goods experiments, see Ostrom (2000).
} 
typical pattern of social interaction shown in many public good experiments (see, for instance, Fischbacher and Gächter 2010). In the first five periods, the average fee amounts to 0.59 (0.49) in chat/IP (noChat/IP); it increases to 0.69 (0.63) in the last five periods. Overall, the presence of communication does not seem to avoid deteriorating cooperation levels; overall fee levels are not significantly different between chat/IP and noChat/IP (MWU-test $\mathrm{z}=0.924$, $\mathrm{p}=.3556)$. $^{15}$

Figure 2.5. Average license fees over periods by treatment and within chat/IP
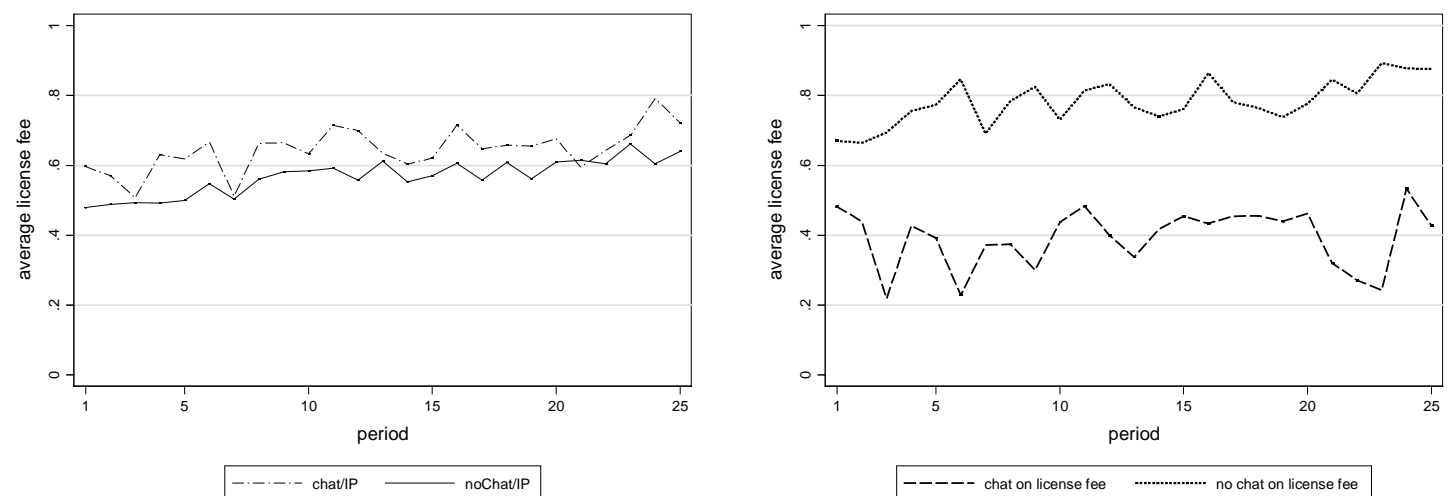

We additionally distinguish groups that use chat communication to discuss license fee levels from those that do not. ${ }^{16}$ The former tend to be able to maintain lower fees over the course of the experiment. Communicating groups start off at low fees and are able to avoid a deterioration of cooperation. Observing group members that refrain from communication might be interpreted as a strong statement for the unwillingness to cooperate in general, which then leads to higher fees in comparison to treatments in which there is no opportunity to communicate in the first place. However, this difference within the chat/IP treatment might be due to self-selection. The difference cannot be held as evidence in support of a positive communication effect.

Overall, we conclude that, but for a small subset of groups, chat communication is by and large not used to solve the collective action problem introduced by the presence of IP. We interpret this finding as lending additional support to RESULT 3: communication is not an

\footnotetext{
${ }^{15}$ Please note that increasing license fees are not due to more extensions being built as the game proceeds. In fact, for both IP treatments license fees tend to be lower for extensions (chat/IP for the first half of the game $m=0.61$, $s d=0.28$ and for the second half $m=0.65$, $s d=0.29$; noChat/IP for the first half $m=0.50$, sd=0.20 and for the second half $\mathrm{m}=0.57$, $\mathrm{sd}=0.24$ ) in comparison to roots (chat/IP for the first half of the game $\mathrm{m}=0.66$, $\mathrm{sd}=0.58$ and for the second half $\mathrm{m}=0.71$, $\mathrm{sd}=0.29$; noChat $/ \mathrm{IP}$ for the first half $\mathrm{m}=0.58, \mathrm{sd}=0.22$ and for the second half $\mathrm{m}=0.65$, $\mathrm{sd}=0.23$ ).

${ }^{16}$ Note that out of 12 groups in chat/IP only 5 groups actually used chat communication and only 4 specifically discussed the levels of license fees to choose.
} 
appropriate means to prevent the detrimental effect of intellectual property rights in our sequential innovation setting.

The average level of license fees increases over time; nonetheless, the best predictor for the fee levels in the latter part of the experiment are fee levels in the first three periods. Figure 2.6 shows a strong positive correlation of the average license fee in the first three and in the subsequent 22 periods.

Figure 2.6. License fees path dependency

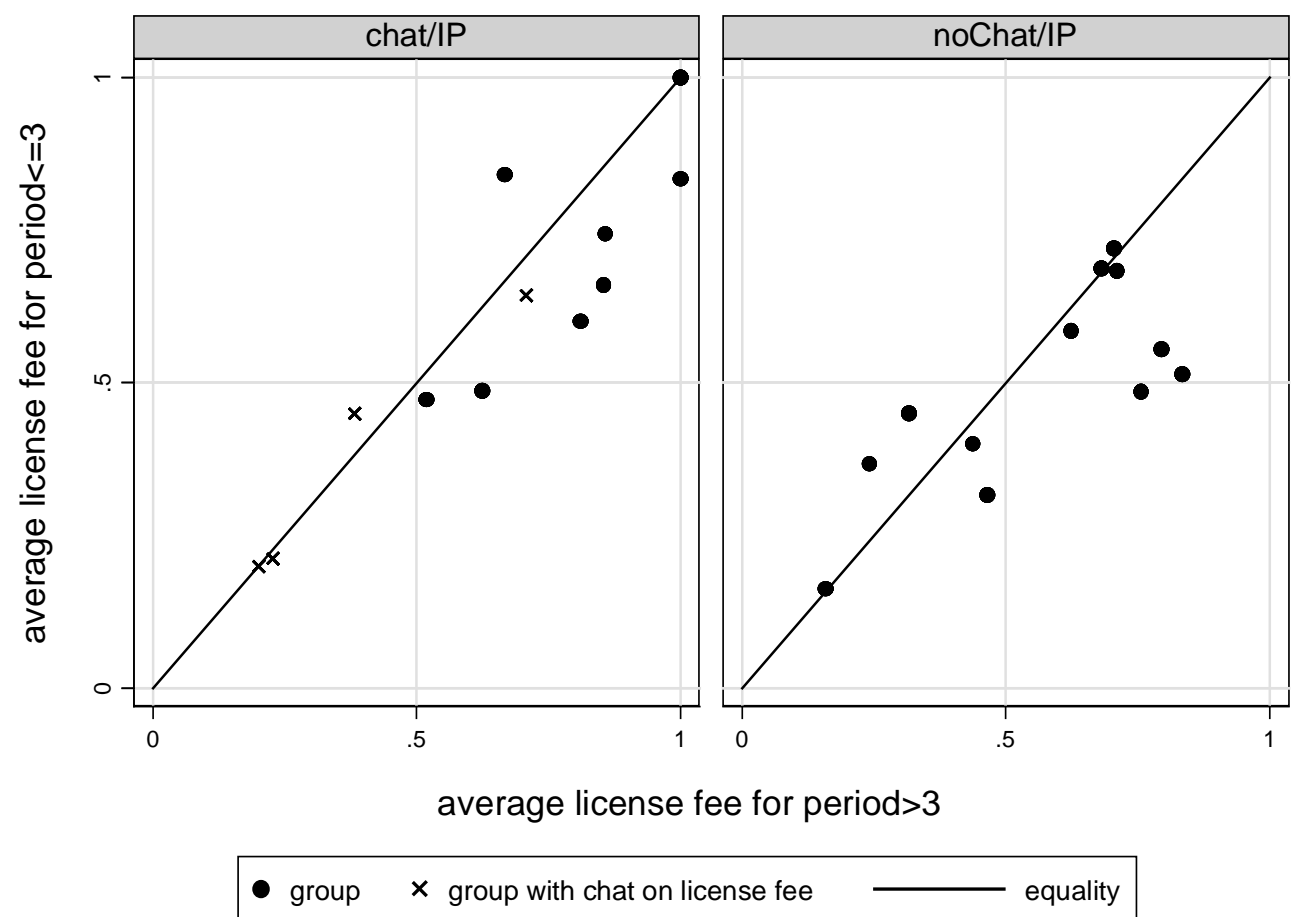

Since average fees are increasing over time, there are some deviations toward the right hand side of the perfect correlation line. However, these deviations are rather modest. For chat/IP the correlation amounts to $0.9108(\mathrm{p}<.0000)$ and for noChat/IP correlation is 0.7663 $(\mathrm{p}<.0000)$. This points to a higher share of groups that are able to agree upon a rather stable level of license fees by means of communication. If we further focus on the groups that use the chat to talk about fee levels, the correlation is $(0.9739$, compared to 0.7494 for noncommunicating groups). We confirm the finding that some groups are able to use communication to achieve fee stability at low levels. As above, we cannot ascribe for sure this result to communication in general, since self-selection is at play. The average level of license fees for the whole game is foremost determined by actions in the very first periods rather than communication. 
RESULT 6: Cooperation as measured by license fees demanded proves path-dependent and tends to decrease over time; its level is determined by actions in the very first stages of the game.

\subsubsection{Importance of demanded license fees}

We showed that introducing IP reduces total welfare in our sequential innovation experiment. License fee levels serve as an indicator for cooperation that we found to be path dependent but by and large independent of the chat communication. However, actual license fee levels might explain variation in welfare created across groups, as one might expect groups agreeing upon low fees to perform in a similar way to the ones acting in absence of IP. Figure 2.7 plots, for each group, average fee levels against achieved welfare as measured by total net value.

Figure 2.7. Average license fees and total net value RNV

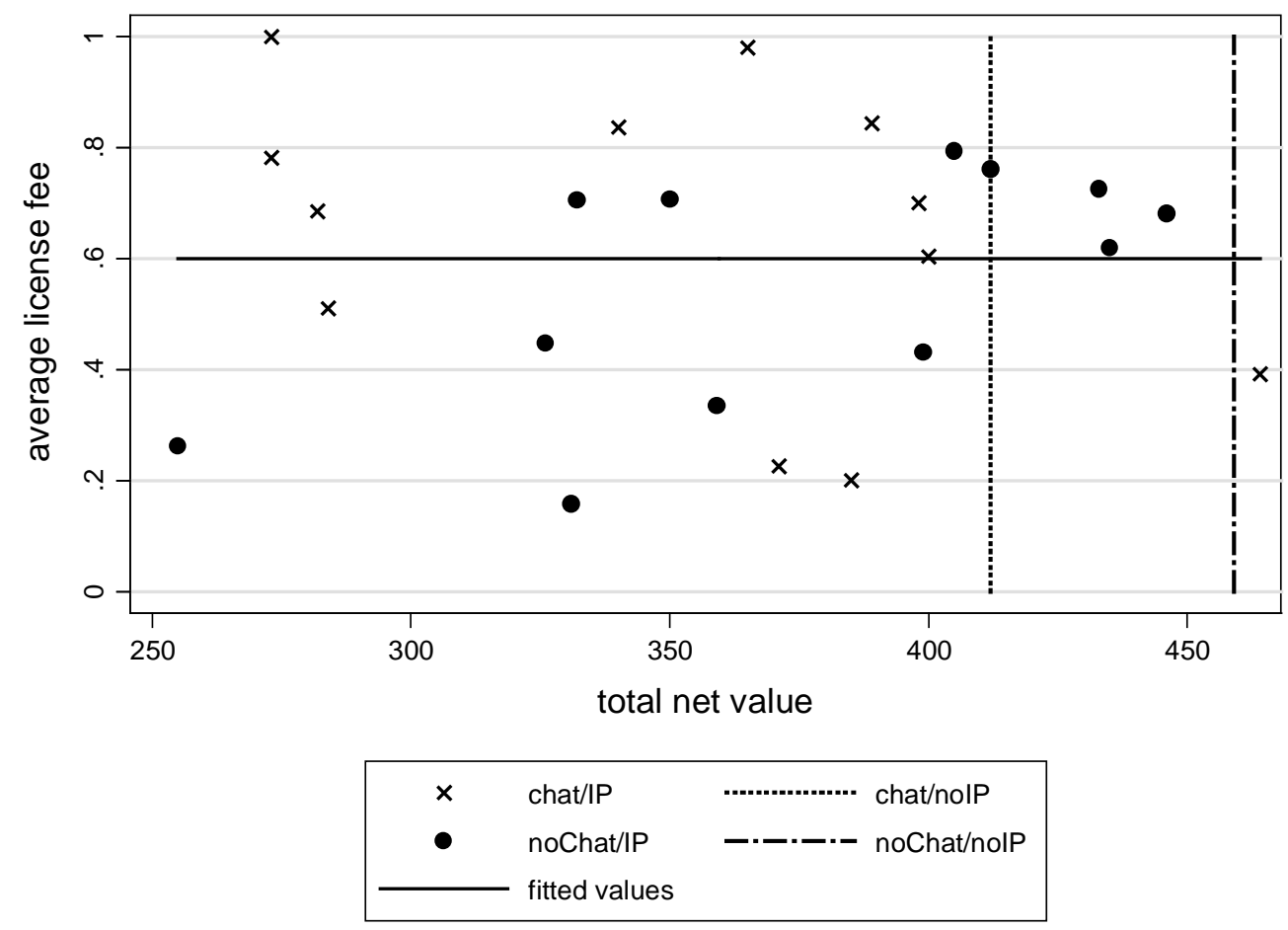

While there seems to be a weak negative correlation of fee levels and total net value when there is chat communication, this relationship is reversed without communication. Pooling together both IP treatments gives a correlation of average license fee and total value created that is close to $0(\rho<-0.0000)$. Endogenously chosen fee levels are hence not systematically 
related with the group's total output. We conclude that introducing an IP regime has a negative effect per se: the absolute levels of license fees are irrelevant.

RESULT 7: Absolute levels of license fees are of no importance for the detrimental effect of an IP regime.

\subsection{Conclusion}

This paper contributes to the debate on the role of intellectual property rights by means of a laboratory experiment. We recreate in the laboratory a sequential innovation environment, and use a word-creation task that combines the central features of innovation, investment and creativity, in one experiment. We use this task to investigate the effects of the presence or absence of intellectual property rights on innovation activity and welfare. We further assess the effect of communication with and without IP.

Results clearly show that the introduction of intellectual property hinders innovation. In presence of IP the economy produces less valuable innovations, and welfare decreases. Introducing IP causes a shift towards more basic innovations and a higher degree of autarky i.e., relying on the self-produced prior innovations rather than building on the best available opportunity within the economy at large. Conversely, the absence of IP results in more sophisticated and more valuable innovations and provides incentives to stand on the shoulders of giants, opening up more profitable innovation paths. Moreover, the negative effects of IP are not a short term phenomenon, but rather worsen over time as license fees tend to increase, leading to the breakdown of cooperative efforts and the use of autarkic strategies.

These results are robust to the introduction of communication. The possibility to cooperate directly via chat, i.e. the possibility to negotiate a mutually beneficial level of license fees, is only seldom exploited, and if so, it does not lead to increased levels of innovation and welfare.

Our experimental approach gives us distinct control over confounding factors, and produces clean causal evidence. At the same time, the validity of results from the lab for actual field conditions might be questioned. Therefore, we chose a task that included several features of real innovations - the sequential nature, the intrinsic plus the potential value of innovations, the role of creativity, knowledge, cooperation, competition, and skill, the presence of risky investments -, that were at the same time intuitive for subjects and completely controllable by the experimenters. To the extent that the characteristics of our task match the ones of actual innovation industries our results can be applied also outside the laboratory. 
Our results suggest that in industries where innovations are strongly sequential - as in pharmaceutical, bioengineering, and software industries - granting intellectual property rights might slow down the rate of innovation and reduce welfare. Thus, our findings lend support to the arguments against the extension of intellectual property to new fields, especially if they are characterized by fast, frequent, small and cumulative innovations - as is the case of software patents. Our findings are in line with insights from the model of Bessen and Maskin (2009) and the case against IP made by Boldrin and Levine (2013).

In our experiment both innovation and welfare thrive without IP, as it happened to several industries in the past, and are hampered by the presence of intellectual property rights, whose stated reason to exist is, paradoxically, to foster innovation. 


\section{Acknowledgments}

Financial support for conducting the laboratory experiments from the German Federal Ministry of Education and Research and the German Aerospace Center is gratefully acknowledged (Grant number 01UN1014A). Further support of the German Federal Ministry of Education and Research via the Hans-Böckler-Stiftung is gratefully acknowledged. We would like to thank Dennis Kotte for student assistance in programming and running the experiments.

\section{References}

Aghion, Philippe, Nicholas Bloom, Richard Blundell, Rachel Griffith, and Peter Howitt. 2002. "Competition and innovation. An inverted U relationship.” NBER Working Paper 9296.

Arrow, Kenneth J. 1962. "Economic welfare and the allocation of resources for invention." In The rate and direction of inventive activity. Economic and social factors, ed. Richard R. Nelson. Princeton, NJ: Princeton University Press, 609-26.

Bessen, James and Eric Maskin. 2009. "Sequential innovation, patents, and imitation.” The RAND Journal of Economics, 40(4): 611-35.

Bessen, James and Michael J. Meurer. 2008. “Do patents perform like property?” The Academy of Management Perspectives, 22(3): 8-20.

Bochet, Olivier, Talbot Page, and Louis Putterman. 2006. "Communication and punishment in voluntary contribution experiments." Journal of Economic Behavior \& Organization, 60(1): 11-26.

Boldrin, Michele and David K. Levine. 2008. "Perfectly competitive innovation.” Journal of Monetary Economics, 55(3): 435-53.

Boldrin, Michele and David K. Levine. 2013. “The case against patents.” The Journal of Economic Perspectives, 27(1): 3-22.

Buccafusco, Christopher and Christopher Sprigman. 2010. "Valuing intellectual property. An experiment.” Cornell Law Review, 96(1): 1-46.

Buchanan, Joy A. and Bart J. Wilson. 2014. "An experiment on protecting intellectual property.” Experimental Economics, 17(4): 691-716.

Cantner, Uwe, Werner Güth, Andreas Nicklisch, and Torsten Weiland. 2009. "Competition in product design. An experiment exploring innovation behavior." Metroeconomica, 60(4): 724-52.

Crosetto, Paolo. 2010. "To patent or not to patent. A pilot experiment on incentives to copyright in a sequential innovation setting." In IFIP advances in information and communication technology, Open source software. New horizons. 6th International IFIP WG 2.13 Conference on Open Source Systems, ed. Pär J. Ågerfalk, Cornelia Boldyreff, Jesús M. González-Barahona, Gregory R. Madey, and John Noll. Berlin, New York: Springer, 53-72.

Croson, Rachel T. 2007. “Theories of commitment, altruism and reciprocity. Evidence from linear public goods games.” Economic Inquiry, 45(2): 199-216.

Denicolò, Vincenzo. 2008. "Ecomonic theories of the nonobviousness requirement for patentability. A survey.” Lewis \& Clark Law Review, 12(2): 443-59. 
Dimmig, Anne-Kathrin and Mathias Erlei. 2013. "Quasi-rational R\&D behavior in an environment with fundamental uncertainty.” TUC Working Papers in Economics 0008.

Dosi, Giovanni, Luigi Marengo, and Corrado Pasquali. 2006. "How much should society fuel the greed of innovators? On the relations between appropriability, opportunities and rates of innovation.” Research Policy, 35(8): 1110-21.

Eckartz, Katharina, Oliver Kirchkamp, and Daniel Schunk. 2012. "How do incentives affect creativity?” CESifo Working Paper 4049.

Ederer, Florian and Gustavo Manso. 2013. "Is pay-for-performance detrimental to innovation?” Management Science, 59(7): 1496-513.

Ernst, Holger. 2001. "Patent applications and subsequent changes of performance. Evidence from time-series cross-section analyses on the firm level." Research Policy, 30(1): 14357.

Fershtman, Chaim and Sarit Markovich. 2010. "Patents, imitation and licensing in an asymmetric dynamic R\&D race.” International Journal of Industrial Organization, 28(2): 113-26.

Fischbacher, Urs and Simon Gächter. 2010. "Social preferences, beliefs, and the dynamics of free riding in public goods experiments." The American Economic Review, 100(1): 541-56.

Furukawa, Yuichi. 2007. "The protection of intellectual property rights and endogenous growth. Is stronger always better?” Journal of Economic Dynamics and Control, 31(11): 3644-70.

Gallini, Nancy T. and Suzanne Scotchmer. 2002. "Intellectual property. When is it the best incentive system?” In Innovation policy and the economy. Volume 2, ed. Adam B. Jaffe, Josh Lerner, and Scott Stern. Chicago: MIT Press, 51-77.

Green, Jerry R. and Suzanne Scotchmer. 1995. "On the division of profit in sequential innovation.” The RAND Journal of Economics, 26(1): 20-33.

Greiner, Ben. 2004. “An online recruitment system for economic experiments.” In GWDG Bericht, Forschung und wissenschaftliches Rechnen, ed. Kurt Kremer and Volker Macho. Göttingen, 79-93.

Hall, Bronwyn H. and Dietmar Harhoff. 2012. "Recent research on the economics of patents.” NBER Working Paper 17773.

Hall, Bronwyn H., Adam B. Jaffe, and Manuel Trajtenberg. 2005. "Market value and patent citations.” The RAND Journal of Economics, 36(1): 16-38.

Hashmi, Aamir R. 2013. "Competition and innovation. The inverted-U relationship revisited." The Review of Economics and Statistics, 95(5): 1653-68.

Heller, Michael A. and Rebecca S. Eisenberg. 1998. "Can patents deter innovation? The anticommons in biomedical research.” Science, 280(5364): 698-704.

Hunt, Robert M. 2004. “Patentability, industry structure, and innovation.” The Journal of Industrial Economics, 52(3): 401-25.

Jaffe, Adam B. 2000. "The U.S. patent system in transition. Policy innovation and the innovation process.” Research Policy, 29(4): 531-57.

Kirchkamp, Oliver and J. P. Reiß. 2011. "Out-of-equilibrium bids in first-price auctions. Wrong expectations or wrong bids.” The Economic Journal, 121(557): 1361-97. 
Lakhani, Karim R. and Eric von Hippel. 2003. "How open source software works. "Free” user-to-user assistance.” Research Policy, 32(6): 923-43.

Lanjouw, Jean O. and Josh Lerner. 2000. "The enforcement of intellectual property rights. A survey of the empirical literature." In The economics and econometrics of innovation, ed. David Encaoua, Bronwyn H. Hall, François Laisney, and Jacques Mairesse. Boston, MA: Springer, 201-24.

Lerner, Josh. 2009. “The empirical impact of intellectual property rights on innovation. Puzzles and clues.” The American Economic Review, 99(2): 343-48.

Machlup, Fritz. 1958. “An economic review of the patent system.” U.S. Congress. Government Printing Office. Study of the Subcommitee on Patents, Trademarks and Copyrights of the Committee on the Judiciary 15.

Meloso, Debrah, Jernej Copic, and Peter Bossaerts. 2009. "Promoting intellectual discovery. Patents versus markets.” Science, 323(5919): 1335-39.

Moschini, Gian C. and Oleg Yerokhin. 2008. "Patents, research exemption, and the incentive for sequential innovation.” Journal of Economics \& Management Strategy, 17(2): 379-412.

Nordhaus, William D. 1969. Invention, growth and welfare. A theoretical treatment of technological change. Cambridge, MA: MIT Press.

Ostrom, Elinor. 2000. "Collective action and the evolution of social norms.” The Journal of Economic Perspectives, 14(3): 137-58.

Qian, Yi. 2007. "Do national patent laws stimulate domestic innovation in a global patenting environment? A cross-country analysis of pharmaceutical patent protection, 1978-2002." The Review of Economics and Statistics, 89(3): 436-53.

Scherer, Frederic M. 1972. "Nordhaus' theory of optimal patent life. A geometric reinterpretation.” The American Economic Review, 62(3): 422-27.

Scotchmer, Suzanne. 1991. "Standing on the shoulders of giants. Cumulative research and the patent law." The Journal of Economic Perspectives, 5(1): 29-41.

Scotchmer, Suzanne. 2004. Innovation and incentives. Cambridge, MA: MIT Press.

Sørensen, Flemming, Jan Mattson, and Jon Sundbo. 2010. "Experimental methods in innovation research.” Research Policy, 39(3): 313-23.

Stiglitz, Joseph E. 2008. "Economic foundations of intellectual property rights.” Duke Law Journal, 57(6): 1693-724.

Toubia, Olivier. 2006. "Idea generation, creativity, and incentives." Marketing Science, 25(5): 411-25.

Williams, Heidi L. 2013. "Intellectual property rights and innovation. Evidence from the human genome.” Journal of Political Economy, 121(1): 1-27. 


\section{Appendix}

\section{Appendix A}

Performance in the control task

Before starting the experiment, we ran a control task to measure the subjects' word-creation abilities, with the aim of creating a variable to control for skill heterogeneity in our regression analysis. The control task is built on Eckartz et al. (2012). All subjects are endowed with the same alphabetically ordered set of 12 letters (accehhikllst), and have 3 minutes to build as many words as possible, using only letters from the set. Each word earns the subject points. The value of the words created increases more than proportionally in length: a three-letter word yields 6 points, a four-letter words 10, a five-letter word 15, etc. In total, the given letter set allows to build 330 words, worth 5585 points. ${ }^{17}$ The task is incentivized by rewarding the performance of the best three subjects in each session with $€ 1$. Figure A2.1 gives an overview of the distribution of the groups' performance across treatments as measured by points earned.

Figure A2.1. Performance in the control task by group and treatment

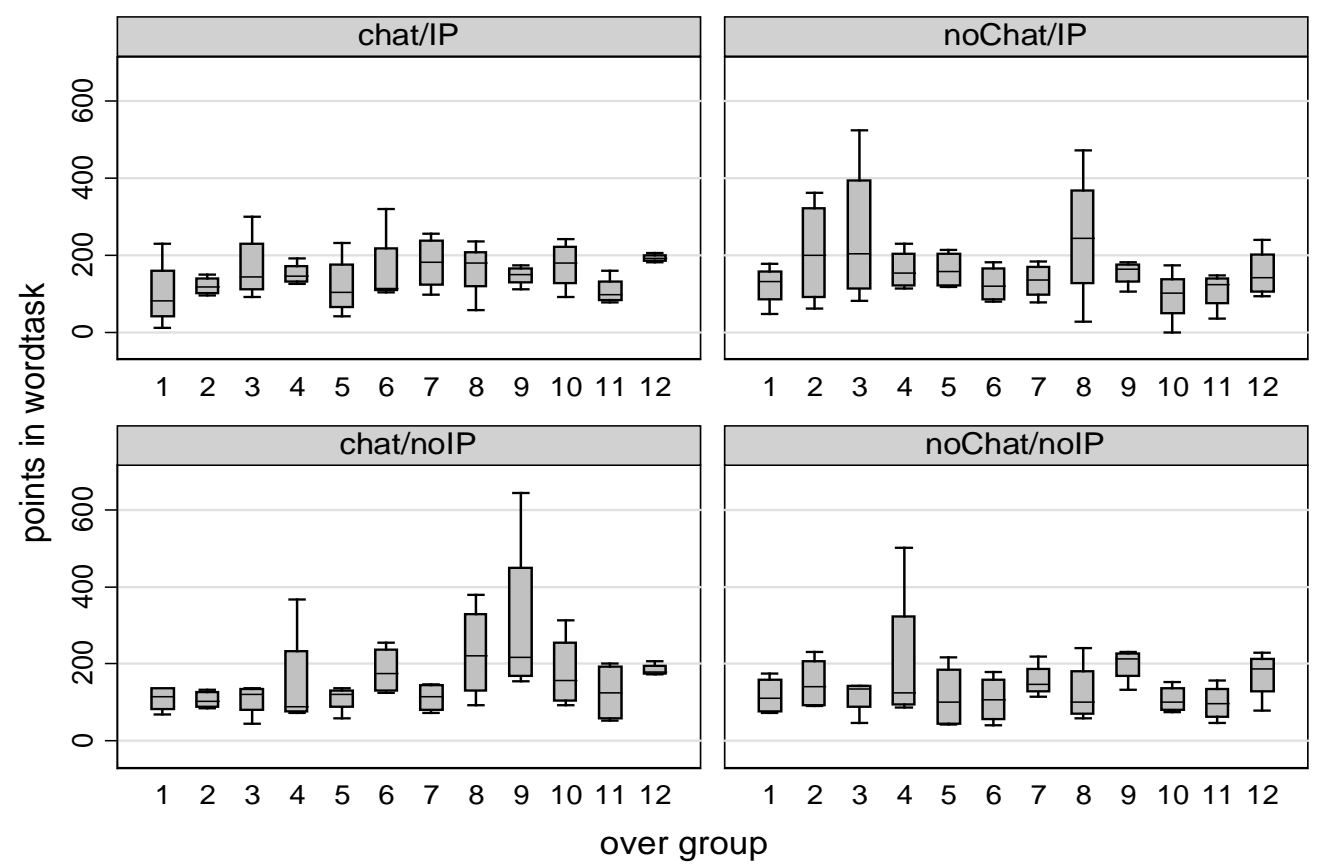

While there is some heterogeneity on the group level, differences equal out at the treatment level. Applying a Kruskal-Wallis test on the group level, we fail to reject the Null of equal performance across treatments $\left(\chi^{2}=1.021\right.$ with $\left.\mathrm{df}=3, \mathrm{p}=.7962\right)$. Overall, our groups do not statistically differ in word-creation skills across treatments. Individuals' differences in the control task are used to control for individual skills in the regressions of section 2.3.3.

\footnotetext{
${ }^{17}$ The instructions for the control task can be found in appendix C.
} 


\section{Appendix B}

Instructions

Note: We report here the English translation of the original German instructions for all treatments. The differences between treatments are indicated in square brackets. The original German instructions are available upon request.

\section{The Game}

In this experiment, your task is to build words out of letters as in the board game "Scrabble". By building words you increase your payoff: For each word you get a payoff calculated by the sum of the values of each letter. You start the game with an endowment of 4 letters. During the course of the game, you are able to buy additional letters.

During the course of the game, you will play in a group of 4 players [chat treatments: with whom you are able to chat].

\section{Payoffs}

Your payoff depends on the sum of the value of your letters, which is calculated in experimental tokens. One token is converted to 0.12 Euro at the end of the experiment. You start the game with an endowment of 75 tokens. Note that it is possible to end the experiment with less than your starting endowment.

Please note the table below containing all letters, their value (in tokens) and the frequency with which they occur in the game. During the game the letters are always displayed along with their value.

Table A2.1. List of letters

\begin{tabular}{|c|c|c|c|c|c|c|c|c|}
\hline Letter & Value & Frequency & Letter & Value & Frequency & Letter & Value & Frequency \\
\hline $\mathrm{A}$ & 1 & 10 & $\mathrm{~J}$ & 6 & 2 & $\mathrm{~S}$ & 1 & 14 \\
\hline $\mathrm{B}$ & 3 & 4 & $\mathrm{~K}$ & 4 & 4 & $\mathrm{~T}$ & 1 & 12 \\
\hline $\mathrm{C}$ & 4 & 4 & $\mathrm{~L}$ & 2 & 6 & $\mathrm{U}$ & 1 & 12 \\
\hline $\mathrm{D}$ & 1 & 8 & $\mathrm{M}$ & 3 & 8 & $\mathrm{~V}$ & 6 & 2 \\
\hline $\mathrm{E}$ & 1 & 30 & $\mathrm{~N}$ & 1 & 18 & $\mathrm{~W}$ & 3 & 2 \\
\hline $\mathrm{F}$ & 4 & 4 & $\mathrm{O}$ & 2 & 6 & $\mathrm{X}$ & 8 & 2 \\
\hline $\mathrm{G}$ & 2 & 6 & $\mathrm{P}$ & 4 & 2 & $\mathrm{Y}$ & 10 & 2 \\
\hline $\mathrm{H}$ & 2 & 8 & $\mathrm{Q}$ & 10 & 2 & $\mathrm{Z}$ & 3 & 2 \\
\hline $\mathrm{I}$ & 1 & 12 & $\mathrm{R}$ & 1 & 12 & & & \\
\hline
\end{tabular}

On the next page you will find a screenshot of the main board of the game and some explanations to get a first overview of the game. A detailed explanation of the game ensues. 


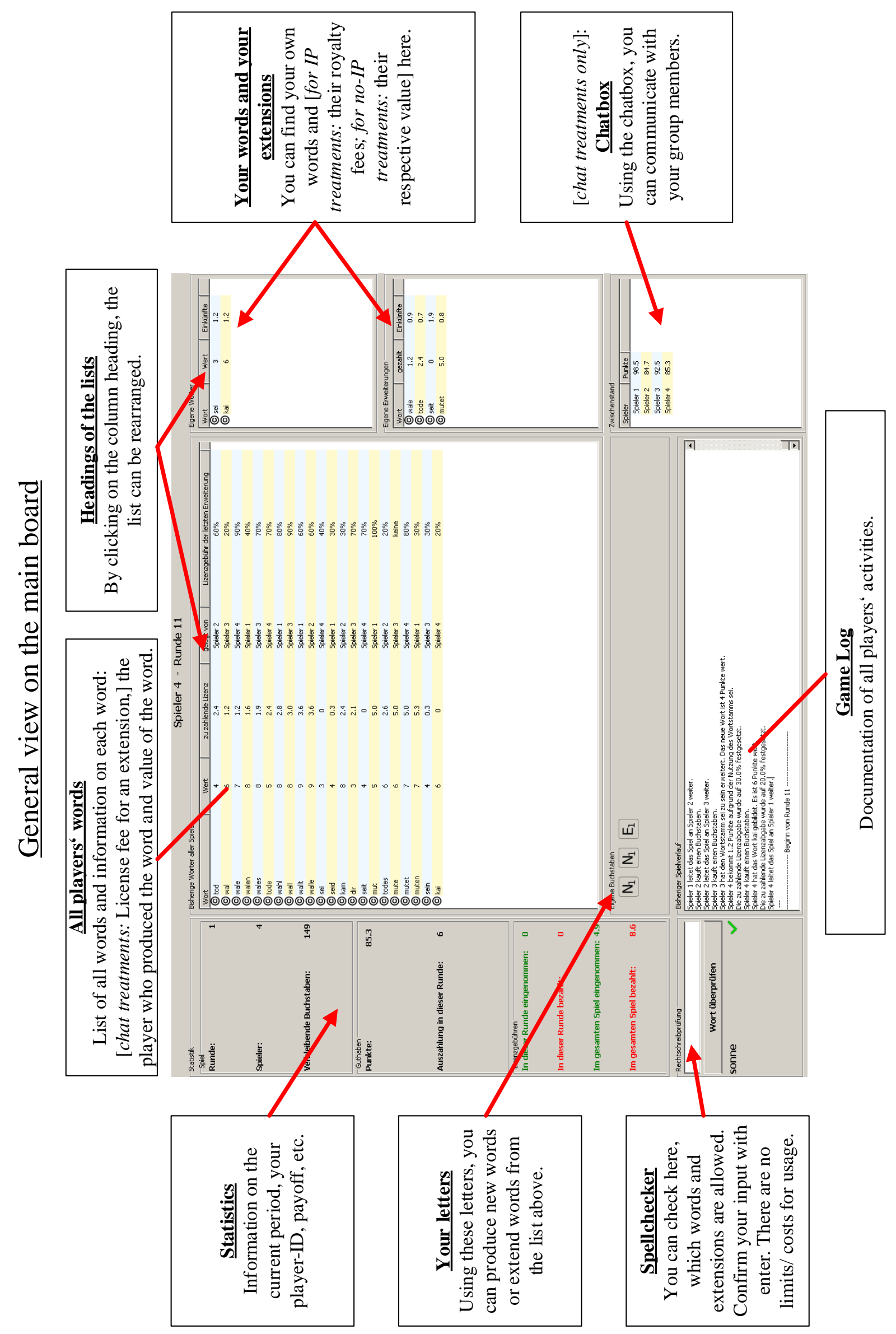




\section{Course of a turn}

When it is your turn, a dialog pops up asking you for choices. During your turn you cannot use the spellchecker [chat treatments: and the chat]. You have 45 seconds for your decisions. You can see the remaining time on the top-left corner of the screen. If your time expires, you are subtracted 1 token for every additional 10 seconds from your endowment.

Every turn consists of two phases [IP treatments: three phases]:

\section{Buying phase}

\section{Your activity: Buying letters}

You can choose to buy or not to buy one letter at the price of 2 tokens. If you buy a letter, it will be chosen randomly from the list of letters shown on table A2.1. At the beginning you are given four letters for free. Each letter can only be used once: After producing or extending a word the letter will be deleted from your letter set.

\section{Word phase}

\section{Your activity: Producing or extending words}

You can use German words, their conjugations and declinations and some names of places and persons. You can test if a word is correct using the spellchecker when it is not your turn. Correct words can be built as follows:

\section{Option 1: Producing a 3-letter word}

a) You can produce a word using exactly three of your letters. The payoff that you earn for creating a word is given by the sum of the value of the letters (Example: ,pol': $p=4, o=2, l=2$. This results in $4+2+2=8$ tokens).

To create a word, you will have to type in the letters with your keyboard.

Please note that you cannot undo mistakes: if you make an error while inputting the word (i.e. inputting a too long, too short, nonexistent or misspelled word, or pressing the enter key on an empty field) the turn passes to the next player. You will have the opportunity to reiterate your entry correctly only in the next period, during your next turn.

\section{Option 2: Extending a word}

b) You can extend an existing word inserting one letter in any position in the word. For example 'ast' can be extended into 'last', 'rast' and 'aste', and 'last' again into 'laust' and this into 'klaust'. It is not possible to rearrange existing words (e.g. to build from 'ast' the word 'Star').

Your payoff results from the sum of the value of the letters of the newly-extended word. By extending e.g. 'last' into 'laust' you get $\mathrm{l}=2, \mathrm{a}=1, \mathrm{u}=1, \mathrm{~s}=1, \mathrm{t}=1$, so $2+1+1+1+1=6$ tokens. Every word can only be produced once but can subsequently be used for as many extensions as possible. 


\section{Option 3: Passing}

c) In case you are not able to produce nor to extend any word, you can pass the turn to the next player.

\section{License phase [IP treatments only]}

\section{Your activity: Setting a license fee}

After producing a word you have to set a license fee which other players are required to pay when creating extensions. The fee must be set between 0 and 100 percent of the value of the word.

Figure A2.2. Intellectual property choice

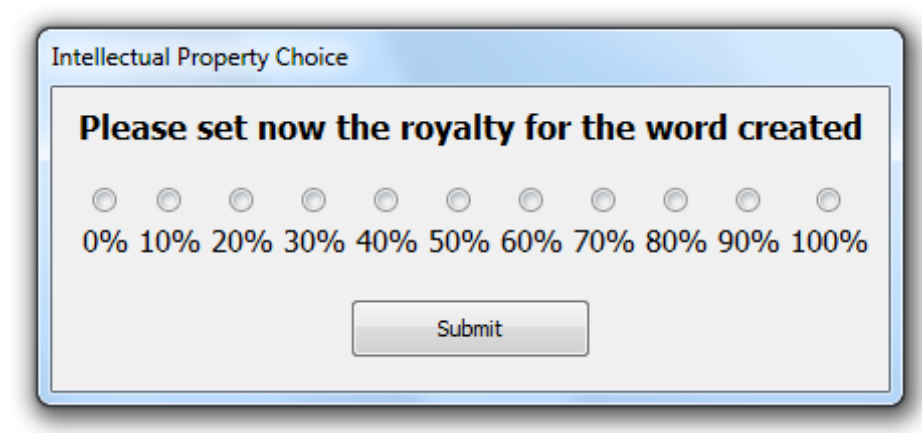

If another player extends your word, he automatically transfers the fee to you.

- 0 percent means that the word is entirely free for other players.

- At 100 percent, the next player only receives the value of his added letter.

- The choice of 20 percent means that the respective player has to pay 20 percent of the value of the word to you.

The license fee for a word remains fixed during the entire game. The word appears on the list of public words on the main board and can be used by everyone. However, other players have to pay the license fee when extending the word.

Furthermore, you will have to set a license fee if you extend a word with one letter. In this case, you decide on the fee only for your added letter. Your payoff results from the sum of the value of all letters minus the license fee for the word you built on.

After that, your turn ends and it is the next player's turn. The game is played for 25 periods. Finally, for clarification, some payoff-examples are offered:

\section{Examples for potential payoffs [IP treatments]:}

Example 1: If player 1 sets a license fee of 90 percent for the word 'ast' (value of the word 3 tokens: $\mathrm{a}=1, \mathrm{~s}=1, \mathrm{t}=1$ ) and player 2 extends the word into 'hast' (value of $\mathrm{h}=2$ ), this results in the following payoffs:

Player 1: 90 percent of 3 tokens $=2.7$ tokens (license fee for player 1)

Player 2: $3-2.7$ tokens (to player 1 ) +2 tokens for the letter ' $h$ ' $=0.3$ tokens +2 tokens $=2.3$ tokens 
Example 2: If player 1 sets the license fee of 0 percent for 'ast', player 2 receives the sum of the value of all letters for extending it into 'hast':

Player 1: 0 percent of 3 tokens $=0$ token

Player 2: 100 percent of 5 tokens $=5$ tokens

Example 3: After extending a word, the player has to set a license fee for the added letter. Player 1 sets a license fee of 10 percent for 'ast' and player 2 sets a license fee of 50 percent for the letter ' $h$ ' in 'hast'. If player 3 then extends 'hast' into 'haust', this results in the following payoffs:

Player 1: 10 percent of 3 tokens $=0.3$ (license fee for player 1 )

Player 2: 50 percent of 2 tokens $=1$ (license fee for player 2)

Player 3: 6 tokens for ,haust ${ }^{\prime}-0.3$ tokens (to player 1 ) -1 token (to player 2 ) $=4.7$ tokens

\section{Examples for potential payoffs [no-IP treatments]:}

Example 1: Player 1 produces the word 'ast'. The values of the letters are a $=1$ token, $s=1$ token, $\mathrm{t}=1$ token. Therefore, he gets $1+1+1=3$ tokens for his word.

Example 2: If player 2 extends 'ast' into 'hast', he will get 5 tokens, as all values of letters of the word ( $\mathrm{h}=2$ tokens, $\mathrm{a}=1$ token, $\mathrm{s}=1$ token, $\mathrm{t}=1$ token) will be added: $2+1+1+1=5$ tokens.

\section{Appendix C}

Instructions for the control task

Note: The instructions for the word task were shown on screen.

In the next screen you will see a string composed of 9 letters.

You will be asked to create as many German words as possible using these letters within 3 minutes.

You can type the words you create in the field beneath the string of 9 letters, and you submit them by hitting Enter.

You can use each letter only once per word and a word cannot be shorter than 3 letters.

Longer words generate more points.

3-letter word: $3+2+1=6$ points

4-letter word: $4+3+2+1=10$ points

etc.

After the 3 minutes will have expired, the test will end and you will be shown your results.

As soon as you enter the next screen, the timer will start ticking.

To go to the next screen, please press the letter 'R' on your keyboard. 


\section{Experimental evidence on the effects of innovation contests}

with Lukas Meub

cege Discussion Paper 251, Georg-August-Universität Göttingen, June 2015.

Download: http://wwwuser.gwdg.de/ cege/Diskussionspapiere/DP251 


\begin{abstract}
Economic research on innovation has long discussed which policy instruments best foster innovativeness in individuals and organizations. One of the instruments easily accessible to policy-makers is innovation contests; however, there is ambiguous empirical evidence concerning how such contests should be designed. Our experimental study provides evidence by analyzing the effects of two different innovation contests on subjects' innovativeness: a prize for the aggregate innovativeness and a prize for the best innovation. We implement a creative real effort task simulating a sequential innovation process, whereby subjects determine royalty fees for their created products, which also serve as a measure of cooperation. We find that both contest conditions reduce the willingness to cooperate between subjects compared to a benchmark condition without an innovation contest. However, the total innovation activity is not influenced by introducing innovation contest schemes. From a policy perspective, the implementation of state-subsidized innovation contests in addition to the existing intellectual property rights system should be questioned.
\end{abstract}

\title{
Keywords
}

competition, creativity, innovation policy, innovation prizes, laboratory experiment, real effort task

\section{JEL-Classification}

C91, D89, O31 


\subsection{Introduction}

Innovations are considered the driving force for economic growth in modern economies, prompting governments to stimulate private and public innovation activities. Most recently, the European Union announced increasing investment in R\&D to three percent of GDP by 2020 and - in a similar effort - the United States legislated the "America COMPETES Reauthorization Act” to improve their competitiveness by boosting R\&D (COM (2010) 2020; H.R.5116). Policy-makers can draw upon three categories of instruments to implement such strategies: regulatory instruments such as intellectual property rights, economic and financial regulations such as subsidies or tax exemptions and soft instruments such as voluntary agreements (Bemelmans-Videc et al. 1998; Borrás and Edquist 2013). The determination of states to increase domestic innovativeness has initiated a large research debate, discussing how to best combine these instruments to achieve an effective policy mix (Flanagan et al. 2011; Guerzoni and Raiteri 2015). ${ }^{18}$

Innovation contests are one of the most frequently discussed financial regulatory instruments, commonly modeled as a competitive game with one or more players investing to create innovations (Kremer and Williams 2010; Adler 2011; Clancy and Moschini 2013). ${ }^{19}$ Economic research has analyzed innovation contests with respect to design specifics and their potential outcome by considering e.g. single or multiple solvers and prizes, its duration and most prominently - its incentive structure (Adamczyk et al. 2012; Williams 2012). The distinct design of incentive structures analyzed comprise e.g. ex-post prizes rewarding previous work (Moser and Nicholas 2013) or ex-ante prizes with unknown outcome (Murray et al. 2012), as well as proportional prize contests, whereby the prize is granted relative to participants’ achievements (Cason et al. 2010).

Numerous theoretical and empirical contributions have aimed at deriving policy implications for the most efficient design of innovation contests. However, empirical research shows ambiguous findings concerning the impact of innovation contests (Boudreau et al. 2011; Brunt et al. 2012; Nicholas 2013). Similarly, there are mixed results developed in theoretical contributions (Wright 1983; Taylor 1995; Moldovanu and Sela 2001; Che and Gale 2003; Ganuza and Hauk 2006; Cohen et al. 2008; Schöttner 2008; Chari et al. 2012). We contribute to this unresolved debate by presenting novel empirical evidence from a laboratory experiment and derive policy implications for the optimal design of innovation contests.

\footnotetext{
${ }^{18}$ For a broader literature overview regarding the effect of public subsidies on innovativeness, see ZúñigaVicente et al. (2014) and David et al. (2000); a similar study on the effect of taxes is provided by Hall and van Reenen (2000). For an overview of the necessity of subsidizing innovations from a financial market perspective, see Hall and Lerner (2010).

${ }^{19}$ See Williams (2012) and Adamczyk et al. (2012) for a review on the current literature on innovation contests.
} 
We follow an experimental approach to overcome some shortcomings of previous research in evaluating the effects of various contest schemes on innovativeness. Empirical research relying on field data is bound to data availability and thus a profound analysis across contest schemes is not feasible. Economic experiments allow generating data that enables a ceteris paribus comparison of different contest schemes (Blasio et al. 2014). Therefore, we would argue along with Sørensen et al. (2010) that economic experiments are "a promising approach” (Sørensen et al. 2010, 313) and a fruitful methodological addition to the existing innovation research.

Based upon this notion, experimental studies can analyze the effects of different policy instruments e.g. by simulating sequential innovation processes (Cantner et al. 2009; Meloso et al. 2009; Buchanan and Wilson 2014). Dealing with innovation in laboratory experiments necessarily induces a trade-off between simulating the complex interactions of creative and dynamic sequential innovation processes accurately and keeping the task manageable for participants. While this obviously places certain limits upon the external validity of an experimental approach, we are confident that we are able to achieve a meaningful analysis of innovation contests in our setting, given that we implement the key features of actual innovation settings like risky investment choices and creativity. Therefore, we build upon a prior setting, investigating the effects of introducing intellectual property rights for innovations, whereby subjects are rewarded for their innovativeness and are able to license their innovations by demanding royalty fees (Crosetto 2010; Brüggemann et al. 2015).

However, in our analysis, we focus on two specific types of innovation contests, implementing (1) a prize for the aggregate innovativeness and (2) a prize for the best innovation. According to a between-subject design, the two treatments are subsequently compared to (3) a benchmark treatment without an innovation contest. All treatments include the possibility to license innovations that allow measuring cooperation behavior and only differ with respect to the payment structure. Particularly for investigating the effects of a prize for the aggregate innovativeness, we implement a contest with a relative payoff-scheme disproportionally rewarding the most innovative subject. In the treatment with the prize for the best innovation, subjects are paid proportionally for each innovation while an additional bonus is awarded to the subject who has created the most valuable innovation. In the benchmark treatment, subjects are merely paid proportionally to their innovations. This experimental set-up allows us to test for the specific effects of introducing innovation contests on individual creativity and innovation performance, as well as concerning how cooperation among innovators evolves with and without contest schemes. 
We find that both types of innovation contests - the prize for the aggregate innovativeness and the prize for the best innovation - reduce the willingness to cooperate as measured by the average royalty fees demanded. However, the actual cooperation does not decrease, as subjects tend to accept the higher royalty fees to build upon other subjects' previous innovations to win the innovation contest. With respect to innovativeness, our results indicate that neither a prize for the aggregate innovativeness nor a prize for the best innovation have a positive overall impact. Therefore, our behavioral evidence suggests that both types of contests investigated cannot unambiguously be recommended as effective policy instruments due to welfare concerns. This becomes apparent when considering potential distortions to generate the revenue to spend on innovation contests and diminished cooperation among innovators.

The remainder of this paper is organized as follows. Section 3.2 reviews the related literature, before section 3.3 outlines our experimental design and hypotheses. Section 3.4 presents our results and section 3.5 concludes.

\subsection{Literature Review}

There is a large body of literature dealing with the effects of innovation contests. Williams (2012) reviews this literature with a focus on innovation prizes in the United States, emphasizing the importance of both estimating an appropriate size of prizes and considering the sequentiality of innovations for spurring subsequent innovations. Williams claims that additional research on the effectiveness of prizes and the specific construction of prize designs is required. Adamczyk et al. (2012) review the current literature on innovation contests by drawing upon the distinct perspectives from economic, management, education, innovation and sustainability research. From an economic research perspective, they point out that more innovators will participate in contests if there is a high monetary award. Similar to Williams (2012), they suggest that further research should focus on the particular design of innovation contests. Clancy and Moschini (2013) provide an overview of different financial regulation instruments to foster innovation. They state that innovation contests can potentially overcome deadweight losses caused through the monopoly rights of patents and moral hazard problems of contracted research. Comparing the different instruments, they claim that a hybrid system in which innovators can choose to receive either a patent or a prize is superior to a pure patent system in terms of output. ${ }^{20}$

\footnotetext{
${ }^{20}$ For further reviews on innovation prizes, see Gallini and Scotchmer (2002) and Maurer and Scotchmer (2004).
} 
A number of theoretical studies consider the optimal design of innovation contests, yielding ambiguous implications. Taylor (1995) models innovation contests with homogeneous contestants, showing that restricting the entry may be beneficial for the contest designer. Wright (1983) investigates patents, prizes and contracts as rewards for winning innovation contests, finding advantages of patents over prizes due to private information. Comparing a contest comprising multiple prizes with a contest offering a single prize, Moldovanu and Sela (2001) find that the latter leads to an optimal allocation of resources. Ganuza and Hauk (2006) study vertical and horizontal competition in contests, finding multiple equilibria. Cohen et al. (2008) analyze the design of innovation contests and their potential of maximizing either the overall or the maximum effort, finding that the optimal prize can both increase and decrease participants’ effort. Comparing a first-price auction with a fixed-prize tournament in innovation contests, Schöttner (2008) suggests that the latter is superior.

Furthermore, there are some empirical studies on the effects of specific innovation prizes, which also show mixed evidence. Murray et al. (2012) investigate the ex-ante influence of the Progressive Automotive Insurance X PRIZE as an example of a grand innovation prize. Boudreau et al. (2011) analyze the results of a computer programming contest with respect to the size of the participant pool on individual effort levels. If more competitors are permitted, the aggregate innovativeness will decrease, while the probability of a high valued innovation increases. Nicholas (2013) examines the effectiveness of innovation prizes in Japan's Meiji era, finding strong evidence that prizes lead to a substantial boost of new patents. Relying on a similar approach, Brunt et al. (2012) estimate a substantial increase in patenting activities in the Royal Agricultural Society of England between 1839 and 1939 due to innovation prizes.

Another methodological approach to empirically investigate innovation prizes is to conduct economic experiments. ${ }^{21}$ There are few studies relying on a search task to imitate the innovation process. In a field experiment, Boudreau and Lakhani (2012) discover the impact of different types of innovation prizes by allowing subjects to choose between competitive and cooperative regimes. In comparison to a benchmark treatment, the problem-solving performance almost doubled in the competitive regime and increased by one-third in the

\footnotetext{
${ }^{21}$ A large body of experimental research deals with the question of the best incentive structure in contests focusing on investment and organizational structures, while excluding the innovative part of the process. For an overview on winner-takes-it-all and rank-order tournaments with fixed prizes, see Irlenbusch (2006). Fullerton et al. (1999) test the predictions of Taylor's search model of tournaments, finding that R\&D contests achieve very high levels of efficiency in the laboratory and that the level of research effort tends to be close to the theoretical predictions. Comparing a winner-takes-it-all-contest with a proportional-payment design, Cason et al. (2010) find more entries and higher total achievement in the proportional-payment scheme, as a single very capable player often dejects other participants in the winner-takes-it-all scheme.
} 
cooperative regime when subjects could choose their preferred institutional setting. Using a word task, Eckartz et al. (2012) identify only very small effects of different payment schemes, given that subjects were intrinsically motivated by the self-rewarding task. Furthermore, analyzing exploration behavior and risk aversion under different payment schemes, Ederer and Manso (2013) present a searching task in a multi-dimensional space. They find that a combination of tolerance for early failure and rewards for long-term success are effective in fostering innovation. Buchanan and Wilson (2014) use a search task similar to Ederer and Manso (2013) to simulate intellectual property and additionally provide subjects with the option to produce a non-creative good. When intellectual property is available to subjects, the creation of non-rivalrous innovation knowledge goods is greatest. However, prices increase as substantial monopoly profits are acquired by the innovators. In the absence of intellectual property rights, subjects still create non-rivalrous innovations, although they also resort to intellectual property theft from other subjects. Rijnsoever et al. (2012) examine the influence of an environmental change on innovative behavior, whereby subjects have to make a risky investment decision over several periods to achieve a second stage with a prize contest and environmental change. In a second study, the measure of innovative behavior was transferred to a business context. The authors find support for a U-shaped relationship between economic status and innovative behavior in both cases.

By choosing to implement non-creative real effort search tasks, the experiments reviewed above tend to exclude the creativity required in an innovation process. However, transferring this immanent feature of the innovation process to the lab might be crucial to achieve meaningful results at a satisfactory level of external validity. Only few papers implement creativity tasks to more closely simulate innovation processes to examine the influence of incentive structures on innovativeness. Bradler (2015) compares the incentives of a tournament with a fixed payment scheme for a creative task, finding support for self-selection into tournaments according to risk attitudes and self-assessments, yet no such effect for creative productivity. Crosetto (2010) presents experimental evidence on innovation behavior in the presence of intellectual property rights, including open source. The author introduces a real effort word creation task in which subjects - similar to the board game Scrabble innovate by creating and extending words. Crosetto's results suggest that open source only emerges in treatments with high royalty fees rather than low ones, although high royalty fees tend to foster anticommons effects. Building upon this study and introducing endogenous license fees, Brüggemann et al. (2015) show that overall innovativeness increases in a setting without intellectual property rights. 
We contribute to the literature reviewed above by implementing such a real effort word creation task to research into the effects of introducing varying incentive schemes for innovations. In particular, we are interested in two types of innovation contests: (1) a prize for the aggregate innovativeness and (2) a prize for the best innovation.

\subsection{Experimental Design}

\subsubsection{Design}

Many features determine the outcomes of an innovation contest, e.g. the available information and the number of participants. However, in our study, we concentrate on one crucial feature, namely the external incentive scheme designed by public policy-makers to foster innovativeness and eventually cooperation among competitors. Our basic framework implements a real effort word creation task, representing a sequential innovation setting with the possibility to license innovations. This basic framework is based upon Crosetto (2010) and Brüggemann et al. (2015) and is modified to test for the effects of a prize for the aggregate innovativeness and a prize for the best innovation.

To implement task characteristics like creativity and to account for the subjects' different skills, we recreate the board game Scrabble for our laboratory experiment. Therefore, subjects can earn a certain payoff by creating words from letters, which they can buy from the experimenter. They have the option to determine license fees for produced words, which can be extended in the following, thus representing the sequentiality of the innovation process. Thus, subjects have to act strategically and creatively by facing both an investment decision (buying new letters) as well as the real effort task of building words from randomly assigned letters. The game is played by groups of 4 randomly matched subjects. The group composition remains constant throughout the 25 periods of the game. The initial endowment for each subject comprises 75 experimental tokens and 4 randomly pre-selected letters. ${ }^{22}$

In all treatments, subjects can take three actions upon each turn: first, deciding to invest by buying a letter; second, producing a word; and third, choosing a royalty fee.

\section{Investment phase}

Initially, a subject has to decide whether to buy a random letter for a fixed price of 2 tokens. The letter set comprises 191 letters, whose valuation is determined by the inverse of a letter's frequency in the set, leading to an average letter value of 1.87 . Therefore, buying a letter

\footnotetext{
${ }^{22}$ The English translation of the original German experimental instructions is provided in appendix A, including a screenshot of the main board and the details of the letterset.
} 
potentially leads to negative returns, as a letter's price is somewhat above its average value. The letters are allocated randomly to the subjects, although the sequence of letters given out is predetermined and fixed for all groups, which makes the action sets across groups more comparable.

\section{Production phase}

Following the investment phase, the respective subject chooses to produce a three-letter word (root), extend an existing word (extension) or pass and do nothing in the respective period. When building an extension, a subject is only allowed to extend an existing word with one additional letter, which can be placed in any position of the existing word. For instance, if a subject owns the letters $a, d$, $i$ and $p$, she can create the roots aid or dip. ${ }^{23}$ For example, aid can be extended to paid, maid or arid, while arid can then be extended into acrid and so on. All produced words yield a payoff equal to the sum of the letter values, although a word can only be produced once. Accordingly, longer words tend to be more valuable. When extending a word, not only the one letter added but rather all letters of the new word generate payoff. For instance, extending arid (worth $1+1+1+1=4$ tokens) into acrid with the letter $c$ - which itself is worth 4 tokens - results in a payoff of 8 tokens.

\section{Royalty phase}

After having created a root or an extension, each subject is able to determine a royalty fee. A royalty fee for an extension only refers to the one letter added. Royalty fees range from $0 \%$ to $100 \%$ in steps of $10 \%$. The chosen royalty fee becomes public information and is fixed for the rest of the game. However, no one can be excluded from using the word altogether. By choosing higher royalty fees, subjects earn more when their word creations are extended by other subjects. Nevertheless, at the group level, royalty fees are merely a mechanism of redistributing income as there are no transaction costs.

For example, subject A produces aid - worth 3 tokens - and chooses a royalty fee of $40 \%$. Every subject who extends aid pays A 1.2 tokens. Consider subject B extending aid into paid, which is worth 7 tokens: 1.2 tokens are transferred to subject A, subject B earns 5.8 tokens and has to set a royalty fee for the letter $p$, worth 4 tokens. If she chooses $50 \%$, the next subject adding a letter to the word paid will have to pay 1.2 tokens to subject A and 2 tokens ( $50 \%$ of 4 tokens, namely the value of the letter $p$ ) to subject B. In order to keep the decision

\footnotetext{
${ }^{23}$ For an easier understanding, we report the following examples in English, although the experiment was run in German.
} 
for subjects simple, the amount of royalty fees incurred by using a word is always presented to subjects on the main board (see appendix A).

When subjects are not at turn, the main board of the game is shown. On this board, subjects are shown their payoffs so far, they can observe the actions of their group members and are able to come up with their next word creations using the list of extendable public words, their own letters and testing new creations with an interactive spellchecker. The spellchecker can be used without restriction to check whether a word is accepted in the game. A word is accepted when it is included in the MS Windows dictionary implemented in the game. The list of public words comprises all words produced in the respective group thus far. Furthermore, the information on the value of these public words, the respective amount of royalty fees and the respective owner of the word is documented.

\subsubsection{Treatment conditions and experimental procedure}

We implement a between-subject design with three treatments, as shown in table 3.1.

Table 3.1. Overview of the treatment conditions

\begin{tabular}{lccc}
\hline treatment & \multicolumn{2}{c}{ Variation } & number of participants \\
\hline & $\begin{array}{c}\text { prize for the aggregate } \\
\text { innovativeness }\end{array}$ & $\begin{array}{c}\text { prize for the best } \\
\text { innovation }\end{array}$ & \\
\cline { 2 - 3 } control & no & no & 48 \\
ranking & yes & no & 48 \\
bonus & no & yes & 48 \\
\hline
\end{tabular}

In control, accumulated tokens are converted by an exchange rate of 1 token to $€ 0.12$ at the end of the game. ${ }^{24}$ In ranking, subjects are paid relative to the performance of the other group members and receive a prize for their aggregate innovativeness. The subject who has accumulated the most tokens at the end of the game receives $€ 24$, while the other three group members receive a show-up fee of $€ 12$ each. ${ }^{25}$ Accordingly, in ranking, an additional box showing the current ranking is displayed on the main board, which allows subjects to constantly evaluate their performance. In bonus, the payoff is the same as in control, aside

\footnotetext{
${ }^{24}$ Please note that we used the data of the treatment noChat/IP from Brüggemann et al. (2015) as our control treatment. Both experiments have been conducted in the same laboratory and the recruitment of subjects was from the same pool of student participants; however, no subject was allowed to participate in both experiments.

${ }^{25}$ In case two or more players had the same number of tokens and all were ranked first, each player would have received $€ 24$. Therefore, it would have been possible for all players to do nothing and receive €24; however, this did not occur.
} 
from a $€ 10$ bonus awarded to the subject building the most valuable word and thus for the best innovation. Precisely, this means that the subject adding the last letter to the word with the highest value receives an additional $€ 10 .{ }^{26}$ Similar to ranking, an additional box on the main board displays a list of all subjects' current most valuable words. To provide an additional control variable for individual creativity, we implemented an incentivized word-finding control task before starting the main task. ${ }^{27}$

Experiments were conducted in the Laboratory for Behavioral Economics at the University of Göttingen. Participants were recruited using ORSEE (Greiner 2004) and were allowed to participate in one session only, which lasted around 90 minutes. The 13 sessions for control took place in August and September 2013. In February, March and April 2014, we conducted the sessions for ranking and bonus with 144 subjects in total. To successfully participate in the experiment, subjects necessarily have to speak German well. Therefore, we carried out the same language test as Kirchkamp and Reiß (2011), thus essentially excluding non-native speakers. ${ }^{28}$ Participants were on average 23.7 years old and $48.6 \%$ were female, with $37.5 \%$ being students of economics. On average, each participant earned $€ 16$ in sessions lasting around 90 minutes, with a minimum payoff of $€ 5.9$ and a maximum of $€ 32.4$.

\subsubsection{Hypotheses}

Overall innovativeness - which we define as the aggregate value created in the game by building words - will decline over the course of the game if subjects merely build roots due to the lower expected value of a letter (1.87 tokens) when compared to its cost (2 tokens). Thus overall innovativeness only increases when subjects build extensions and re-use existing words. Therefore, cooperation among participants - i.e. the tendency to make use of others' innovations, as well as not trying to exclude others from one's own innovations - might be crucial for aggregate welfare.

Our first hypothesis applies two different measures of cooperation: the demanded royalty fees and the extensions created from other subjects' roots. Subjects demanding low royalty fees for their roots foster the production of additional extensions. This can be interpreted as willingness to cooperate, which may increase groups' overall innovativeness. However, at an individual level, it might be reasonable to set high royalty fees to generate additional income from creating innovations. In turn, at the group level, this might have a detrimental effect as

\footnotetext{
${ }^{26}$ In case two players achieve the same highest value - which did not occur in any case - both would have been rewarded the bonus.

${ }^{27}$ The instructions for the word task can be found in appendix B, the results in appendix C.

${ }^{28}$ The participants had to find the correct word or form to complete a sentence. Those who failed the language test on more than two out of 10 items were not allowed to participate.
} 
subjects could cease using other subjects' words to avoid paying royalty fees and to build more roots. These considerations emphasize the game's inherent social dilemma character in the presence of royalty fees, which might affect overall innovativeness, i.e. the ratio of basic (roots) and more sophisticated innovations (extensions).

Therefore, we interpret the level of royalty fees chosen by subjects as the willingness to cooperate, whereas the number of extensions of other subjects' words can be understood as the level of actual cooperation. The willingness to cooperate shows potentially adverse effects of the competition framework implemented in ranking and bonus. Previous findings in both the innovation contest and the experimental literature point to decreasing cooperation due to competitive settings (Boudreau et al. 2011; Chaudhuri 2011). We thus assume increased competition with a prize for the aggregate innovativeness (ranking) and a prize for the best innovation (bonus) to lower the willingness to cooperate, as measured by higher royalty fees demanded. Furthermore, we expect a decrease in actual cooperation measured by the frequency of using other subjects' words in both innovation contests, namely ranking and bonus.

\section{Hypothesis 1 (“Competition and cooperation”)}

a) The willingness to cooperate is lower in ranking and bonus.

b) The actual cooperation is lower in ranking and bonus.

Our second hypothesis addresses the effect of contest schemes on innovativeness. There is no clear consensus within the innovation literature regarding which design of an innovation contest best fosters innovativeness (Williams 2012). However, based upon previous studies pointing to rather positive effects of innovation contests on innovativeness (Brunt et al. 2012; Nicholas 2013), we hypothesize that the total innovation activity will increase given a contest scheme. Accordingly, we formulate the following:

\section{Hypothesis 2 ("Innovation activity”)}

Total innovation activity increases in ranking and bonus.

\subsection{Results}

We first analyze the effects of introducing an innovation contest on the willingness to cooperate and actual cooperation, before subsequently investigating overall innovativeness. We finally check the robustness of our results against the actual choice set by introducing a 
measure providing the degree to which individuals were able to exploit their specific opportunities of producing words in each period. ${ }^{29}$

\subsubsection{Competition and cooperation}

\subsubsection{Willingness to cooperate}

For all treatments, the game allows subjects to license their innovations by demanding royalty fees between $0 \%$ and $100 \%$. Royalty fees can be interpreted as a measure of cooperation as they give the prices for building upon others' prior innovations. Subjects who are reluctant to cooperate will ask for higher royalty fees, while those interested in cooperation choose lower fees and might expect some reciprocal behavior. Remember that letters induce costs when they are bought but can be reused several times, which generates an income premium for cooperation, i.e. a surplus at the group level. Put simply, at lower royalty fees, subjects might be more willing to build upon the same words several times and thus create more sophisticated innovations, which benefits the whole group. Figure 3.1 illustrates the average royalty fees demanded by treatment.

Figure 3.1. Royalty fees demanded by treatment

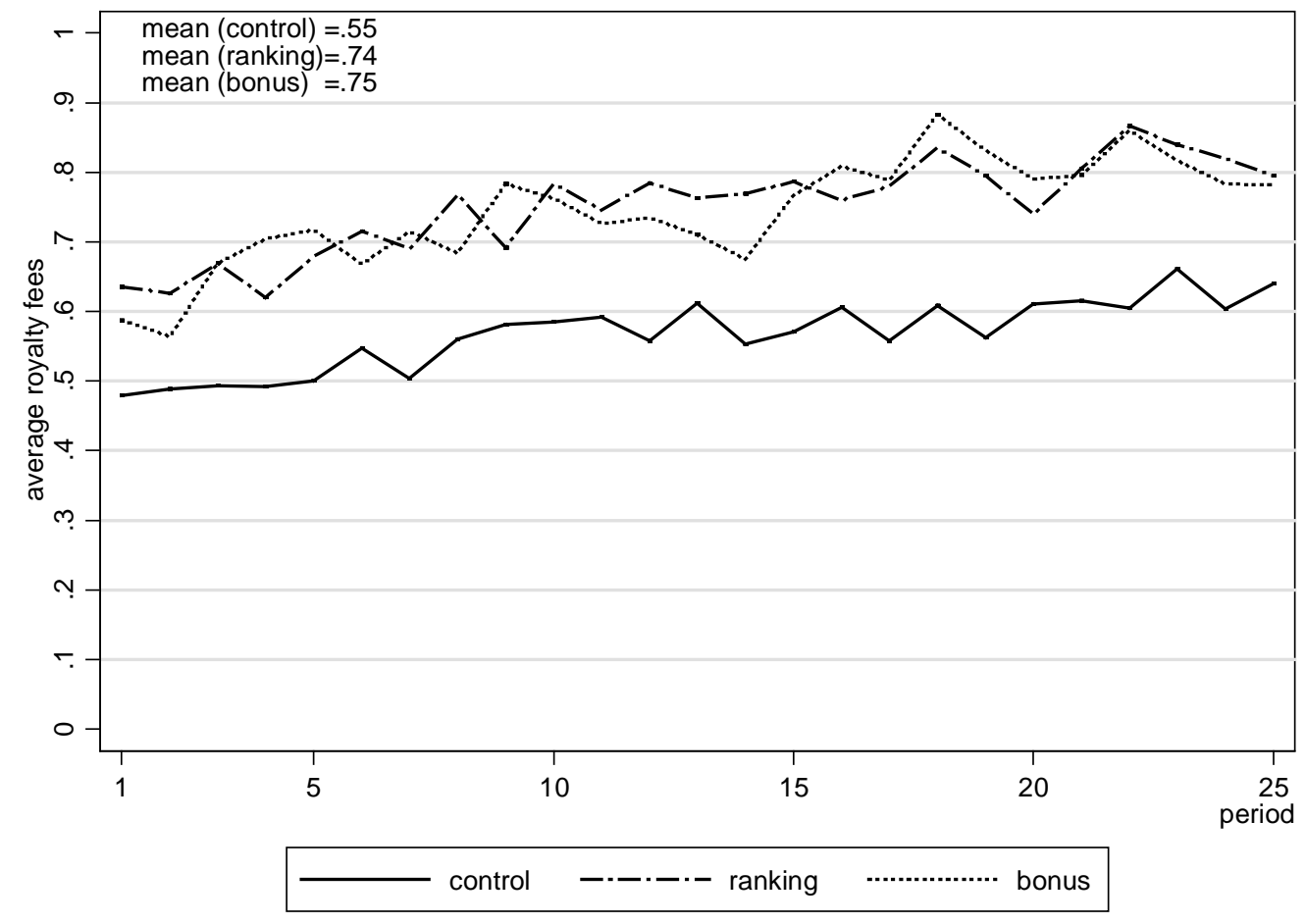

\footnotetext{
${ }^{29}$ Note that we can rule out the notion that treatment differences are driven by a particular distribution of task specific knowledge due to the results of our control task (appendix C).
} 
For all treatments, there is an upward trend in royalty fees demanded, which connects well to the findings of the public good experiment literature, typically identifying decreasing cooperation over time (Chaudhuri 2011). However, royalty fees demanded are lowest in control (Mann-Whitney-U (MWU) test for control vs. ranking $\mathrm{z}=-2.136$ and $\mathrm{p}=.0327$; for control vs. bonus $\mathrm{z}=-2.194$ and $\mathrm{p}=.0282)^{30}$, whereby the difference amounts to about 20 percentage points and is constant over time.

RESULT 1: There is strong evidence in support of H1a. While the royalty fees demanded gradually increase over time for all payment schemes, there is a substantial downward shift in the willingness to cooperate when introducing innovation contests.

\subsubsection{Actual cooperation}

Recall that royalty payments are merely a matter of redistributing income; thus, the shift in royalty fees demanded does not necessarily reduce innovation activity or welfare. By contrast, higher royalty fees might stimulate innovation activity as produced words generate additional income when used by others. Conversely, less cooperation might lead to more basic and less sophisticated innovation activity as subjects might want to circumvent royalty fees, whereby revenues of reusing inputs (letters) are thus foregone. In the following, we investigate the relevance of these two contradicting views, which refer to Hypotheses 1b, i.e. whether the actual cooperation is lower in the contest treatments.

We can measure whether the higher royalty fees demanded in ranking and bonus transfer to a less cooperative innovation process by considering figure 3.2, which details the share of extensions of other subjects' roots plotted against the level of royalty fees demanded.

The figure again shows the overall higher level of royalty fees demanded in ranking and bonus. We can now answer the question of whether the unwillingness to cooperate merely increases the price of cooperation or if cooperation itself is decreasing. Although the share of others' words extensions tends to be higher for control with mean $=0.69$ and $s d=0.07$, the difference fails to be significant for ranking with mean=0.64 and $\mathrm{sd}=0.09$ (MWU-test $\mathrm{z}=$ =1.447, $\mathrm{p}=.1479)$ and bonus with mean=0.66 and $\mathrm{sd}=0.11(\mathrm{z}=-0.636, \mathrm{p}=.525)$.

\footnotetext{
${ }^{30}$ Unless indicated otherwise, all tests are performed at the group level, i.e. each group gives one independent observation only.
} 
Figure 3.2. Share of extensions of others' roots and royalty fees by group

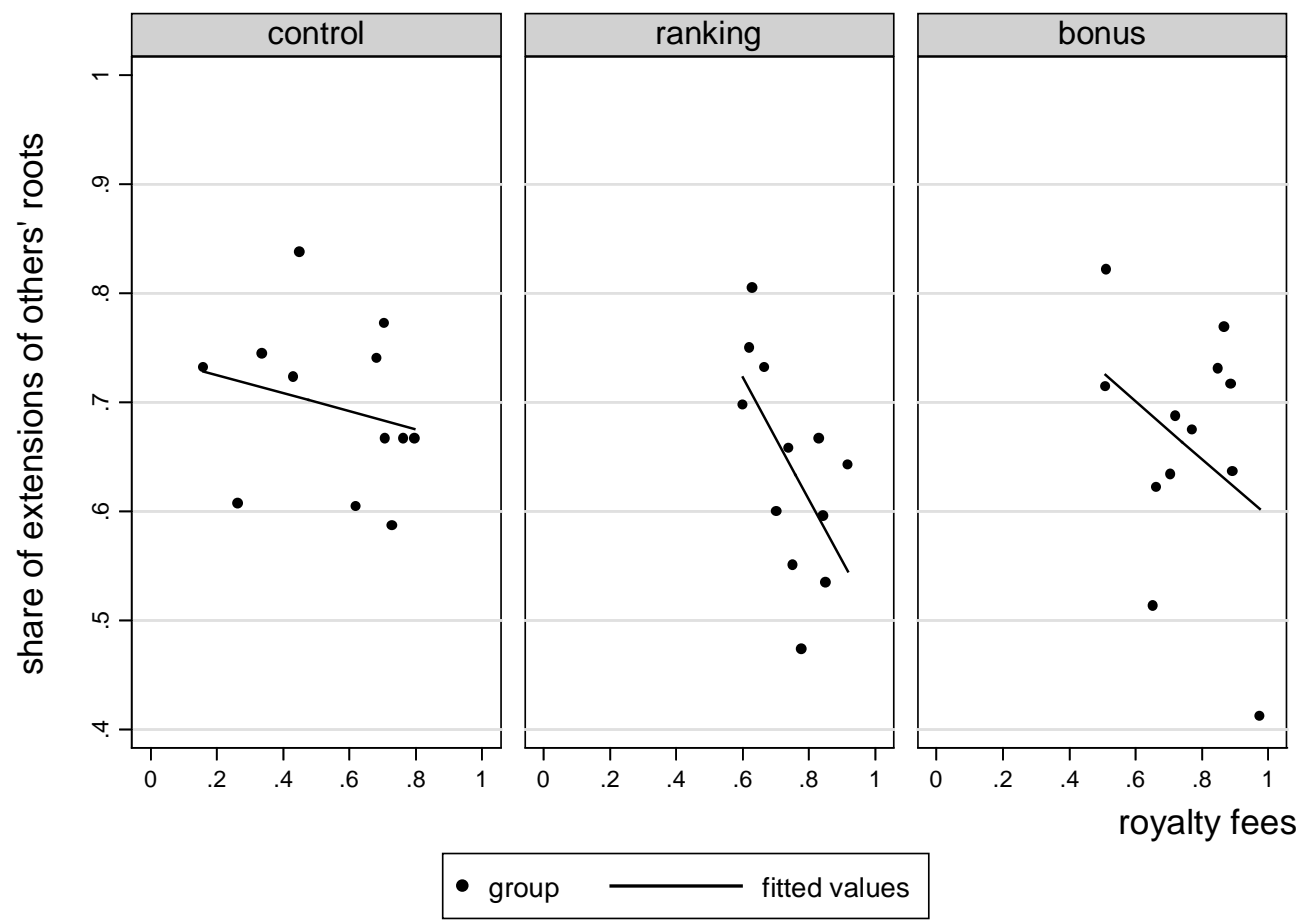

RESULT 2: While the willingness to cooperate is lower for a competitive payment scheme in innovation contests (H1a), the actual cooperation as measured by the tendency to use others' prior innovations is not significantly lower $(\mathrm{H} 1 b)$.

\subsubsection{Innovation activity}

\subsubsection{Total innovation activity}

Aggregate income for groups is given by the total value of the produced words minus costs for the letters bought, denominated in the following as total net value. An individual's income is defined as the aggregate value of the produced words minus the royalty fees paid and the costs for the letters bought.

To assess innovation activity, we distinguish between basic and more sophisticated innovations. Extensions always build upon prior roots and potentially prior extensions. As explained above, using letters several times is beneficial as the letters only have to be paid once. The ratio of extensions to roots crucially influences total innovativeness as sunk costs for the letter endowment within a group become less relevant the more extensions are created. This ratio is also reflected in the average word length and the average word value within groups. Table 3.2 summarizes the key figures of innovation activity by treatment. 
Table 3.2. Overview of words and value created by treatment

\begin{tabular}{|c|c|c|c|c|}
\hline & & control & ranking & bonus \\
\hline letters bought & mean (sd) & $\begin{array}{c}84.3 \\
(8.05)\end{array}$ & $\begin{array}{l}82.17 \\
(5.78)\end{array}$ & $\begin{array}{c}85 \\
(5.48)\end{array}$ \\
\hline \multirow[t]{4}{*}{ total net value } & mean (sd) & $\begin{array}{l}204.92 \\
(46.23)\end{array}$ & $\begin{array}{l}201.83 \\
(44.69)\end{array}$ & $\begin{array}{l}190.33 \\
(65.32)\end{array}$ \\
\hline & median & 210 & 197 & 205.5 \\
\hline & $\min$ & 103 & 142 & 74 \\
\hline & $\max$ & 274 & 299 & 281 \\
\hline word length & mean (sd) & $\begin{array}{c}4.49 \\
(0.32)\end{array}$ & $\begin{array}{c}4.53 \\
(0.31)\end{array}$ & $\begin{array}{c}4.54 \\
(0.31)\end{array}$ \\
\hline word value & mean (sd) & $\begin{array}{c}6.62 \\
(0.37)\end{array}$ & $\begin{array}{c}6.74 \\
(0.49)\end{array}$ & $\begin{array}{c}6.91 \\
(0.69)\end{array}$ \\
\hline max. word value & mean (sd) & $\begin{array}{c}12 \\
(2.00)\end{array}$ & $\begin{array}{l}11.92 \\
(2.07)\end{array}$ & $\begin{array}{l}15.08 \\
(3.34)\end{array}$ \\
\hline no. extensions & mean (sd) & $\begin{array}{l}43.33 \\
(6.21)\end{array}$ & $\begin{array}{c}41.5 \\
(5.35)\end{array}$ & $\begin{array}{l}38.58 \\
(8.37)\end{array}$ \\
\hline no. roots & mean (sd) & $\begin{array}{c}13 \\
(2.22)\end{array}$ & $\begin{array}{l}12.67 \\
(2.61)\end{array}$ & $\begin{array}{l}13.33 \\
(2.67)\end{array}$ \\
\hline extensions per root & mean (sd) & $\begin{array}{c}3.41 \\
(0.74)\end{array}$ & $\begin{array}{c}3.46 \\
(1.03)\end{array}$ & $\begin{array}{c}3.06 \\
(1.17)\end{array}$ \\
\hline
\end{tabular}

Almost all key figures indicate similar results across treatments. ${ }^{31}$ The maximum word value achieved is significantly higher in bonus when compared to control (MWU-test for control vs. bonus $\mathrm{z}=-2.278$ and $\mathrm{p}=.0228$ ). Figure 3.3 illustrates the distribution of the total net value across treatments in further detail. Again, there are no substantial differences.

\footnotetext{
${ }^{31}$ Applying a Mann-Whitney-U test at the group level does not indicate any significant differences between control and bonus or control and ranking.
} 
Figure 3.3. Value of words produced within ranked groups by treatment
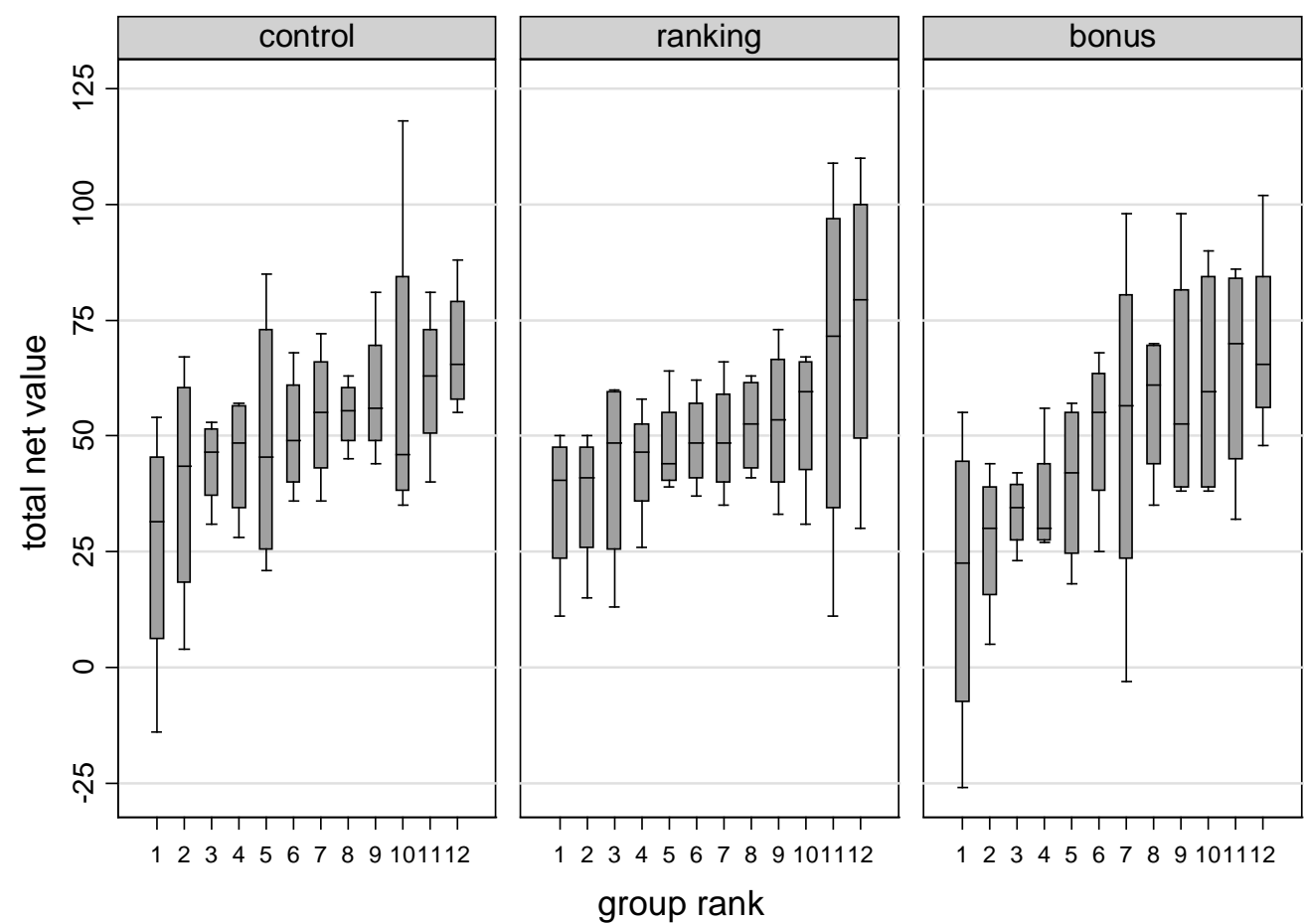

RESULT 3: We find no support for H2, given that there are no significant differences in the total innovation activity regardless of the innovation contest. Nevertheless, the most sophisticated innovation is significantly more valuable when there is a prize for the best innovation.

\subsubsection{Controlling for the actual choice set}

In this section, we control for the actual choice set to check the robustness of our results presented in the previous section. As the game is characterized by path dependency given by the extendibility of words produced early in the game, differences across treatments and groups might be driven by the actual choice set available. We aimed at minimizing the importance of this aspect by endowing each group with the same letter set, although each action in the game still determines the choice set for future innovations due to the game's sequentiality. Nonetheless, the sequentiality and uncertainty in terms of path dependency are essential characteristics of the innovation process and thus have to be incorporated into a well-designed innovation experiment.

We draw upon a reduced - or rather myopic - approach of rationality, given that it is not expected that subjects are able to calculate the optimal choice with respect to the whole 25 periods owing to the high complexity, uncertainty and path dependency. However, subjects 
might choose optimally in terms of the opportunities in the current period. Therefore, we calculate the relative net value (RNV) (Brüggemann et al. 2015). Let $C_{i t}$ denote the actual choice set for subject $i$ in a specific period $t$, determined by the available letters and the words already produced. The payoff in each period $\pi\left(c_{i t}\right)$ is a function of the actual choice taken $c_{i t} \epsilon C_{i t}$ and equals the aggregate value of the letters used minus the paid royalty fees and the cost for letters. The maximum payoff is defined as $M_{i t}=\max \left\{\pi\left(c_{i t}\right), c_{i t} \epsilon C_{i t}\right\}$ and the minimum is defined as $m_{i t}=\left\{\pi\left(c_{i t}\right), c_{i t} \epsilon C_{i t}\right\}$. The relative net value $\mathrm{RNV}_{\mathrm{it}}$ is subsequently given by:

$$
R N V_{i t}=\left(\pi_{i t}-m_{i t}\right) /\left(M_{i t}-m_{i t}\right)
$$

Since the payoff for the actual choice is always within the boundaries of the minimum and maximum payoff, it holds that $R N V_{i t} \epsilon[0,1], m \leq 0, M \geq 0$ and $m \leq c \leq M$. Accordingly, a higher RNV is associated with higher payoffs. We can thus capture path dependency by identifying superior actions conditional upon the actual choice set. The RNV serves as a perfect linear transformation of actual payoffs. ${ }^{32}$ In contrast to the aggregate created value, the RNV might decrease over periods, in which case subjects fail to take advantage of upcoming opportunities given by new word creations. However, the RNV increases when subjects learn to better exploit innovation opportunities. Table 3.3 summarizes the RNV by treatments.

Table 3.3. Relative Net Value across treatments. Summary statistics

\begin{tabular}{|c|c|c|c|c|}
\hline & \multicolumn{4}{|c|}{ RNV } \\
\hline & average (sd) & Median & $\min$ & $\max$ \\
\hline control & $\begin{array}{c}0.317 \\
(0.0309)\end{array}$ & 0.311 & 0.274 & 0.378 \\
\hline ranking & $\begin{array}{c}0.328 \\
(0.0366)\end{array}$ & 0.329 & 0.272 & 0.372 \\
\hline bonus & $\begin{array}{c}0.375 \\
(0.049)\end{array}$ & 0.375 & 0.294 & 0.451 \\
\hline
\end{tabular}

In contrast to our findings in section 3.4.2.1, the RNV is not equal across treatments (Kruskal-Wallis test on the group level, $\chi^{2}=10.245$ with $\mathrm{df}=2 ; \mathrm{p}=.006$ ). The average $\mathrm{RNV}$ in bonus is significantly higher than in control (MWU-test for control vs. bonus $\mathrm{z}=-2.887$ and $\mathrm{p}=.0039$ ), while there are no significant differences between control and ranking (MWU-test

\footnotetext{
${ }^{32}$ Keep in mind that the RNV is not a measure of the optimality of decisions for groups at large. This would require us to calculate each potential path and outcome for each decision. Obviously, this calculation task is unlikely to be solved by subjects, which prompted us to build our analysis upon the myopic maximization problem.
} 
for control vs. ranking $\mathrm{z}=-0.635$ and $\mathrm{p}=.5254)$. Accordingly, subjects in bonus tend to perform better when controlling for path dependency.

Figure 3.4. Average values for the RNV's determinants over periods by treatment

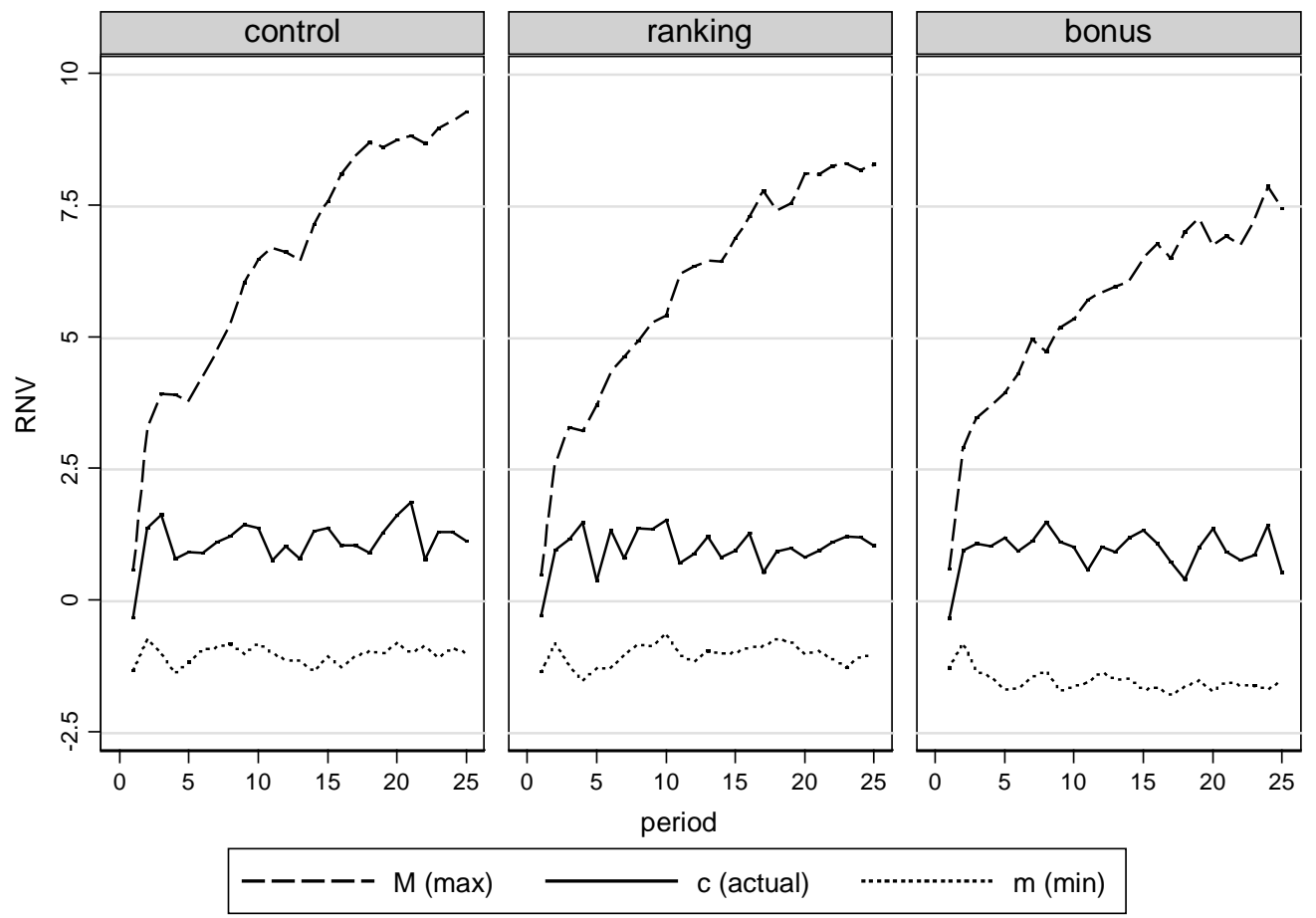

Figure 3.4 illustrates the dynamics of the RNV and its determinants over periods for all treatments. The graph hints at a superior creation of opportunities (M) in control, which can be explained by higher levels of cooperation. Nonetheless, subjects fail to keep up with the increase in opportunities, which leads to the inferior RNV values illustrated in table 3.3. Overall, the same pattern of subjects not being able to exploit expanding opportunities is evident for all treatments. The creation of opportunities is lower in bonus and ranking, which restricts the maximal achievable income and thus leads to a higher average RNV in bonus. ${ }^{33}$ This difference becomes apparent in figure 3.5, which further shows that the RNV is deteriorating over time for all treatments, corresponding to the increasing number of untapped opportunities as the game proceeds. Recall that the actual payoff $\pi\left(c_{i t}\right)$ depends on the royalty fees that have to be paid. Therefore, the decrease in the maximal achievable income in ranking and bonus has to be explained by lower royalties demanded in control.

\footnotetext{
33 Applying a Mann-Whitney-U test for control vs. bonus for the maximum $\mathrm{M}$ (minimum $\mathrm{m}$ ) indicates a significant difference, with $\mathrm{z}=1.848$ and $\mathrm{p}=.0647(\mathrm{z}=3.522$ and $\mathrm{p}=.0004)$. There are no such differences between control and ranking, with $\mathrm{z}=1.213$ and $\mathrm{p}=.2252$ ( $\mathrm{z}=0.462$ and $\mathrm{p}=.6442)$ for $\mathrm{M}(\mathrm{m})$.
} 


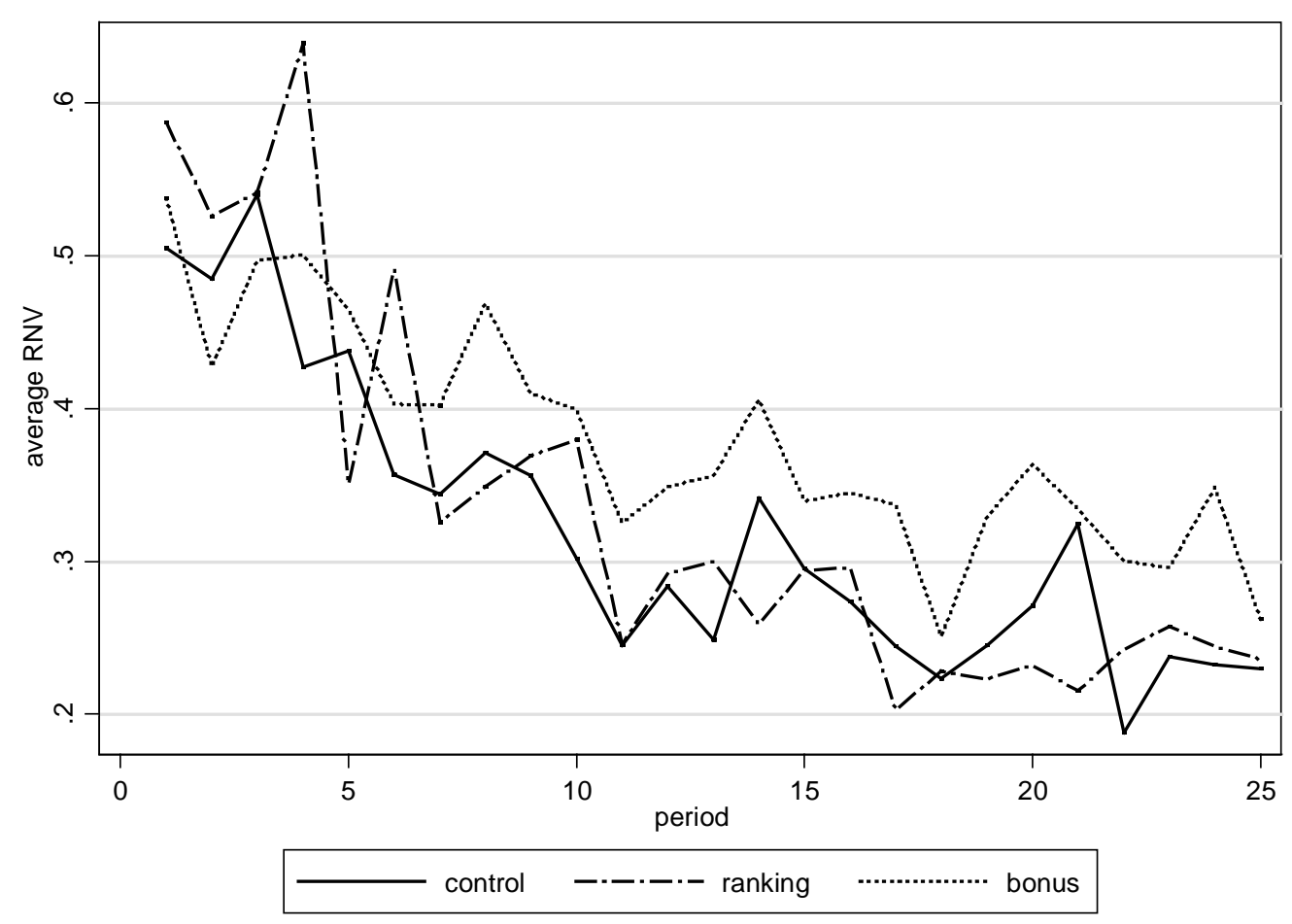

RESULT 4: When controlling for the actual choice set, a prize for the best innovation substantially increases the exploitation of innovation opportunities, whereas a prize for the aggregate innovativeness does not lead to similar effects. This effect is driven by differences in the demanded royalty fees. The increase in exploitation of innovation opportunities for a prize for the aggregate innovativeness is thus not due to better performance but rather reflects the inferior creation of individual income opportunities.

\subsection{Concluding Remarks}

The present article provides novel empirical perspective on the discussion regarding the use of innovation contests as a policy instrument to foster innovation activity. Accordingly, we transfer a sequential innovation setting to the lab by building upon a real effort word creation task. We analyze cooperation behavior and innovativeness in two types of innovation contests, namely a prize for the aggregate innovativeness and an additional prize for the best innovation. Our results show that both types of contests substantially reduce the willingness to cooperate among subjects, as demanded royalty fees significantly increase. Nevertheless, this does not reduce the actual cooperation, i.e. the propensity to make use of other innovators' products. Despite the higher royalty fees in the innovation contest treatments, the total innovativeness remains constant across treatments. This finding illustrates that subjects accept 
paying higher royalty fees when striving to win an innovation contest. Our results further indicate that the intensified competition in innovation contests tends to reduce the individual income opportunities, given that higher royalty fees have to be paid.

Moreover, we derive some general policy implications. Let us consider the potential effects of innovation contests on aggregate welfare. Our results show that welfare is not necessarily increased, especially when opportunities to innovate are restricted, e.g. by the sequentiality of the process itself or constraints in the available investment capital. Furthermore, when considering the transaction costs for organizing the contest and the costs of the prize itself, overall welfare might substantially decrease. This issue is particularly relevant for statesubsidized contests, whereby taxes are reallocated while no adequate gains in innovation activity might be achieved.

Furthermore, the decreasing willingness to cooperate due to innovation contests hints at the emergence of patent races. It has been shown both experimentally and theoretically that patent races might lead to excessive spending on innovation activity and welfare losses (Loury 1979; Zizzo 2002; Silipo 2005; Judd et al. 2012). Therefore, we would suggest that the additional competitive pressure induced by prizes is likely to lead to adverse effects, particularly in domains that require broad cooperation among different individuals and groups.

It is important to note that innovation contests boost the effectiveness and importance of intellectual property rights as higher royalty fees are demanded. The willingness to cooperate decreases and an innovation system dominated by competition becomes prevalent. The simultaneous use of these policy instruments - i.e. contests and intellectual property rights thus might have mutually amplifying negative effects, reducing aggregate welfare. Put briefly, intellectual property rights and innovation contests overlap and as intellectual property rights are established in almost every industrialized country, the implementation of state-subsidized innovation contests to foster innovation should be called into question. As suggested by Clancy and Moschini (2013), a system with a hybrid use - where innovators choose between intellectual property rights and an innovation prize - might be a solution to prevent these negative overlapping effects. 


\section{Acknowledgments}

We would like to thank Kilian Bizer, Paolo Crosetto and Till Proeger for their helpful comments and Dennis Kotte for student assistance in programming and running the experiments. Further, financial support from the German Federal Ministry of Education and Research via the Hans-Böckler-Stiftung is gratefully acknowledged.

\section{References}

Adamczyk, Sabrina, Angelika C. Bullinger, and Kathrin M. Möslein. 2012. "Innovation contests. A review, classification and outlook.” Creativity and Innovation Management, 21(4): 335-60.

Adler, Jonathan H. 2011. "Eyes on a climate prize. Rewarding energy innovation to achieve climate stabilization.” Harvard Environmental Law Review, 35(1): 1-45.

Bemelmans-Videc, Marie-Louise, Ray C. Rist, and Evert Vedung, ed. 1998. Carrots, sticks \& sermons. Policy instruments \& their evaluation. New Brunswick, NJ: Transaction Publishers.

Blasio, Guido de, Davide Fantino, and Guido Pellegrini. 2015. "Evaluating the impact of innovation incentives. Evidence from an unexpected shortage of funds.” Industrial and Corporate Change, 24(6): 1285-1314.

Borrás, Susana and Charles Edquist. 2013. “The choice of innovation policy instruments.” Technological Forecasting and Social Change, 80(8): 1513-22.

Boudreau, Kevin J., Nicola Lacetera, and Karim R. Lakhani. 2011. "Incentives and problem uncertainty in innovation contests. An empirical analysis.” Management Science, 57(5): 843-63.

Boudreau, Kevin J. and Karim R. Lakhani. 2012. "The confederacy of heterogeneous software organizations and heterogeneous developers. Field experimental evidence on sorting and worker effort." In The rate and direction of inventive activity revisited, ed. Josh Lerner and Scott Stern. Chicago, IL: University of Chicago Press, 483-502.

Bradler, Christiane. 2015. "How creative are you? An experimental study on self-selection in a competitive incentive scheme for creative performance.” ZEW Discussion Paper 15021.

Brüggemann, Julia, Paolo Crosetto, Lukas Meub, and Kilian Bizer. 2015. "Intellectual property rights hinder sequential innovation. Experimental evidence.” cege Discussion Paper 227.

Brunt, Liam, Josh Lerner, and Tom Nicholas. 2012. "Inducement prizes and innovation.” The Journal of Industrial Economics, 60(4): 657-96.

Buchanan, Joy A. and Bart J. Wilson. 2014. "An experiment on protecting intellectual property.” Experimental Economics, 17(4): 691-716.

Cantner, Uwe, Werner Güth, Andreas Nicklisch, and Torsten Weiland. 2009. "Competition in product design. An experiment exploring innovation behavior." Metroeconomica, 60(4): 724-52. 
Cason, Timothy N., William A. Masters, and Roman M. Sheremeta. 2010. "Entry to winner-take-all and proportional-prize contests. An experimental study." Journal of Public Economics, 94(9): 604-11.

Chari, V. V., Mikhail Golosov, and Aleh Tsyvinski. 2012. "Prizes and patents. Using market signals to provide incentives for innovations." Journal of Economic Theory, 147(2): 781-801.

Chaudhuri, Ananish. 2011. "Sustaining cooperation in laboratory public goods experiments. A selective survey of the literature.” Experimental Economics, 14(1): 47-84.

Che, Yeon-Koo and Ian Gale. 2003. "Optimal design of research contests.” The American Economic Review, 93(3): 646-71.

Clancy, Matthew S. and Gian C. Moschini. 2013. "Incentives for innovation. Patents, prizes, and research contracts.” Applied Economic Perspectives and Policy, 35(2): 206-41.

Cohen, Chen, Todd R. Kaplan, and Aner Sela. 2008. "Optimal rewards in contests.” The RAND Journal of Economics, 39(2): 434-51.

COM (2010) 2020. "Europe 2020. A strategy for smart, sustainable and inclusive growth.” (http://eur-lex.europa.eu/LexUriServ/LexUriServ.do?uri=COM:2010:2020:FIN:EN:PDF) last accessed on $14^{\text {th }}$ Dec. 2015.

Crosetto, Paolo. 2010. "To patent or not to patent. A pilot experiment on incentives to copyright in a sequential innovation setting." In IFIP advances in information and communication technology, Open source software. New horizons. $6^{\text {th }}$ International IFIP WG 2.13 Conference on Open Source Systems, ed. Pär J. Ågerfalk, Cornelia Boldyreff, Jesús M. González-Barahona, Gregory R. Madey, and John Noll. Berlin, New York: Springer, 53-72.

David, Paul A., Bronwyn H. Hall, and Andrew A. Toole. 2000. "Is public R\&D a complement or substitute for private R\&D? A review of the econometric evidence." Research Policy, 29(4-5): 497-529.

Eckartz, Katharina, Oliver Kirchkamp, and Daniel Schunk. 2012. "How do incentives affect creativity?” CESifo Working Paper 4049.

Ederer, Florian and Gustavo Manso. 2013. "Is pay-for-performance detrimental to innovation?” Management Science, 59(7): 1496-513.

Flanagan, Kieron, Elvira Uyarra, and Manuel Laranja. 2011. "Reconceptualising the 'policy mix' for innovation.” Research Policy, 40(5): 702-13.

Fullerton, Richard, Bruce G. Linster, Michael McKee, and Stephen Slate. 1999. "An experimental investigation of research tournaments.” Economic Inquiry, 37(4): 624-36.

Gallini, Nancy T. and Suzanne Scotchmer. 2002. "Intellectual property. When is it the best incentive system?” In Innovation Policy and the Economy. Volume 2, ed. Adam B. Jaffe, Josh Lerner, and Scott Stern: Chicago: MIT Press, 51-77.

Ganuza, Juan-Jose and Esther Hauk. 2006. "Allocating ideas. Horizontal competition in tournaments.” Journal of Economics \& Management Strategy, 15(3): 763-87.

Greiner, Ben. 2004. “An online recruitment system for economic experiments.” In GWDG Bericht, Forschung und wissenschaftliches Rechnen, ed. Kurt Kremer and Volker Macho. Göttingen, 79-93. 
Guerzoni, Marco and Emilio Raiteri. 2015. "Demand-side vs. supply-side technology policies. Hidden treatment and new empirical evidence on the policy mix." Research Policy, 44(3): 726-47.

H.R.5116. "America COMPETES Reauthorization Act of 2010." (http://www.nsf.gov/statistics/about/BILLS-111hr5116enr.pdf) last accessed on $14^{\text {th }}$ Dec. 2015.

Hall, Bronwyn H. and Josh Lerner. 2010. "The financing of R\&D and innovation.” In Handbook of the economics of innovation. Volume 1, ed. Bronwyn H. Hall and Nathan Rosenberg. Amsterdam: Elsevier, 609-39.

Hall, Bronwyn H. and John van Reenen. 2000. "How effective are fiscal incentives for R\&D? A review of the evidence.” Research Policy, 29(4-5): 449-69.

Irlenbusch, Bernd. 2006. "Experimental perspectives on incentives in organisations." Central European Journal of Operations Research, 14(1): 1-24.

Judd, Kenneth L., Karl Schmedders, and Şevin Yeltekin. 2012. "Optimal rules for patent races.” International Economic Review, 53(1): 23-52.

Kirchkamp, Oliver and J. P. Reiß. 2011. "Out-of-equilibrium bids in first-price auctions. Wrong expectations or wrong bids.” The Economic Journal, 121(557): 1361-97.

Kremer, Michael and Heidi Williams. 2010. "Incentivizing innovation. Adding to the tool kit.” In Innovation policy and the economy. Volume 10, ed. Josh Lerner and Scott Stern. Chicago, IL: University of Chicago Press.

Loury, Glenn C. 1979. "Market structure and innovation." The Quarterly Journal of Economics, 93(3): 395-410.

Maurer, Stephen M. and Suzanne Scotchmer. 2004. "Procuring knowledge.” In Advances in the study of entrepreneurship, innovation and economic growth 15, Intellectual property and entrepreneurship, ed. Gary D. Libecap. Greenwich, CT: Emerald Group Publishing, 1-31.

Meloso, Debrah, Jernej Copic, and Peter Bossaerts. 2009. "Promoting intellectual discovery. Patents versus markets.” Science, 323(5919): 1335-39.

Moldovanu, Benny and Aner Sela. 2001. “The optimal allocation of prizes in contests.” The American Economic Review, 91(3): 542-58.

Moser, Petra and Tom Nicholas. 2013. "Prizes, publicity and patents. Non-monetary awards as a mechanism to encourage innovation." The Journal of Industrial Economics, 61(3): 763-88.

Murray, Fiona, Scott Stern, Georgina Campbell, and Alan MacCormack. 2012. "Grand innovation prizes. A theoretical, normative, and empirical evaluation." Research Policy, 41(10): 1779-92.

Nicholas, Tom. 2013. "Hybrid innovation in Meiji, Japan.” International Economic Review, 54(2): 575-600.

Rijnsoever, Frank J. van, Meeus, Marius T. H., and Donders, A. Rogier T. 2012. "The effects of economic status and recent experience on innovative behavior under environmental variability. An experimental approach.” Research Policy, 41(5): 833-47.

Schöttner, Anja. 2008. "Fixed-prize tournaments versus first-price auctions in innovation contests.” Economic Theory, 35(1): 57-71. 
Silipo, Damiano B. 2005. "The evolution of cooperation in patent races. Theory and experimental evidence.” Journal of Economics, 85(1): 1-38.

Sørensen, Flemming, Jan Mattson, and Jon Sundbo. 2010. "Experimental methods in innovation research.” Research Policy, 39(3): 313-23.

Taylor, Curtis R. 1995. "Digging for golden carrots. An analysis of research tournaments." The American Economic Review, 85(4): 872-90.

Williams, Heidi. 2012. "Innovation inducement prizes. Connecting research to policy." Journal of Policy Analysis and Management, 31(3): 752-76.

Wright, Brian D. 1983. "The economics of invention incentives. Patents, prizes, and research contracts.” The American Economic Review, 73(4): 691-707.

Zizzo, Daniel John. 2002. "Racing with uncertainty. A patent race experiment." International Journal of Industrial Organization, 20(6): 877-902.

Zúñiga-Vicente, José Á., César Alonso-Borrego, Francisco J. Forcadell, and José I. Galán. 2014. "Assessing the effect of public subsidies on firm R\&D investment . A survey.” Journal of Economic Surveys, 28(1): 36-67. 


\section{Appendix}

\section{Appendix A}

Instructions for all treatments

Note: The differences between treatments are indicated in square brackets. The original instructions were in German and are available from the authors upon request.

\section{The Game}

In this game, your task is to build words using letters as in the board game "Scrabble". By building words, you increase your payoff: for each word, you receive a payoff calculated by the sum of the values of each letter. You start the game with an endowment of 4 letters. During the course of the game, you are able to buy additional letters.

During the course of the game, you will play in a group of 4 players.

\section{The Payoff}

[bonus: Your payoff results from two components: 1 . The sum of the value of your letters] Your payoff depends on the sum of the value of your letters, which is calculated in experimental tokens. You start the game with an endowment of 75 tokens.

[control and bonus: One token is converted to $€ 0.12$ at the end of the experiment. Note that it is possible to end the experiment with less than your starting endowment.]

[bonus: €10-bonus for the "most valuable" word: Additionally, you compete with your 3 group members: The "most valuable" word is rewarded with a bonus of $€ 10$ at the end of the game. The player who added the last letter to the word that is valued with the most tokens receives the $€ 10$ bonus.]

[ranking: In this game, you compete with your three group members. Your payoff at the end of the experiment depends on the tokens you score compared to your group members: The player with the most tokens receives $€ \mathbf{2 4}$, while each of the other three players receives $€ \mathbf{1 2}$.] [ranking and bonus: You can see how well you are performing compared to your group members at the bottom-right on the general view on the main board (see page 2).]

Please note the table below containing all letters, their value (in tokens) and the frequency with which they occur in the game. During the game, the letters are always displayed along with their value.

Table A3.1. List of letters

\begin{tabular}{|c|c|c|c|c|c|c|c|c|}
\hline Letter & Value & Frequency & Letter & Value & Frequency & Letter & Value & Frequency \\
\hline $\mathrm{A}$ & 1 & 10 & $\mathrm{~J}$ & 6 & 2 & $\mathrm{~S}$ & 1 & 14 \\
\hline $\mathrm{B}$ & 3 & 4 & $\mathrm{~K}$ & 4 & 4 & $\mathrm{~T}$ & 1 & 12 \\
\hline $\mathrm{C}$ & 4 & 4 & $\mathrm{~L}$ & 2 & 6 & $\mathrm{U}$ & 1 & 12 \\
\hline $\mathrm{D}$ & 1 & 8 & $\mathrm{M}$ & 3 & 8 & $\mathrm{~V}$ & 6 & 2 \\
\hline $\mathrm{E}$ & 1 & 30 & $\mathrm{~N}$ & 1 & 18 & $\mathrm{~W}$ & 3 & 2 \\
\hline $\mathrm{F}$ & 4 & 4 & $\mathrm{O}$ & 2 & 6 & $\mathrm{X}$ & 8 & 2 \\
\hline $\mathrm{G}$ & 2 & 6 & $\mathrm{P}$ & 4 & 2 & $\mathrm{Y}$ & 10 & 2 \\
\hline $\mathrm{H}$ & 2 & 8 & $\mathrm{Q}$ & 10 & 2 & $\mathrm{Z}$ & 3 & 2 \\
\hline $\mathrm{I}$ & 1 & 12 & $\mathrm{R}$ & 1 & 12 & & & \\
\hline
\end{tabular}

On the next page, you will find a screenshot of the main board of the game and some explanations to gain a first overview of the game. A detailed explanation of the game ensues. 


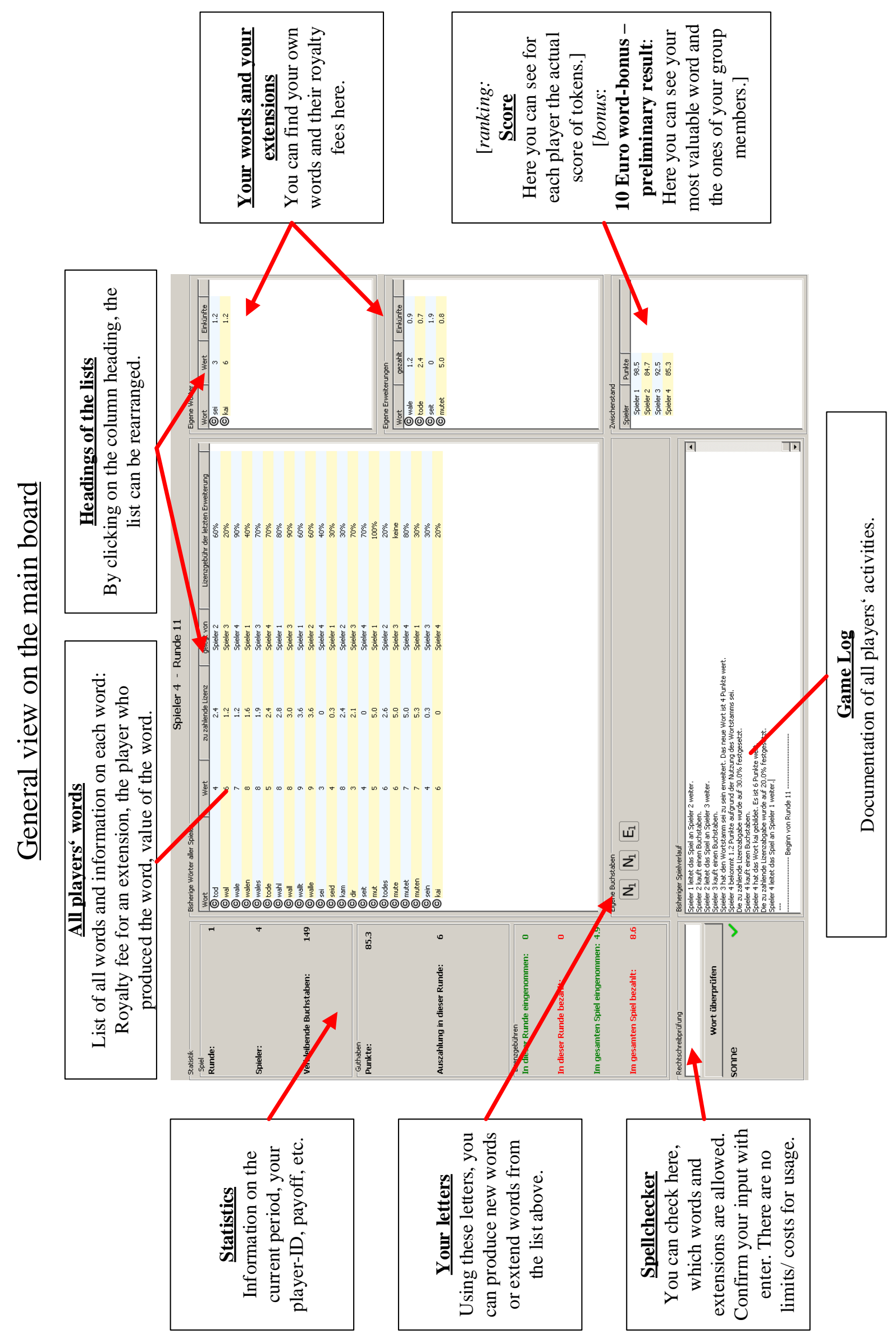




\section{Course of a Turn}

When it is your turn, a dialog pops up asking you for choices. During your turn, you cannot use the spellchecker. You have 45 seconds for your decisions. You can see the remaining time at the top-left corner of the screen. If your time expires, you are subtracted 1 token from your endowment for every additional 10 seconds.

Every turn comprises three phases:

\section{Buying phase}

\section{Your activity: Buying letters}

You can choose to buy or not to buy one letter at the price of 2 tokens. If you buy a letter, it will be chosen randomly from the list of letters shown on the table A3.1. At the beginning, you are given four letters for free. Each letter can only be used once: after producing or extending a word, the letter will be deleted from your letter set.

\section{Word phase}

\section{Your activity: Producing or extending words}

You can use German words, their conjugations and declinations and some names of places and persons. You can test if a word is correct using the spellchecker when it is not your turn. Correct words can be built as follows:

\section{Option 1: $\quad$ Producing a 3-letter word}

a) You can produce a word using exactly three of your letters.

The payoff that you earn for creating a word is given by the sum of the value of the letters (Example: 'pol': $\mathrm{p}=4, \mathrm{o}=2, \mathrm{l}=2$. This results in $4+2+2=8$ tokens).

To create a word, you have to type in the letters with your keyboard.

Please note that you cannot undo mistakes: if you make an error while inputting the word (i.e. inputting a too long, too short, non-existent or misspelled word, or pressing the enter key on an empty field), the turn passes to the next player. You will only have the opportunity to reiterate your entry correctly in the next period, during your next turn.

\section{Option 2: $\quad$ Extending a word}

b) You can extend an existing word by inserting one letter in any position in the word. For example, 'ast' can be extended into 'last', 'rast' and 'aste', and 'last' again into 'laust' and this into 'klaust'. It is not possible to rearrange existing words (e.g. to build from 'ast' the word 'star').

Your payoff results from the sum of the value of the letters of the newly-extended word. By extending e.g. 'last' into 'laust', you get $\mathrm{l}=2, \mathrm{a}=1, \mathrm{u}=1, \mathrm{~s}=1, \mathrm{t}=1$, so $2+1+1+1+1=6$ tokens. Every word can only be produced once but can subsequently be used for as many extensions as possible. 


\section{Option 3: $\quad$ Passing}

c) In case you are unable to produce or extend any word, you can pass the turn to the next player.

\section{Royalty phase}

\section{Your activity: Setting a royalty fee}

After producing a word, you have to set a royalty fee that other players are required to pay when creating extensions. The fee must be set between 0 and 100 percent of the value of the word.

Figure A3.1. Intellectual property choice

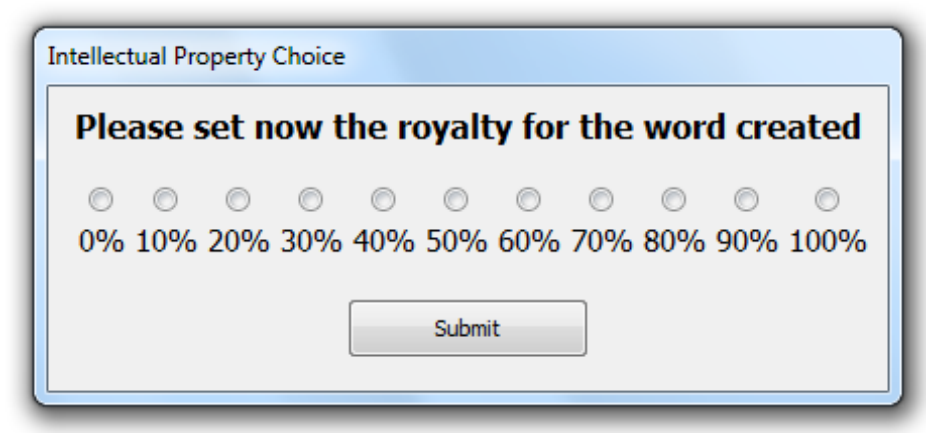

If another player extends your word, he automatically transfers the fee to you.

- 0 percent means that the word is entirely free for other players.

- At 100 percent, the next player only receives the value of his added letter.

- The choice of 20 percent means that the respective player has to pay 20 percent of the value of the word to you.

The royalty fee for a word remains fixed during the entire game. The word appears on the list of public words on the main board and can be used by everyone. However, other players have to pay the royalty fee when extending the word.

Furthermore, you will have to set a royalty fee if you extend a word with one letter. In this case, you decide on the fee only for your added letter. Your payoff results from the sum of the value of all letters minus the royalty fee for the word that you built upon.

After that, your turn ends and it is the next player's turn. The game is played for 25 periods. Finally, some payoff-examples are offered for clarification:

\section{Examples of Potential Payoffs:}

Example 1: If player 1 sets a royalty fee of 90 percent for the word 'ast' (value of the word 3 tokens: $\mathrm{a}=1, \mathrm{~s}=1, \mathrm{t}=1$ ) and player 2 extends the word into 'hast' (value of $\mathrm{h}=2$ ), this results in the following payoffs:

Player 1: 90 percent of 3 tokens $=2.7$ tokens (royalty fee for player 1 )

Player 2: $3-2.7$ tokens (to player 1 ) +2 tokens for the letter ' $h$ ' $=0.3$ tokens +2 tokens $=2.3$ tokens 
Example 2: If player 1 sets the royalty fee of 0 percent for 'ast', player 2 receives the sum of the value of all letters for extending it into 'hast':

Player 1: 0 percent of 3 tokens $=0$ token

Player 2: 100 percent of 5 tokens $=5$ tokens

Example 3: After extending a word, the player has to set a royalty fee for the added letter. Player 1 sets a royalty fee of 10 percent for 'ast' and player 2 sets a royalty fee of 50 percent for the letter ' $h$ ' in 'hast'. If player 3 then extends 'hast' into 'haust', this results in the following payoffs:

Player 1: 10 percent of 3 tokens $=0.3$ (royalty fee for player 1 )

Player 2: 50 percent of 2 tokens $=1$ (royalty fee for player 2)

Player 3: 6 tokens for 'haust' -0.3 tokens (to player 1 ) -1 token (to player 2 ) $=4.7$ tokens

\section{Appendix B}

Instructions for the word task

Note: The instructions for the word task were shown on screen.

In the next screen, you will see a string comprising 9 letters.

You will be asked to create as many German words as possible using these letters within 3 minutes.

You can type the words you create in the field beneath the string of 9 letters and submit them by hitting Enter.

You can use each letter only once per word and a word cannot be shorter than 3 letters.

Longer words generate more points.

3-letter word: $3+2+1=6$ points

4-letter word: $4+3+2+1=10$ points

etc.

After the 3 minutes have expired, the test will end and you will be shown your results.

As soon as you enter the next screen, the timer will start ticking.

To proceed to the next screen, please press the letter ' $R$ ' on your keyboard. 


\section{Appendix C}

Results of the control task

Treatment or group comparisons might heavily depend on the task-specific knowledge of some participants. As four subjects interact and potentially cooperate on only one innovation market, observations are not independent. A group's performance might be driven by a single subject showing very high or very low ability with respect to the word task. Therefore, we carried out an additional task before the experiment, which allows us to control for individual task-specific knowledge when analyzing innovation activity. We implement a task introduced by Eckartz et al. (2012): within three minutes, subjects are asked to build as many words as possible out of a 12-letter set (accehhikllst). Subjects accumulate points by building words, where points assigned increase disproportionally with word length. According to the aggregate points, the best three subjects of each session are paid $1 €$, which should guarantee that subjects put real effort into building words according to their best ability. Figure A3.2 shows the achieved points over groups by treatment.

Figure A3.2. Control task results over group by treatment
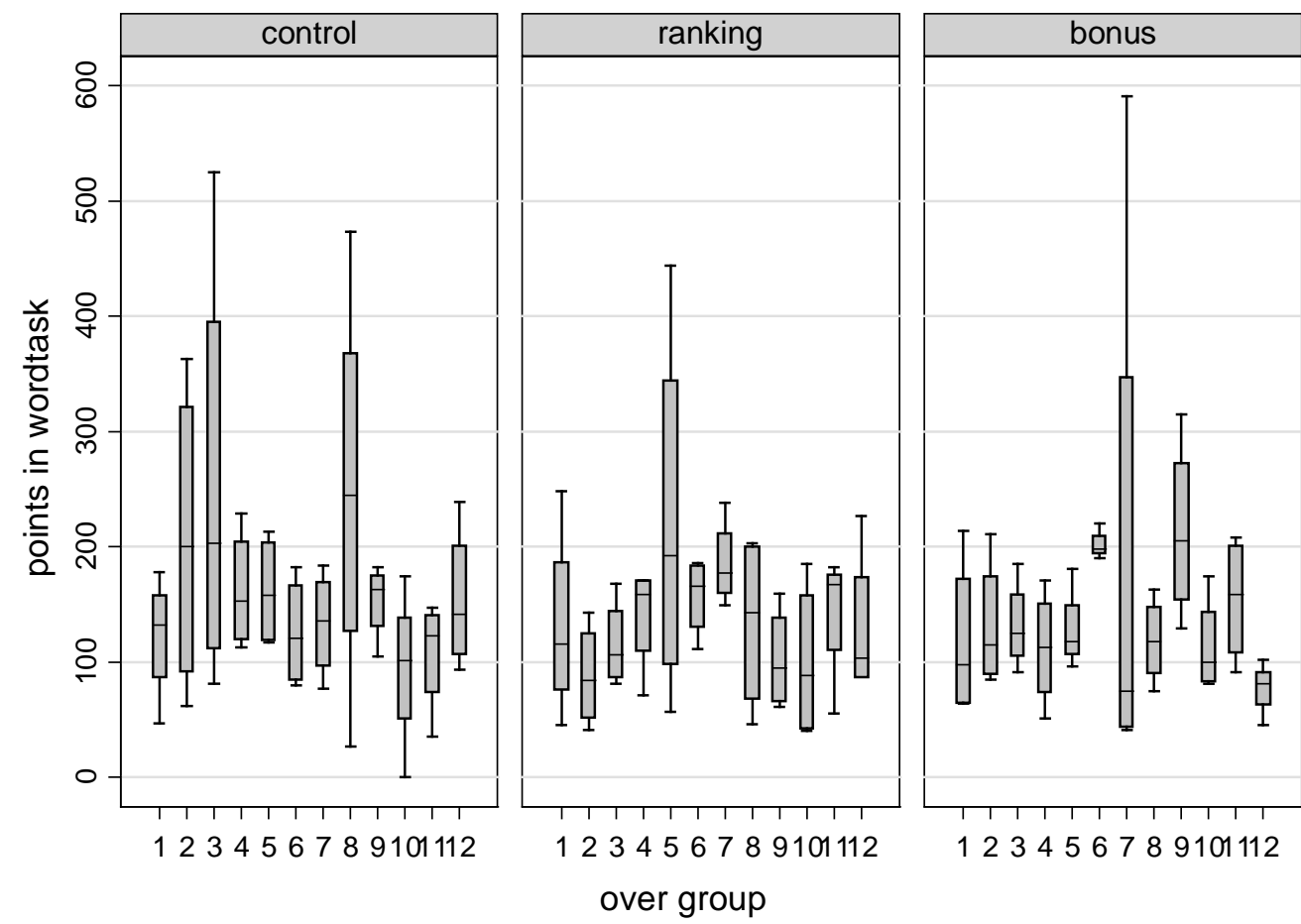

There are no substantial differences across treatments (Kruskal-Wallis test gives $\chi^{2}=1.461$ with $\mathrm{df}=2$ and $\mathrm{p}=.4817$ ), while evidently there is some heterogeneity in task-specific knowledge across groups within treatments. 


\section{The effectiveness of public subsidies for private innovations. An experimental approach}

cege Discussion Paper 266, Georg-August-Universität Göttingen, Nov. 2015. Download: http://wwwuser.gwdg.de/ cege/Diskussionspapiere/DP266 


\begin{abstract}
The effects of public subsidies in supporting private innovative activity is subject to longstanding political and scientific debates. Since the empirical findings remain largely inconclusive, this study adds to this debate with counterfactual evidence from a laboratory experiment. In a creative real effort task simulating the innovation process, two distinct means of allocating subsidies are compared to a benchmark treatment without subsidies to identify their effects in fostering innovativeness. Furthermore, subjects' cooperative behavior in relation to subsidies is investigated. Overall, subsidies lead to a substantial crowding-out of private investment. While the individual revenues increase due to the subsidy, the innovative activity fails to increase and less sophisticated innovations are realized. Consequently, subsidies have no positive and even negative effects on overall welfare, depending on the subsidy specifics. However, subsidies do not influence cooperative behavior. These findings imply that the additional costs of subsidies for innovations might not be warranted by gains from additional innovations and increased welfare.
\end{abstract}

\title{
Keywords
}

creativity, innovation policy, laboratory experiment, real effort task, subsidies

\section{JEL-Classification}

C91, H25, O31 


\subsection{Introduction}

Industrialized states use a broad composition of different policy instruments to stimulate innovations and thus promote the growth of their economies. This long-standing political objective has fostered broad discussions among policy-makers as well as in the scientific community about the determinants of innovation-based growth and the most effective policy mix in terms of incentivizing firms and individuals to innovate (Flanagan et al. 2011; Guerzoni and Raiteri 2015). Among the most frequently used regulatory instruments are direct monetary subsidies in the form of government grants provided to firms that develop and implement innovative products and services. Advocates of this form of governmental support claim that subsidies can help to increase the overall level of innovative activity, which would otherwise fail to reach a desirable level from a welfare perspective. Furthermore, it is argued that monetary subsidies can be distributed efficiently; for example, by implementing specific tax regulations or funding specific projects. By contrast, opponents of innovation subsidies point to a selection bias problem, criticizing that the distribution of subsidies tends to be selective and often fails to allocate funds optimally, thereby providing support for firms that are considered successful beforehand and would succeed regardless. Moreover, it is argued that the supported firms might use the grants more carelessly than their own resources, possibly resulting in dissipating or idle behavior. In addition, it is pointed out that the administration and allocation of subsidies entails considerable costs for the state and potentially leads to a crowding-out of private investment without increasing innovations and growth overall (Jaffe 2002).

The controversial debate on innovation subsidies among policy-makers is reflected in the scientific debate, which has yielded inconclusive findings on the economic effects of subsidies in fostering innovation activities (Zúñiga-Vicente et al. 2014). Aiming to craft more effective economic policies using theoretical and empirical analyses, a large number of empirical studies have examined the effect of subsidies. The results of these studies range from an additive effect on private R\&D (Aerts and Schmidt 2008), no effect (González and Pazó 2008) to a crowding-out of private investment (Wallsten 2000). Furthermore, the effects of subsidies and cooperation on innovative firm behavior are emphasized, with a number of studies arguing that cooperation can positively influence innovative activities (Czarnitzki et al. 2007; Fornahl et al. 2011; Nishimura and Okamuro 2011). Blasio et al. (2014) sum up the ambiguous findings on the effectiveness of subsidies and the lack of unequivocal evidence with a basic methodological problem: "Beyond public declarations and legitimate hopes, however, there is little agreement on the effectiveness of public spending to foster private 
R\&D. The reason is that to evaluate the effects of government-sponsored programs it is necessary to address the intrinsically difficult counterfactual question of what would have happened without the subsidies” (Blasio et al. 2014, 26).

Building upon the statement by Blasio and colleagues, this paper aims to contribute novel empirical evidence regarding the effectiveness of innovation subsidies by creating an experimental setting that enables investigating counterfactual questions. Similar to Sørensen et al. (2010)'s suggestion, a series of laboratory experiments is conducted to analyze the effects of subsidies on the investment in and emergence of innovations. This setting is implemented to simulate the innovation process and thus compare ceteris paribus whether innovators receiving different forms of subsidies act systematically differently from those without external funding. While replicating the creative and dynamic innovation process within a task feasible for student subjects places certain restraints on the external validity of the results, the methodological approach has strong advantages; namely, the first counterfactual analysis of the effects of different forms of innovation subsidies can be presented, which includes the key features of innovation - i.e. risky investments, ownership and creativity - and thus completely reproduces the cumulative innovation process. To this end, a novel experimental setting is used that builds upon the board game Scrabble, in which subjects use letters to create words, are compensated for their innovation and are allowed to set license fees for their newly-created words (Crosetto 2010; Brüggemann et al. 2015).

In the first experiment, a benchmark treatment without subsidies is compared to a treatment in which subjects are provided with additional material resources in the form of extra letters; thus, the subsidy is limited to the use in innovative activities. In the second experiment, the benchmark is compared to a treatment providing subjects with monetary subsidies that can be used to buy additional letters. On a continuum ranging from a restrictive grant-in-aid to a freely-usable financial assistance, this experiment implements two distinct variants that tend towards either end of the continuum. In both settings, license fees can be imposed on innovations, which provide a measure of cooperative behavior among participants. The experiments thus only differ with respect to the form of the subsidies. In both benchmark treatments, subjects are required to buy their letters: in the first experiment, subjects receive a free letter each period; while in the second experiment, they receive an additional payoff worth one letter in each period. With this experimental design, the effect of the two different forms of subsidies on individual investment and cooperation behavior can be tested to assess which more effectively increases innovativeness. 
The results indicate that subsidies have no positive effects on individual innovativeness and overall welfare. Providing additional material resources restricted to the use in innovations yield no differences in welfare; indeed, offering freely-usable additional monetary resources even leads to a loss in overall welfare. Although innovators' individual incomes increase due to the subsidies, no increase in the innovative activity results; rather, subsidies substantially crowd out private investment. Regarding the specifics of innovations, subsidies foster the realization of less sophisticated innovations. In turn, cooperative behavior - as measured by the level of license fees chosen - is not affected by subsidies. From a policy perspective, the results indicate that subsidies may not yield positive effects in terms of innovativeness and overall welfare and they could even induce negative overall welfare effects when accounting for their additional costs to the state.

The remainder of this paper is structured as follows. Section 4.2 presents a review of the literature on subsidies and innovation, before section 4.3 explains in detail the experimental design and section 4.4 describes the behavioral hypotheses. The experimental results are provided in section 4.5 and section 4.6 provides policy implications and finally concludes.

\subsection{Literature Review}

There is a large body of empirical literature discussing the effectiveness of public subsidies by examining different government programs. ${ }^{34}$ In a literature review, David et al. (2000) report that no crowding-out of private innovation investments through public subsidies occurs in two-thirds of the studies, whereby the crowding-out effect seems stronger in the USA compared with Europe. Therefore, in the majority of the studies reviewed, public subsidies are shown to have a positive impact on the innovative activity. Overall, Klette et al. (2000) also find positive results when comparing five empirical studies in detail, yet they also point to methodological problems inherent in the studies. By contrast, in a more recent review, Zúñiga-Vicente et al. (2014) sum up the literature by stating that the effectiveness of public subsidies has to be called into question due to the improved data quality in recent years. From a financial market perspective, Hall and Lerner (2010) survey the discussion of a "funding gap” in the investment for innovations and emphasize that further research should be conducted, ideally in an experimental or quasi-experimental setting. ${ }^{35}$

Overall, the empirical evidence for developed countries is inconclusive, with many studies pointing to a positive impact on private innovative activity (Almus and Czarnitzki 2003; Czarnitzki and Hussinger 2004; Aerts and Schmidt 2008; Hussinger 2008; Aschhoff 2009;

\footnotetext{
${ }^{34}$ For a generalist overview of innovation research see Hong et al. (2012).

${ }^{35}$ For the specific effects of tax incentives see Hall and van Reenen (2000).
} 
Aschhoff and Sofka 2009; Duch et al. 2009; Czarnitzki and Lopes Bento 2012; Czarnitzki and Lopes Bento 2014). Similarly, a number of studies also identify mixed effects on the innovative activity (Cerulli and Potì 2008; Busom 2000; Heijs and Herrera 2004; González et al. 2005; Görg and Strobl 2007; Clausen 2009; Fantino and Cannone 2013; Bronzini and Iachini 2014; Becker 2015). Conversely, other studies do not support these results and find no positive effects of public support on innovative activity (Lach 2002; Hujer and Radić 2005; González and Pazó 2008; Norrman and Bager-Sjögren 2010; Blasio et al. 2014). Furthermore, a few authors show a full or partial crowding-out of private investment as an unintended negative effect of subsidies (Goolsbee 1998; Wallsten 2000).

Moreover, many studies on the determinants of innovativeness find a positive impact of cooperation on the innovation output (Branstetter and Sakakibara 2002; Becker and Dietz 2004; Aschhoff and Schmidt 2008; Faria et al. 2010; Schwartz et al. 2012). Discussing the effects of cooperation on subsidized innovative activity, Czarnitzki et al. (2007) assume that the innovative output of collaborating by non-subsidized firms would increase when participating in grant-in-aid programs. Nishimura and Okamuro (2011) show positive effects of subsidies on joint innovative activity after subsidy programs have ended, with their results indicating that indirect support programs have a strong impact on the innovative activity. For firms cooperating in research activities, Fornahl et al. (2011) show that state subsidies increase the innovative activity, as measured by patent applications. However, this finding does not hold for single firms. Falck et al. (2010) find positive effects on the innovative activity of firms that pursue a cluster-oriented policy, yet a decrease in private innovation expenditure. Furthermore, Sakakibara (2001) shows that subsidies have a slightly negative effect on cooperating firms’ investment in innovation.

From a methodological perspective, Blasio et al. (2014) and Cerulli (2010) provide an overview of the existing empirical methods to analyze the effects of subsidies on innovativeness and discuss the problems concerned with analyzing the data in this particular field. They state that the impact of innovation subsidies cannot be effectively separated from unrelated effects and they declare that counterfactual evidence is required for more definite empirical evidence. Therefore, Sørensen et al. (2010) suggest that experimental methods should be introduced to innovation research. To date, a small number of experimental studies have dealt with topics of innovation and analyzing different innovation policy instruments. Eckartz et al. (2012) test the effects of different incentive schemes and find no substantial differences between payment schemes. Cantner et al. (2009) simulate a patent race by means of a multidimensional search task with uncertainty, finding that the difference in the subjects' 
earnings has a positive impact on their investment in the next periods. Ederer and Manso (2013) analyze different payment schemes for innovators by implementing a search task and observe that the possibility of early failure and rewarding long-term success motivates innovators more than pay-for-performance or a fixed wage. Focusing on the policy instrument of intellectual property rights, Buchanan and Wilson (2014) also conduct a search task to simulate innovative activity, providing evidence that innovative activity is fostered by intellectual property rights yet simultaneously induces higher prices for innovations. Meloso et al. (2009) use the knapsack problem as a search task, in which participants have to combine items of a specific value and weight in the optimal combination to simulate the innovation process. They show that innovativeness is higher in a free market-based system compared with a patent-based system.

Extending these studies to more accurately simulate the crucial features of innovation processes in the laboratory, recent experiments have introduced elements of investment, ownership and creativity in their tasks. Crosetto (2010) first implemented a real effort word creation task to test for innovation behavior, providing subjects the possibility to choose the preferred regulatory incentive scheme, namely open source or fixed license fees. Based upon the board game Scrabble, the innovation process is simulated by having subjects create and extend words. Following this approach, Brüggemann et al. (2015) extend the design by implementing endogenous license fees and thus showing an increase in welfare without intellectual property rights. Considering different institutional mechanisms for fostering innovation, Brüggemann and Meub (2015) use the same experimental approach, showing that innovation contests reduce the willingness to cooperate between innovators and do not lead to additional gains in innovative activity and welfare. Further building upon the experimental design introduced by Crosetto (2010), a real effort word creation task is implemented to test the effectiveness of subsidies as a policy instrument. Hence, two experiments are run to investigate the effect of two different forms innovation subsidies, namely providing resources exclusively determined for use in innovations and providing additional financial resources unrestricted to a specific application.

\subsection{Experimental Design}

\subsubsection{Design}

General properties of the game

To determine the effect of subsidies on the individual innovation behavior in a sequential setting, a real effort word creation task inspired by the board game Scrabble is implemented. 
During the experiment, subjects have to act both strategically and creatively, facing the investment decision of buying letters and acting creatively by building words, thus generating their payoff. Additionally, subjects are able to set a license fee for their newly-created words, which can be extended by other players in the course of the game. The experiment closely builds upon the experimental design introduced by Crosetto (2010) and has been modified by Brüggemann et al. (2015) and Brüggemann and Meub (2015).

This basic setting is extended using a within-subject design, whereby each subject plays 12 periods of the real effort word creation task twice, once in the control group and once in the treatment group. The order of control and treatment groups is reversed for half of the subjects to control for distortions due to the sequence of treatments. The game is played in groups of four players, who are randomly matched for the first part over 12 periods. Once all subjects have finished the first part, subjects are again randomly matched for the second part of the game, similarly comprising 12 periods. In both parts of the game, each subject is endowed with 50 tokens and four randomly pre-selected letters. ${ }^{36}$

\section{Course of a turn}

In each period and treatment, subjects run through five phases, for which figure 4.1 provides an overview.

Figure 4.1. Overview of a subject's turn

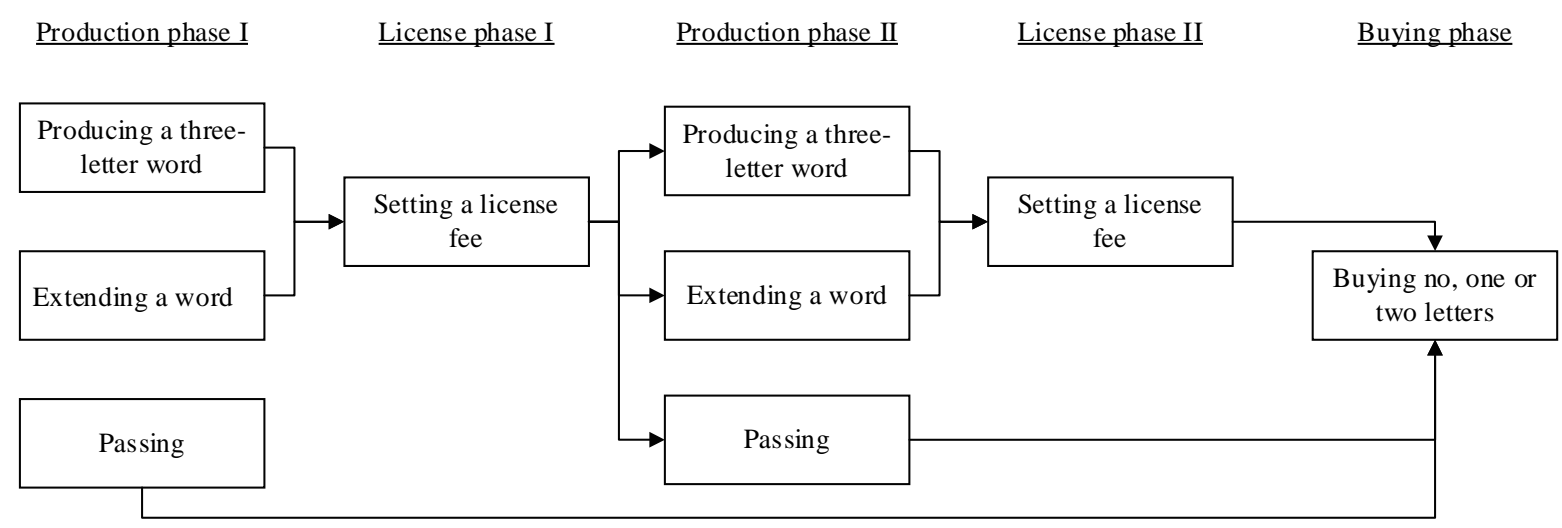

In the production phase, subjects are asked to choose between producing a three-letter word (root), extending an already existing word (extension) or passing the turn. If subjects create or extend a word, they are asked whether or not they wish to set a license fee in the

\footnotetext{
${ }^{36}$ Before the main task starts, subjects had to complete a short control task, in which their word-finding skills were tested. The instructions for the control task can be found in appendix B, the results in appendix C.
} 
ensuing license phase. The production and license phases are played twice in each turn. In the last phase of each turn - the investment phase - subjects can buy up to two new letters.

\section{Creating a word}

A root must comprise exactly three letters and it yields a payoff equal to the sum of the values of the letters used. Each word can be extended several times with exactly one letter in each production phase at every position of the original word, although every word can only be produced once in the game. A newly-created or extended word is only accepted if it exists in the standard MS Windows dictionary for German. A letter has the same value as in the German version of the board game Scrabble, which is determined inversely proportional to its frequency in the German language; for example, the letter $e$ has the value 1 and the letter $x$ the value 8. The payoff for each word is calculated by the sum of all letters of the word. This also applies if a player adds a letter without having produced the original word. Thus, adding a letter to an existing word generally yields a higher payoff than producing a root. Consider for example $^{37}$ : given the letters $a, e, r$ and $t$, a subject can create the roots art, ear or rat. If the respective letters are available, art can be extended into arts and dart or part - and part again into apart or party. The root art has a value of $1+1+1=3$ tokens, whereas the extension apart has a value of $1+3+1+1+1=7$ tokens.

\section{Setting license fees and buying letters}

Subjects are required to choose whether they wish to set a license fee or not. If subjects decide to set a license fee for their root, they are required to choose values between $10 \%$ and $100 \%$ of the word value in $10 \%$ steps. The license fee subsequently remains fixed up to the end of the 12 periods. After extending a word, subjects only set the license fee for the newly-added letter, as the license fee for the other letters is already defined by the previous producers. The new word - along with its license fee, the value and the producer - is displayed in the public word list on the game's main screen. By setting license fees, subjects receive additional income whenever another person extends a word with a license fee. However, license fees cannot be used as a mechanism to exclude other subjects from using a word altogether; rather, higher license fees merely make it less profitable for other players to use the word for an extension. Thus, license fees can be interpreted as a measure for cooperative behavior, whereby higher license fees indicate a low willingness to cooperate, i.e. making the access to one's words expensive. Lower fees show a higher willingness to cooperate by making extensions more profitable for other players. Furthermore, there are no transaction costs for

\footnotetext{
37 The game was run in German. However, word examples and instructions are provided in an English translation in appendix A and B.
} 
the license fees, meaning that they can be interpreted as an instrument of redistribution within groups.

To illustrate this mechanism, consider again the example given above: the root art is worth 3 tokens and subject A sets a license fee of $60 \%$. Subsequently, every subject who extends art automatically pays 1.8 tokens to subject A. Afterwards, subject B adds the letter $p-$ worth 3 tokens - and extends art into part. Due to this action, 1.8 tokens are transferred to subject A and subject B earns 1.2 tokens for art plus 3 tokens for the letter $p$, which yields 4.2 tokens for subject B. Furthermore, subject B also has to set a license fee for the $p$ in the word part, e.g. 50\%. Subsequently, subject C creates the word apart and pays 1.8 tokens to subject A, 1.5 tokens to subject B and earns 3.7 tokens.

At the end of each turn, in the investment phase, subjects are asked to buy no, one or two letters for a price of 4 tokens each.

\section{Being not at turn}

Subjects can monitor the main board of the game when it is not their turn. Accordingly, they can see their letters, current earnings, follow the actions of the other subjects and see the list of all words produced. Furthermore, they can prepare their next turn by checking words and extensions with a free interactive spellchecker. This is necessary as new words are only accepted if they are implemented in the MS Windows dictionary.

\section{Welfare considerations}

Altogether, the welfare created in the game depends on the relative number of extensions, given that the expected value of a letter is negative: buying a letter costs 4 tokens, yet the average value of a letter is 1.87 . Therefore, buying a letter is a risky investment for a potential innovator, as it might lead to negative returns. Consequently, if a group only produced roots, it would experience a decline in welfare as their initial endowment would continually decrease during the game. Only by creating extensions can letters be utilized several times and thus increase overall welfare.

\subsubsection{Treatment conditions and experimental procedure}

Two experiments were implemented to test for two potential designs of subsidies. They only differ compared with the control treatment in terms of the allocation of resources, as shown in table 4.1. In a within-subject design, both treatments are tested against control, where subjects do not receive a subsidy and are allowed to buy up to two letters at the end of their respective turn. In the first experiment (ExLetter) in subsidy, subjects receive an additional letter for free 
at the end of their respective turn and are allowed to buy one more letter. In the second experiment (ExMoney), in subsidy, subjects receive four additional tokens at the end of their turns, which is equivalent to the cost of one letter. As in control, they are allowed to buy up to two more letters at the end of their respective turn. In both ExLetter and ExMoney, subjects are informed in each turn that they receive the additional resource or the additional money, respectively. The order of the treatments is reversed in half of the sessions to compensate for learning and other effects related to the order of treatments.

Table 4.1. Overview of the treatment conditions

\begin{tabular}{lcccc}
\hline & \multicolumn{2}{c}{ ExLetter } & \multicolumn{2}{c}{ ExMoney } \\
\hline first part & control & subsidy & control & subsidy \\
second part & subsidy & control & subsidy & control \\
no. of participants & 36 & 36 & 40 & 36 \\
\hline
\end{tabular}

The 191 letters used in the game were distributed in a fixed yet random order to make the actions of the groups better comparable. Therefore, the order in which the letters were allocated to the subjects was randomly predetermined for each game before the experiment. Half of the subjects in each experiment first received the letterset from Brüggemann et al. (2015) in the first part of the game and a newly-created letterset in the second part, which was similarly randomly predetermined. For the other half of the subjects, the order in which the lettersets were used was reversed. This reversal of lettersets was again used to compensate for effects connected to the order of the letters.

The experiments were conducted in the Laboratory for Behavioral Economics at the University of Göttingen with a sample of 148 subjects from different academic disciplines. Participants were recruited using ORSEE (Greiner 2004), whereby each subject was allowed to participate in one session only and none had previously participated in a similar experiment. The experiments took place in April 2014 and each session lasted around 90 minutes. On average, participants were 24.9 years old, $48.0 \%$ were female and $39.2 \%$ were students of economics. Each participant earned $€ 16.99$ on average, with a minimum payoff of $€ 8.3$ and a maximum of $€ 30.2$.

\subsection{Hypotheses}

With this experimental design, novel insight is provided for the counterfactual question concerning what effects result with and without subsidies ceteris paribus. The design provides 
insights concerning how subsidies influence the individual behavior of innovators and thus it complements discussions on innovation subsidies (Zúñiga-Vicente et al. 2014).

First, the potential effects of subsidies on the cooperative behavior of subjects can be addressed. Nishimura and Okamuro (2011) find a positive impact of subsidies on innovative activities pursued in inter-firm cooperations, thus increasing the innovative output of participating firms. Consequently, the output of firms working in innovation networks is often higher compared to that of firms innovating independently (Falck et al. 2010; Fornahl et al. 2011; Nishimura and Okamuro 2011). To further investigate the effect of subsidies on cooperative behavior and the individual innovative activity, the individual choices of license fees can be used in our setting. Based upon the previous studies suggesting a positive effect of subsidies on cooperative behavior in innovative activities, hypothesis 1 is formulated:

\section{Hypothesis 1 (“Cooperation behavior”)}

Cooperative behavior increases in subsidy in both experiments when compared to control.

Second, the investment behavior can be investigated when analyzing the letters acquired and the individual revenue for the innovators. The majority of empirical studies argue that public support does not lead to a crowding-out of private investment in most cases (David et al. 2000). However, some more recent studies question this assumption (Blasio et al. 2014; Zúñiga-Vicente et al. 2014). This open question can be addressed as the individual investment situation has been implemented accordingly. Recall that a letter in this setting costs 4 tokens, while the average return of a letter is 1.87 , which makes buying an additional letter a risky investment. Hence, subjects rationally restrain their investments and refrain from buying as many resources as possible. In this situation, additional resources lead to either increased innovativeness - as intended by regulators - or a crowding-out of private investments and an unchanged number of innovations. Again, following the majority of previous empirical studies, it is hypothesized that subjects will add the subsidies to their private investment; thus, there should be no crowding-out of private investment and individual revenues should increase. Therefore, hypothesis two is formulated as follows:

\section{Hypothesis 2 (“Investment \& revenue”)}

a) There is an increase of private investment in subsidy in both experiments when compared to control. 
b) Crowding-out of private investment does not occur in subsidy when compared to control.

c) The individual revenue is higher in subsidy in both experiments when compared to control.

Third, despite increasing recent doubts regarding the positive effects of subsidizing private innovative activities (Zúñiga-Vicente et al. 2014), a substantial number of studies emphasize that innovation subsidies have positive effects on a country's overall innovative capacities and thus economic welfare (Czarnitzki and Hussinger 2004; David et al. 2000; Czarnitzki and Lopes Bento 2014). To contribute to the ongoing discussion, the overall welfare effects of innovation subsidies are tested in this setting. Following the studies showing positive innovative effects and the previous behavioral hypotheses, the basic expectation is that subsidies will induce additional innovations and thus increase the overall welfare generated, as measured by the aggregated value of all words. Therefore, the following hypothesis is derived:

\section{Hypothesis 3 ("Welfare”)}

a) The aggregated innovative activity is higher in subsidy in both experiments when compared to control.

b) The welfare is higher in subsidy in both experiments when compared to control.

\subsection{Results}

To answer the research questions as formulated in the hypotheses presented above, the results are structured as follows. First, the cooperation behavior is investigated, before the results on the individual level of the game are described, namely subjects' investment and revenue. Subsequently, the innovative activity is analyzed before the welfare perspective is taken into account and different measures of welfare are discussed.

\subsubsection{Cooperation behavior}

After having created a word, subjects were asked whether they would like to choose a license fee or not. If subjects wanted to set a license fee, they could chose between 10 and $100 \%$. As discussed above, the license fees chosen can be interpreted as a measure for cooperative behavior (H1), whereby the higher the license fees, the less subjects are willing to let other subjects benefit from extending their produced words. 
To analyze cooperative behavior, the number of words without license fees can be considered as an initial measure. In ExLetter, in control, 3.31\% of all words did not have a license fee; in subsidy 2.10\%; in ExMoney subjects did not select to set a license fee in control for $3.29 \%$ and in subsidy for $2.92 \%$ of all produced words. This low measures show a strong demand for being rewarded for the created innovations. The major factor is the average license fees over periods for each experiment, as presented in figure 4.2.

Figure 4.2. Average license fees over periods by treatment and experiment

a) ExLetter

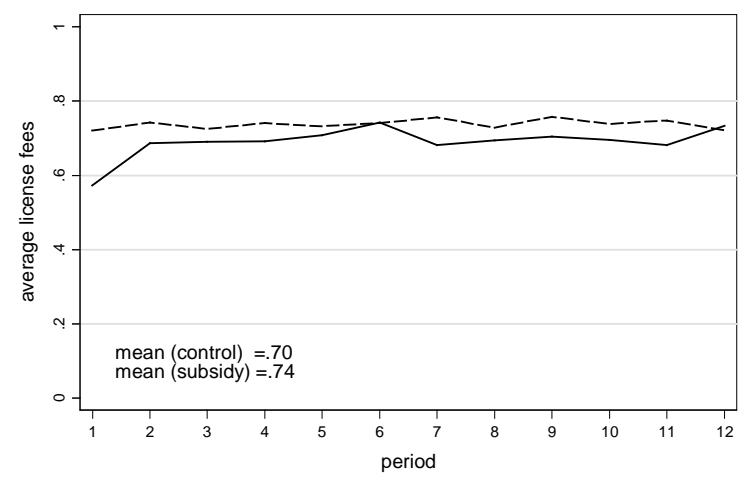

- control ----- subsidy b) ExMoney

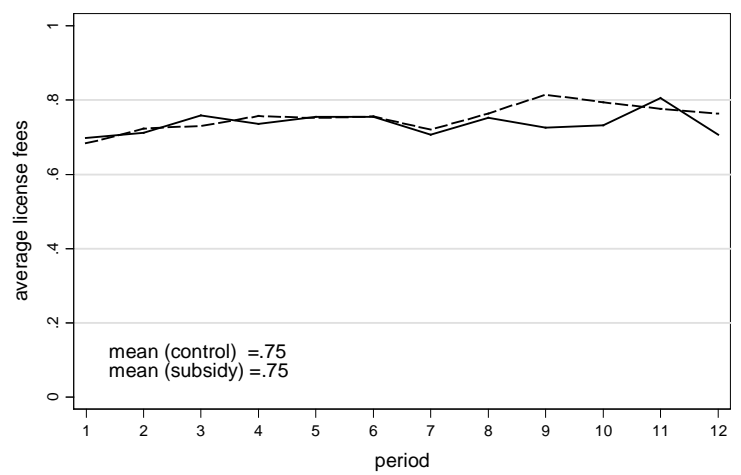

- control ----- subsidy

The level of license fees and thus the cooperative behavior remains fairly constant over time, given that there are no differences across treatments (Wilcoxon signed-rank (WSR) test for ExLetter $\mathrm{z}=-0.631, \mathrm{p}=.5277$; for ExMoney $\mathrm{z}=0.161, \mathrm{p}=.8721$ ). There are no learning or last-round effects that occur due to the within-subject design, as assessed by testing whether there are differences due to the order of treatments. The difference in the level of license fees is calculated between the order (1) control and subsidy and the alternative treatment order (2) subsidy and control. There are no significant differences when comparing the differences with respect to the order for the level of license fees (Mann-Whitney-U (MWU) test for ExLetter $\mathrm{z}=-1.634, \mathrm{p}=.1023$, for ExMoney $\mathrm{z}=-1.470, \mathrm{p}=.1416)$.

Overall, subsidies do not have a detrimental influence on the cooperation behavior in our setting. Accordingly, it could be argued that the findings by Nishimura and Okamuro (2011) who showed positive effects of subsidies on cooperative innovative activities - might not hold at the individual level.

RESULT 1: There is no evidence in favor of H1 as cooperative behavior remains stable over time and across treatments. 


\subsubsection{Investment and individual revenue}

To gain an overview of individual behavior in the experiments, the revenue and the investment behavior are discussed, whereby revenue is represented by the cumulative income with and without the subsidy and investment by the letters acquired during the game. Recall that in control and subsidy of ExMoney, a group as a whole can buy up to 88 letters, while in ExLetter in subsidy, 44 letters are received for free and 44 letters can be bought by the subjects. The letters stock denotes a subject's average number of unused letters over the course of each treatment. The subsidy is interpreted as the resources transferred to each subject by the state. In ExLetter, the subsidy amounts to the value of four tokens for each letter received for free. In ExMoney, the subsidy equals the amount of the four free tokens, which add up to 44 additional tokens over 11 periods (excluding the final period, where no subsidy is provided). All these main indicators are reported in table 4.2.

Table 4.2. Overview of investment and revenue by treatment and player

\begin{tabular}{|c|c|c|c|c|c|}
\hline & & \multicolumn{2}{|c|}{ ExLetter } & \multicolumn{2}{|c|}{ ExMoney } \\
\hline & & control & subsidy & control & subsidy \\
\hline letters acquired & mean (sd) & $\begin{array}{c}60.78 \\
(10.13)\end{array}$ & $\begin{array}{l}70.83 \\
(7.69)\end{array}$ & $\begin{array}{l}59.79 \\
(8.49)\end{array}$ & $\begin{array}{c}66.74 \\
(11.15)\end{array}$ \\
\hline letters stock & mean (sd) & $\begin{array}{c}3.89 \\
(0.75)\end{array}$ & $\begin{array}{c}4.02 \\
(0.99)\end{array}$ & $\begin{array}{c}3.84 \\
(0.71)\end{array}$ & $\begin{array}{c}4.21 \\
(1.01)\end{array}$ \\
\hline income [tokens] & mean (sd) & $\begin{array}{c}66.47 \\
(15.17)\end{array}$ & $\begin{array}{c}101.96 \\
(19.55)\end{array}$ & $\begin{array}{c}64.03 \\
(13.27)\end{array}$ & $\begin{array}{r}100.28 \\
(13.00)\end{array}$ \\
\hline $\begin{array}{l}\text { income excluding } \\
\text { subsidy [tokens] }\end{array}$ & mean (sd) & $\begin{array}{c}66.47 \\
(15.17)\end{array}$ & $\begin{array}{c}57.96 \\
(19.55)\end{array}$ & $\begin{array}{c}64.03 \\
(13.27)\end{array}$ & $\begin{array}{c}56.28 \\
(13.00)\end{array}$ \\
\hline
\end{tabular}

Note: For letters acquired in ExLetter in subsidy the amount of 44 tokens for letters received for free is added.

The table shows that introducing a subsidy increases the number of letters acquired in both experiments. ${ }^{38}$ However, not the entire amount provided is invested in additional letters. Subjects buy more letters in subsidy in ExLetter (WSR-test z=-3.006, p=.0026), albeit only when including the 44 letters received for free in subsidy. In ExMoney, there are no significant differences in the investment behavior between treatments (WSR-test $\mathrm{z}=-1.269, \mathrm{p}=.2043$ ),

\footnotetext{
${ }^{38}$ Following the procedure outlined in chapter 5.1, the different orders of the treatments do not influence the number of letters acquired: MWU-test for ExLetter $\mathrm{z}=0.972, \mathrm{p}=.3309$, for ExMoney $\mathrm{z}=1.436, \mathrm{p}=.1509$; further, they do not influence income and income excluding subsidy: MWU-test for ExLetter $\mathrm{z}=-1.192, \mathrm{p}=.2332$, for ExMoney $\mathrm{z}=-0.735, \mathrm{p}=.4624$. The sequence order only makes a difference for letters stock: MWU-test for ExLetter $\mathrm{z}=2.075, \mathrm{p}=.0380$ and for ExMoney $\mathrm{z}=2.613, \mathrm{p}=.0090$. Subjects have more letters in stock in the treatment they played first, regardless of the treatment. Consequently, since aggregated values are analyzed, the further analysis is not affected.
} 
thus yielding the interpretation that a substantial crowding-out of private investment occurs. In ExMoney, this is obvious as there are no differences in the investment behavior by introducing a subsidy. For ExLetter, consider that each subject receives letters worth 44 tokens but only invests 70.83 tokens. Compared to the 60.78 tokens in control, less than a quarter of the subsidy is reinvested in additional letters. Respectively, the value of unused resources - i.e. the letters stock - increases, albeit insignificantly in subsidy in both experiments (WSR-test for ExLetter $\mathrm{z}=-0.109, \mathrm{p}=.9133$; for ExMoney $\mathrm{z}=-0.885, \mathrm{p}=.3760$ ), meaning that only slightly more resources are left unused in subsidy in both experiments.

Unsurprisingly, subjects overall generate more income in subsidy in both experiments (WSR-test for ExLetter $\mathrm{z}=-3.593, \mathrm{p}=.0003$; for ExMoney $\mathrm{z}=-3.823, \mathrm{p}=.0001$ ). However, considering the subsidy of 44 tokens - which almost doubles the starting endowment of 50 tokens - and subtracting the subsidy from the revenues, subjects earn less in subsidy in ExMoney (WSR-test $\mathrm{z}=1.912, \mathrm{p}=.0559$ ), while the difference marginally fails to be significant in ExLetter (WSR-test $\mathrm{z}=1.350, \mathrm{p}=.1769$ ).

This result shows that the effectiveness of subsidies in this sequential innovation setting is limited. The tendency to invest increases in ExLetter once a subsidy is provided, although the additional investments do not account for the full amount of the subsidy. For ExMoney, there is no difference in the investment behavior. Thus, subsidies do not add proportionally to the investments but rather lead to a crowding-out of private investment. Therefore, at an aggregate level, the overall revenue is higher when no subsidy is provided, although earnings increase at an individual level. This raises the question of whether the additional resources spent by the state through the subsidies are used in an effective way to incentivize individuals conducting more valuable innovations. Accordingly, this question will be investigated in the next section by analyzing the aggregate welfare created through innovations.

RESULT 2: H2a can partly be rejected as private investment does not increase in ExMoney. Furthermore, introducing a subsidy leads to a crowding-out of private investment, meaning that $\mathrm{H} 2 \mathrm{~b}$ can be rejected. $\mathrm{H} 2 \mathrm{c}$ can only partly be rejected since introducing a subsidy increases the revenue at an individual level yet reduces the revenue at the aggregate level.

\subsubsection{Welfare and innovation}

\subsubsection{Innovative activity}

In this section, the innovative activity is examined and different measures are developed to analyze the welfare effects (H3). Recall that as letters have to be bought at the price of 4 
letters with an average letter value of 1.87 , only the repeated use of letters generates welfare. Therefore, the ratio of extensions to roots is an important indicator for the innovative activity of groups. This ratio is shown in table 4.3, which also displays the average word length and the average word value.

Table 4.3. Overview of words created by treatment

\begin{tabular}{|c|c|c|c|c|c|}
\hline & & \multicolumn{2}{|c|}{ ExLetter } & \multicolumn{2}{|c|}{ ExMoney } \\
\hline & & control & subsidy & control & subsidy \\
\hline word length & mean (sd) & $\begin{array}{c}4.68 \\
(0.42)\end{array}$ & $\begin{array}{c}4.43 \\
(0.46)\end{array}$ & $\begin{array}{c}4.49 \\
(0.30)\end{array}$ & $\begin{array}{c}4.42 \\
(0.28)\end{array}$ \\
\hline word value & mean (sd) & $\begin{array}{c}6.78 \\
(0.95)\end{array}$ & $\begin{array}{c}6.54 \\
(0.92)\end{array}$ & $\begin{array}{c}6.57 \\
(0.66)\end{array}$ & $\begin{array}{c}6.54 \\
(0.50)\end{array}$ \\
\hline no. of extensions & mean (sd) & $\begin{array}{l}35.89 \\
(7.01)\end{array}$ & $\begin{array}{l}35.33 \\
(8.67)\end{array}$ & $\begin{array}{l}35.16 \\
(7.46)\end{array}$ & $\begin{array}{l}33.26 \\
(6.66)\end{array}$ \\
\hline no. of roots & mean (sd) & $\begin{array}{c}9.44 \\
(2.59)\end{array}$ & $\begin{array}{c}12.5 \\
(2.87)\end{array}$ & $\begin{array}{c}9.68 \\
(2.72)\end{array}$ & $\begin{array}{l}11.84 \\
(2.544)\end{array}$ \\
\hline $\begin{array}{l}\text { extensions per } \\
\text { root }\end{array}$ & mean (sd) & $\begin{array}{c}4.17 \\
(1.82)\end{array}$ & $\begin{array}{c}3.05 \\
(1.22)\end{array}$ & $\begin{array}{c}4.03 \\
(1.69)\end{array}$ & $\begin{array}{c}2.96 \\
(1.03)\end{array}$ \\
\hline
\end{tabular}

In general, the sum of the number of roots and extensions can be interpreted as a measure for the innovative activity, as they show how many innovations have been created overall. The table shows that the number of roots is higher in subsidy in both experiments (WSR-test for ExLetter $\mathrm{z}=-2.665, \mathrm{p}=.0077$; for ExMoney $\mathrm{z}=-2.110, \mathrm{p}=.0349$ ), i.e. the tendency to create basic innovations is higher when a subsidy is provided. Since extensions are more sophisticated innovations than roots, they are more desirable from a welfare perspective. Comparing the number of extensions, there are no differences between control and subsidy in ExLetter (WSR-test z=0.240, p=.8103) and only weak differences in ExMoney (WSR-test $\mathrm{z}=1.735, \mathrm{p}=.0827$ ). However, the number of extensions per root is higher in control (WSRtest for ExLetter $\mathrm{z}=1.938, \mathrm{p}=.0526$; for ExMoney $\mathrm{z}=2.093, \mathrm{p}=.0364$ ) in both experiments, which results from the higher total number of roots created in subsidy in both experiments. All other indicators show no differences between treatments and experiments. ${ }^{39}$

This yields the interpretation that although subjects have a higher endowment in subsidy, the innovative activity does not increase. By contrast, as subjects tend to create more roots in

\footnotetext{
${ }^{39}$ Again, the results are not influenced by the sequence in which the treatments were conducted. This is tested using the procedure described in chapter 5.1: MWU-test for word length in ExLetter $\mathrm{z}=-0.751, \mathrm{p}=.4529$, in ExMoney $\mathrm{z}=-0.245, \mathrm{p}=.8065$; MWU-test for word value in ExLetter $\mathrm{z}=-1.457, \mathrm{p}=.1451$, in ExMoney $\mathrm{z}=1.225$, $\mathrm{p}=.2207$; MWU-test for number of roots in ExLetter $\mathrm{z}=0.310, \mathrm{p}=.7563$, in ExMoney $\mathrm{z}=0.659$, p=.5101; MWUtest for number of extensions in ExLetter $\mathrm{z}=0.177, \mathrm{p}=.8595$, in ExMoney $\mathrm{z}=0.983, \mathrm{p}=.3257$; MWU-test for extensions per root in ExLetter $\mathrm{z}=-0.309, \mathrm{p}=.7573$, in ExMoney $\mathrm{z}=0.572$, $\mathrm{p}=.5676$.
} 
subsidy, they seem to use the additional resources for additional basic innovations rather than more sophisticated sequential innovations. This shift towards more basic innovations is not desirable from a welfare perspective.

RESULT 3: There are no differences in the innovative activity between treatments, meaning that HЗa can be rejected. Introducing a subsidy leads to a shift from more sophisticated to basic innovations.

\subsubsection{Measures of welfare}

In order to test for differences in welfare (H3b), three measures can be derived to gain a better understanding of the welfare within groups: first, the total gross value can be estimated, which comprises the value of all created innovations, i.e. the sum of all word values; second, the total net value additionally considers the investment, which includes the costs for the letters received for free (44 letters costing 4 tokens each) in ExLetter; and third, the relative net value (RNV) is used, as in Brüggemann et al. (2015). It includes the path dependency of the game from a myopic perspective, whereby creating a new word opens and closes different future innovation paths during the game. The RNV captures this dynamic element by giving a relative measure between the most and the less valuable innovation decision that each subject could have made in each specific situation of the game. Therefore, $C_{i t}$ is defined as the actual choice set for each subject $i$ in period $t$ defined by the letters owned by player $i$ and the roots and extensions produced by all players at time $t$. The net payoff in each period $\pi\left(c_{i t}\right)$ is subsequently calculated for each choice $c_{i t} \epsilon C_{i t}$ by deducting the investment in letters used and the license fees from the value of the new root or extension. The actual payoff $\pi_{i t}$ is then computed by using the maximum $M_{i t}=\max \left\{\pi\left(c_{i t}\right), c_{i t} \epsilon C_{i t}\right\}$ and minimum $m_{i t}=\left\{\pi\left(c_{i t}\right), c_{i t} \epsilon C_{i t}\right\}$ payoffs achievable from $C_{i t}$. Hence, the relative net value $R N V_{i t}$ is computed as:

$$
R N V_{i t}=\left(\pi_{i t}-m_{i t}\right) /\left(M_{i t}-m_{i t}\right)
$$

Note that $R N V_{i t} \epsilon[0,1], M \geq 0$ and $m \leq c \leq M$. Subjects should aim to maximize the RNV as it increases their payoffs. It is also a measure for subjects' performance conditional upon the opportunities that they have based upon the words already created in the game and the letters owned by each subject in any given situation. ${ }^{40}$ The findings for the three measures are summarized in table 4.4.

\footnotetext{
${ }^{40}$ Note that the RNV is a measure for optimality from a myopic perspective and that the decision might not be optimal for the whole group. To measure the optimum for the whole group, all possible future innovation paths would have to be calculated for each word. This is obviously unrealistic for subjects given their cognitive abilities and thus it is not considered as a measure for the optimal choice. For an elaboration of this issue, see also Brüggemann et al. (2015).
} 
Table 4.4. Different welfare measures by treatment and group

\begin{tabular}{|c|c|c|c|c|c|}
\hline & & \multicolumn{2}{|c|}{ ExLetter } & \multicolumn{2}{|c|}{ ExMoney } \\
\hline & & control & subsidy & control & subsidy \\
\hline \multirow[t]{4}{*}{ total gross value } & mean (sd) & $\begin{array}{l}311.11 \\
(82.59)\end{array}$ & $\begin{array}{c}317 \\
(89.73)\end{array}$ & $\begin{array}{l}297.16 \\
(67.11)\end{array}$ & $\begin{array}{l}295.95 \\
(55.91)\end{array}$ \\
\hline & median & 297.5 & 297 & 302 & 282 \\
\hline & $\min$ & 197 & 200 & 186 & 192 \\
\hline & $\max$ & 487 & 568 & 408 & 410 \\
\hline \multirow[t]{4}{*}{ total net value } & mean (sd) & $\begin{array}{c}68 \\
(62.37)\end{array}$ & $\begin{array}{c}33.67 \\
(80.20)\end{array}$ & $\begin{array}{c}58 \\
(53.93)\end{array}$ & $\begin{array}{c}29 \\
(49.51)\end{array}$ \\
\hline & median & 44.5 & 26.5 & 65 & 32 \\
\hline & $\min$ & 1 & -78 & -54 & -53 \\
\hline & $\max$ & 195 & 280 & 127 & 124 \\
\hline \multirow[t]{4}{*}{$\begin{array}{l}\text { relative net value } \\
\text { (RNV) }\end{array}$} & mean (sd) & $\begin{array}{c}0.475 \\
(0.084)\end{array}$ & $\begin{array}{c}0.460 \\
(0.070)\end{array}$ & $\begin{array}{c}0.464 \\
(0.064)\end{array}$ & $\begin{array}{c}0.425 \\
(0.057)\end{array}$ \\
\hline & median & 0.470 & 0.489 & 0.473 & 0.417 \\
\hline & $\min$ & 0.316 & 0.338 & 0.338 & 0.327 \\
\hline & $\max$ & 0.589 & 0.566 & 0.566 & 0.569 \\
\hline
\end{tabular}

Regarding the total gross value, there are no differences across treatments (WSR-test for ExLetter $\mathrm{z}=-0.283, \mathrm{p}=.7771$; for ExMoney $\mathrm{z}=0.543, \mathrm{p}=.5869) .{ }^{41}$ Figure 4.3 shows the total net value in detail, which corrects for the costs of the letters, including both the individuallybought letters and those received for free.

\footnotetext{
${ }^{41}$ There are no differences due to the sequence order of the treatments, which is tested following the same procedure as described in chapter 5.1: MWU-test for the total gross value in ExLetter $\mathrm{z}=0.000, \mathrm{p}=1.000$, in ExMoney $\mathrm{z}=1.266, \mathrm{p}=.2055$; MWU-test for the total net value in ExLetter $\mathrm{z}=-1.060, \mathrm{p}=.2891$, in ExMoney $\mathrm{z}=-0.653, \mathrm{p}=.5136$; MWU-test for the RNV in ExLetter $\mathrm{z}=1.192$, p=.2332, in ExMoney $\mathrm{z}=0.898, \mathrm{p}=.3691$.
} 
Figure 4.3. Total net value ordered by within-group difference for each treatment and experiment

a) ExLetter

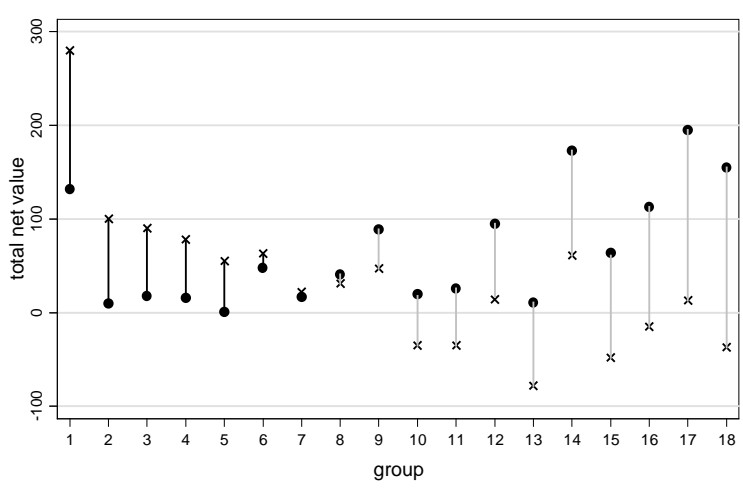

- control $\times$ subsidy b) ExMoney

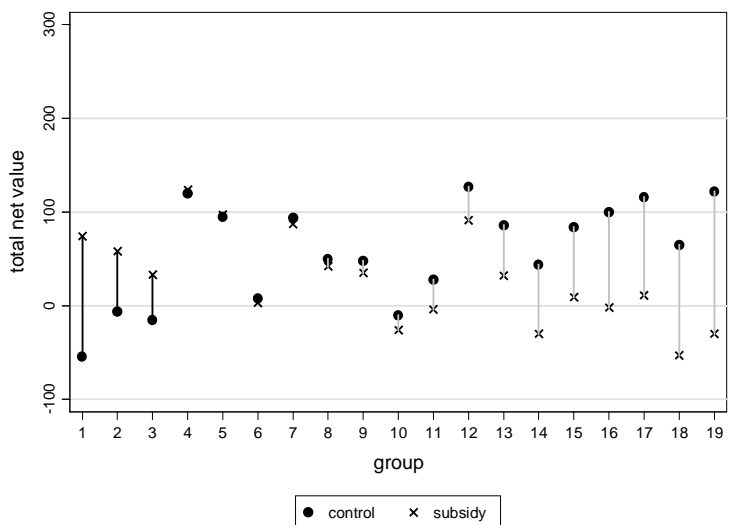

Note: The total net value is ordered by the differences of the groups between control and subsidy within each treatment and experiment. The distance between control and subsidy indicates the differences in performance within the same group in the two treatments. Black lines indicate that a group performed better in subsidy, while gray lines show that a group performed better in control.

In figure 4.3, it can be seen that groups react differently to the subsidy within each experiment: most groups (11 out of 18; 14 out of 19) perform better in control in both experiments (gray lines), in some groups the total net value does not differ and only few groups perform better in subsidy (7 out of 18; 5 out of 19). In sum, the total net value is significantly lower in subsidy in ExMoney (WSR-test z=2.093, p=.0364), while in ExLetter the difference fails to be significant (WSR-test $\mathrm{z}=1.372, \mathrm{p}=.1701$ ). Nevertheless, in ExLetter in subsidy around 33\% and in ExMoney around 28\% of the groups yield a negative total net value, which means that they were unable to create innovations amounting to the sum of their investments. This also occurs in around 22\% of the groups in control in ExMoney but in none of the groups in control in ExLetter.

These findings remain robust when path dependency is included by using the RNV, which integrates a myopic perspective. As a relative measure it can decrease during the game, in contrast to total gross value and the total net value. This might be true if subjects are unable to choose the best opportunity to innovate from the existing words and letters in the respective period. Figure 4.4 shows the development of the average RNV over periods for both experiments. 
Figure 4.4. Average RNV over periods by treatment

a) ExLetter

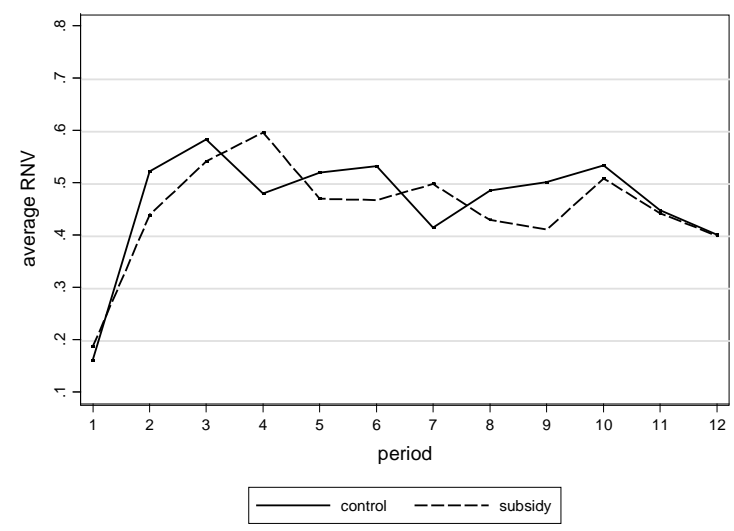

b) ExMoney

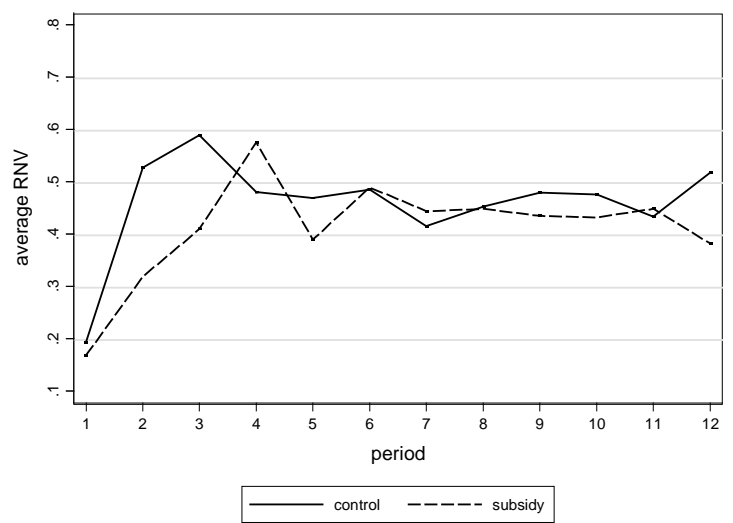

Regarding the RNV, there are no substantial differences across treatments during the course of the game in ExLetter (WSR-test z=0.544, p=.5862). In ExMoney, subjects perform better in control (WSR-test $\mathrm{z}=1.771, \mathrm{p}=.0766$ ). In all treatments, the RNV increases at the beginning of the game. Subsequently, due to the increasing number of potential extensions, subjects become less successful in choosing the most profitable options, which leads to a slight decrease in the average RNV.

In sum, subsidies do not have a positive effect when considering three welfare measures. In fact, in ExMoney, when considering the total net value and the RNV, subjects perform worse when introducing a subsidy. In ExLetter in subsidy, one-third of the groups fail to generate positive welfare gains altogether. These findings of the different welfare measures can be understood from an individual perspective, given that subjects might try to perform best regardless of external incentives or even - in case of pure monetary incentives - reduce their effort to innovate. However, from a welfare perspective, subsidies lead to higher costs, as shown by the lower total net value in subsidy and the lack of additional gains in innovativeness, as indicated by the RNV. Furthermore, the costs for the state through implementing subsidies are not captured with these measures, which might further diminish the welfare effects of allocating subsidies.

RESULT 4: H3b can be rejected as subsidies fail to increase both the individual innovativeness and the overall welfare. 


\subsection{Conclusion}

In this study, laboratory evidence is presented concerning the effects of subsidies in stimulating private innovative activity. An experimental approach introduced by Crosetto (2010) is used and modified, which implements the features of risky investment, creativity and ownership in a laboratory experiment that simulates a cumulative innovation process. Therefore, this experimental design allows adding counterfactual evidence to the existing literature on the effects of public subsidies (Zúñiga-Vicente et al. 2014). Two specific situations in the continuum from restrictive grant-in-aid to freely-usable monetary subsidies are applied, namely through additional material resources and a direct monetary subsidy.

The main findings of this study are that subsidies neither increase private innovative activities nor overall welfare. Furthermore, the investment behavior changes with a subsidy and a substantial crowding-out of private investment occurs. While subjects individually increase their incomes due to the higher endowments with subsidies, their innovation output remains unchanged in both experiments. Moreover, the kind of innovations produced changes due to the subsidy, whereby more basic innovations are created, which are less desirable from a welfare perspective than more sophisticated innovations. In turn, the cooperation behavior as measured by the level of license fees chosen - does not change due to subsidies.

When taking into account different welfare measures, none of them show a positive effect of subsidies on the overall welfare. Following the individual results, subjects' behavior is influenced by the kind of subsidy: when including the costs of a subsidy incurred by the state, the overall welfare decreases in the experiment with a direct monetary subsidy and remains stable in the experiment with additional material resources. Therefore, it can be concluded that subsidies distributed in the form of additional material resources fail to increase welfare, while direct monetary subsidies even have a negative impact. Overall, these results support previous studies arguing that subsidies have little or even negative effects on the innovative activity by failing to increase innovativeness or producing a crowding-out of private investment. Accordingly, due to the additional costs to the state and the doubtful benefits, public subsidies as a policy instrument to foster private innovation might need to be called into question.

While this study has been able to yield novel empirical evidence, it also has several limitations, which should be taken into account in future studies. For instance, only two particular kinds and amounts of subsidies are tested, whereby further studies might test different specifics of innovation subsidies in a laboratory environment. Moreover, the additional costs that the state would have to bear for implementing and distributing the 
subsidies cannot be considered in this setting; accordingly, further studies might include the approximate costs of introducing and distributing subsidies and thus provide an estimation concerning when the benefits of innovation subsidies exceed the costs incurred by the state. 


\section{Acknowledgments}

I am grateful to Till Proeger, Lukas Meub and Kilian Bizer for their very helpful comments on this work, as well as Sven Orzel for his assistance in programming and running the experiments. Financial support from the German Federal Ministry of Education and Research via the Hans-Böckler-Stiftung is gratefully acknowledged.

\section{References}

Aerts, Kris and Tobias Schmidt. 2008. "Two for the price of one? Additionality effects of R\&D subsidies. A comparison between Flanders and Germany.” Research Policy, 37(5): 806-22.

Almus, Matthias and Dirk Czarnitzki. 2003. "The effects of public R\&D subsidies on firms’ innovation activities.” Journal of Business \& Economic Statistics, 21(2): 226-36.

Aschhoff, Birgit. 2009. "The effect of subsidies on R\&D investment and success. Do subsidy history and size matter?” ZEW Discussion Paper 09-032.

Aschhoff, Birgit and Tobias Schmidt. 2008. "Empirical evidence on the success of R\&D cooperation. Happy together?” Review of Industrial Organization, 33(1): 41-62.

Aschhoff, Birgit and Wolfgang Sofka. 2009. "Innovation on demand. Can public procurement drive market success of innovations?” Research Policy, 38(8): 1235-47.

Becker, Lasse. 2015. "Effectiveness of public innovation support in Europe. Does public support foster turnover, employment and labour productivity?” cege Discussion Paper 236.

Becker, Wolfgang and Jürgen Dietz. 2004. "R\&D cooperation and innovation activities of firms. Evidence for the German manufacturing industry.” Research Policy, 33(2): 209-23.

Blasio, Guido de, Davide Fantino, and Guido Pellegrini. 2015. "Evaluating the impact of innovation incentives. Evidence from an unexpected shortage of funds." Industrial and Corporate Change, 24(6): 1285-1314.

Branstetter, Lee G. and Mariko Sakakibara. 2002. "When do research consortia work well and why? Evidence from Japanese panel data." The American Economic Review, 92(1): 143-59.

Bronzini, Raffaello and Eleonora Iachini. 2014. "Are incentives for R\&D effective? Evidence from a regression discontinuity approach.” American Economic Journal: Economic Policy, 6(4): 100-34.

Brüggemann, Julia, Paolo Crosetto, Lukas Meub, and Kilian Bizer. 2015. "Intellectual property rights hinder sequential innovation. Experimental evidence.” cege Discussion Paper 227.

Brüggemann, Julia and Lukas Meub. 2015. "Experimental evidence on the effects of innovation contests.” cege Discussion Paper 251.

Buchanan, Joy A. and Bart J. Wilson. 2014. “An experiment on protecting intellectual property.” Experimental Economics, 17(4): 691-716.

Busom, Isabel. 2000. “An empirical evaluation of the effects of R\&D subsidies.” Economics of Innovation and New Technology, 9(2): 111-48. 
Cantner, Uwe, Werner Güth, Andreas Nicklisch, and Torsten Weiland. 2009. "Competition in product design. An experiment exploring innovation behavior." Metroeconomica, 60(4): 724-52.

Cerulli, Giovanni. 2010. "Modelling and measuring the effect of public subsidies on business R\&D. A critical review of the econometric literature." The Economic Record, 86(274): 421-49.

Cerulli, Giovanni and Bianca Potì. 2008. "Evaluating the effect of public subsidies of firm R\&D activity. An application to Italy using the Community Innovation Survey." CerisCnr Working Paper 9/2008.

Clausen, Tommy H. 2009. "Do subsidies have positive impacts on R\&D and innovation activities at the firm level?” Structural Change and Economic Dynamics, 20(4): 239-53.

Crosetto, Paolo. 2010. “To patent or not to patent. A pilot experiment on incentives to copyright in a sequential innovation setting." In IFIP advances in information and communication technology, Open source software. New horizons. $6^{\text {th }}$ International IFIP WG 2.13 Conference on Open Source Systems, ed. Pär J. Ågerfalk, Cornelia Boldyreff, Jesús M. González-Barahona, Gregory R. Madey, and John Noll. Berlin, New York: Springer, 53-72.

Czarnitzki, Dirk, Bernd Ebersberger, and Andreas Fier. 2007. “The relationship between R\&D collaboration, subsidies and R\&D performance. Empirical evidence from Finland and Germany.” Journal of Applied Econometrics, 22(7): 1347-66.

Czarnitzki, Dirk and Katrin Hussinger. 2004. "The link between R\&D subsidies, R\&D spending and technological performance.” ZEW Discussion Paper 04-56.

Czarnitzki, Dirk and Cindy Lopes Bento. 2012. "Evaluation of public R\&D policies. A cross-country comparison." World Review of Science, Technology and Sustainable Development, 9(2-4): 254-82.

Czarnitzki, Dirk and Cindy Lopes Bento. 2014. "Innovation subsidies: Does the funding source matter for innovation intensity and performance? Empirical evidence from Germany.” Industry and Innovation, 21(5): 380-409.

David, Paul A., Bronwyn H. Hall, and Andrew A. Toole. 2000. "Is public R\&D a complement or substitute for private R\&D? A review of the econometric evidence." Research Policy, 29(4-5): 497-529.

Duch, Néstor, Daniel Montolio, and Mauro Mediavilla. 2009. "Evaluating the impact of public subsidies on a firm's performance. A two-stage quasi-experimental approach." Investigaciones regionales, 16: 143-65.

Eckartz, Katharina, Oliver Kirchkamp, and Daniel Schunk. 2012. "How do incentives affect creativity?” CESifo Working Paper 4049.

Ederer, Florian and Gustavo Manso. 2013. "Is pay-for-performance detrimental to innovation?” Management Science, 59(7): 1496-513.

Falck, Oliver, Stephan Heblich, and Stefan Kipar. 2010. "Industrial innovation. Direct evidence from a cluster-oriented policy." Regional Science and Urban Economics, 40(6): 574-82.

Fantino, Davide and Giusy Cannone. 2013. "Evaluating the efficacy of European regional funds for R\&D.” Temi di Discussione Banca D’Italia 902.

Faria, Pedro de, Francisco Lima, and Rui Santos. 2010. "Cooperation in innovation activities. The importance of partners.” Research Policy, 39(8): 1082-92. 
Flanagan, Kieron, Elvira Uyarra, and Manuel Laranja. 2011. "Reconceptualising the 'policy mix' for innovation.” Research Policy, 40(5): 702-13.

Fornahl, Dirk, Tom Broekel, and Ron Boschma. 2011. "What drives patent performance of German biotech firms? The impact of R\&D subsidies, knowledge networks and their location.” Papers in Regional Science, 90(2): 395-418.

González, Xulia, Jordi Jaumandreu, and Consuelo Pazó. 2005. "Barriers to innovation and subsidy effectiveness.” The RAND Journal of Economics, 36(4): 930-50.

González, Xulia and Consuelo Pazó. 2008. "Do public subsidies stimulate private R\&D spending?” Research Policy, 37(3): 371-89.

Goolsbee, Austan. 1998. "Does government R\&D policy mainly benefit scientists and engineers?” NBER Working Paper 6532.

Görg, Holger and Eric Strobl. 2007. "The effect of R\&D subsidies on private R\&D.” Economica, 74(294): 215-34.

Greiner, Ben. 2004. “An online recruitment system for economic experiments.” In GWDG Bericht, Forschung und wissenschaftliches Rechnen, ed. Kurt Kremer and Volker Macho. Göttingen, 79-93.

Guerzoni, Marco and Emilio Raiteri. 2015. "Demand-side vs. supply-side technology policies. Hidden treatment and new empirical evidence on the policy mix." Research Policy, 44(3): 726-47.

Hall, Bronwyn H. and Josh Lerner. 2010. "The financing of R\&D and innovation.” In Handbook of the economics of innovation. Volume 1, ed. Bronwyn H. Hall and Nathan Rosenberg. Amsterdam: Elsevier, 609-39.

Hall, Bronwyn H. and John van Reenen. 2000. "How effective are fiscal incentives for R\&D? A review of the evidence.” Research Policy, 29(4-5): 449-69.

Heijs, Joost and Liliana Herrera. 2004. "The distribution of R\&D subsidies and its effect on the final outcome of innovation policy.” Documentos de trabajo del IAIF 46.

Hong, Shangqin, Les Oxley, and Philip McCann. 2012. “A survey of the innovation surveys.” Journal of Economic Surveys, 26(3): 420-44.

Hujer, Reinhard and Dubravko Radić. 2005. "Evaluating the impacts of subsidies on innovation activities in Germany.” Scottish Journal of Political Economy, 52(4): 565-86.

Hussinger, Katrin. 2008. "R\&D and subsidies at the firm level. An application of parametric and semiparametric two-step selection models." Journal of Applied Econometrics, 23(6): 729-47.

Jaffe, Adam B. 2002. "Building programme evaluation into the design of public researchsupport programmes.” Oxford Review of Economic Policy, 18(1): 22-34.

Klette, Tor J., Jarle Møen, and Zvi Griliches. 2000. "Do subsidies to commercial R\&D reduce market failures? Microeconometric evaluation studies.” Research Policy, 29(45): 471-95.

Lach, Saul. 2002. "Do R\&D subsidies stimulate or displace private R\&D? Evidence from Israel.” The Journal of Industrial Economics, 50(4): 369-90.

Meloso, Debrah, Jernej Copic, and Peter Bossaerts. 2009. "Promoting intellectual discovery. Patents versus markets.” Science, 323(5919): 1335-39. 
Nishimura, Junichi and Hiroyuki Okamuro. 2011. "Subsidy and networking. The effects of direct and indirect support programs of the cluster policy." Research Policy, 40(5): 714-27.

Norrman, Charlotte and Lars Bager-Sjögren. 2010. "Entrepreneurship policy to support new innovative ventures. Is it effective?" International Small Business Journal, 28(6): 602-19.

Sakakibara, Mariko. 2001. "The diversity of R\&D consortia and firm behavior. Evidence from Japanese data.” The Journal of Industrial Economics, 49(2): 181-96.

Schwartz, Michael, Francois Peglow, Michael Fritsch, and Jutta Günther. 2012. "What drives innovation output from subsidized R\&D cooperation? Project-level evidence from Germany.” Technovation, 32(6): 358-69.

Sørensen, Flemming, Jan Mattson, and Jon Sundbo. 2010. "Experimental methods in innovation research.” Research Policy, 39(3): 313-23.

Wallsten, Scott J. 2000. "The effects of government-industry R\&D programs on private R\&D. The case of the Small Business Innovation Research program.” The RAND Journal of Economics, 31(1): 82-100.

Zúñiga-Vicente, José Á., César Alonso-Borrego, Francisco J. Forcadell, and José I. Galán. 2014. "Assessing the effect of public subsidies on firm $R \& D$ investment. A survey.” Journal of Economic Surveys, 28(1): 36-67. 


\section{Appendix}

\section{Appendix A}

Instructions for all treatments

Note: In general, the control treatment is described, which is the same in both experiments. The differences between treatments are indicated in square brackets, whereby the subsidy treatment of ExLetter is denominated as 'extra letter' and the subsidy treatment of ExMoney as 'extra money'. Furthermore, the order (first, second) in which the treatments were conducted is indicated. The original instructions were in German and are available from the authors upon request.

\section{The Game}

In this game, your task is to build words using letters as in the board game "Scrabble". By building words, you increase your payoff: for each word, you receive a payoff calculated by the sum of the values of each letter. You start the game with an endowment of 4 letters. During the course of the game, you are able to buy additional letters.

[extra letter, first: At the end of your turn, you will additionally receive one letter for free.] [extra money, first: At the end of your turn, you will receive 4 tokens, i.e. the value of one letter, for free.]

You will play in a group of 4 players.

\section{The Payoff}

Your payoff depends on the sum of the value of your letters, which is calculated in experimental tokens. One token is converted to $€ 0.10$ at the end of the experiment. You start this part of the game with an endowment of 50 tokens. Note that it is possible to finish the experiment with less than your starting endowment.

Please note the table below, which contains all letters, their value (in tokens) and the frequency with which they occur in the game.

Table A4.1. List of letters

\begin{tabular}{|c|c|c|c|c|c|c|c|c|}
\hline Letter & Value & Frequency & Letter & Value & Frequency & Letter & Value & Frequency \\
\hline A & 1 & 10 & $\mathrm{~J}$ & 6 & 2 & $\mathrm{~S}$ & 1 & 14 \\
\hline $\mathrm{B}$ & 3 & 4 & $\mathrm{~K}$ & 4 & 4 & $\mathrm{~T}$ & 1 & 12 \\
\hline $\mathrm{C}$ & 4 & 4 & $\mathrm{~L}$ & 2 & 6 & $\mathrm{U}$ & 1 & 12 \\
\hline $\mathrm{D}$ & 1 & 8 & $\mathrm{M}$ & 3 & 8 & $\mathrm{~V}$ & 6 & 2 \\
\hline $\mathrm{E}$ & 1 & 30 & $\mathrm{~N}$ & 1 & 18 & $\mathrm{~W}$ & 3 & 2 \\
\hline $\mathrm{F}$ & 4 & 4 & $\mathrm{O}$ & 2 & 6 & $\mathrm{X}$ & 8 & 2 \\
\hline $\mathrm{G}$ & 2 & 6 & $\mathrm{P}$ & 4 & 2 & $\mathrm{Y}$ & 10 & 2 \\
\hline $\mathrm{H}$ & 2 & 8 & $\mathrm{Q}$ & 10 & 2 & $\mathrm{Z}$ & 3 & 2 \\
\hline $\mathrm{I}$ & 1 & 12 & $\mathrm{R}$ & 1 & 12 & & & \\
\hline
\end{tabular}

On the next page, you will find a screenshot of the main board of the game and some explanations to gain a first overview of the game. A detailed explanation of the game ensues. 


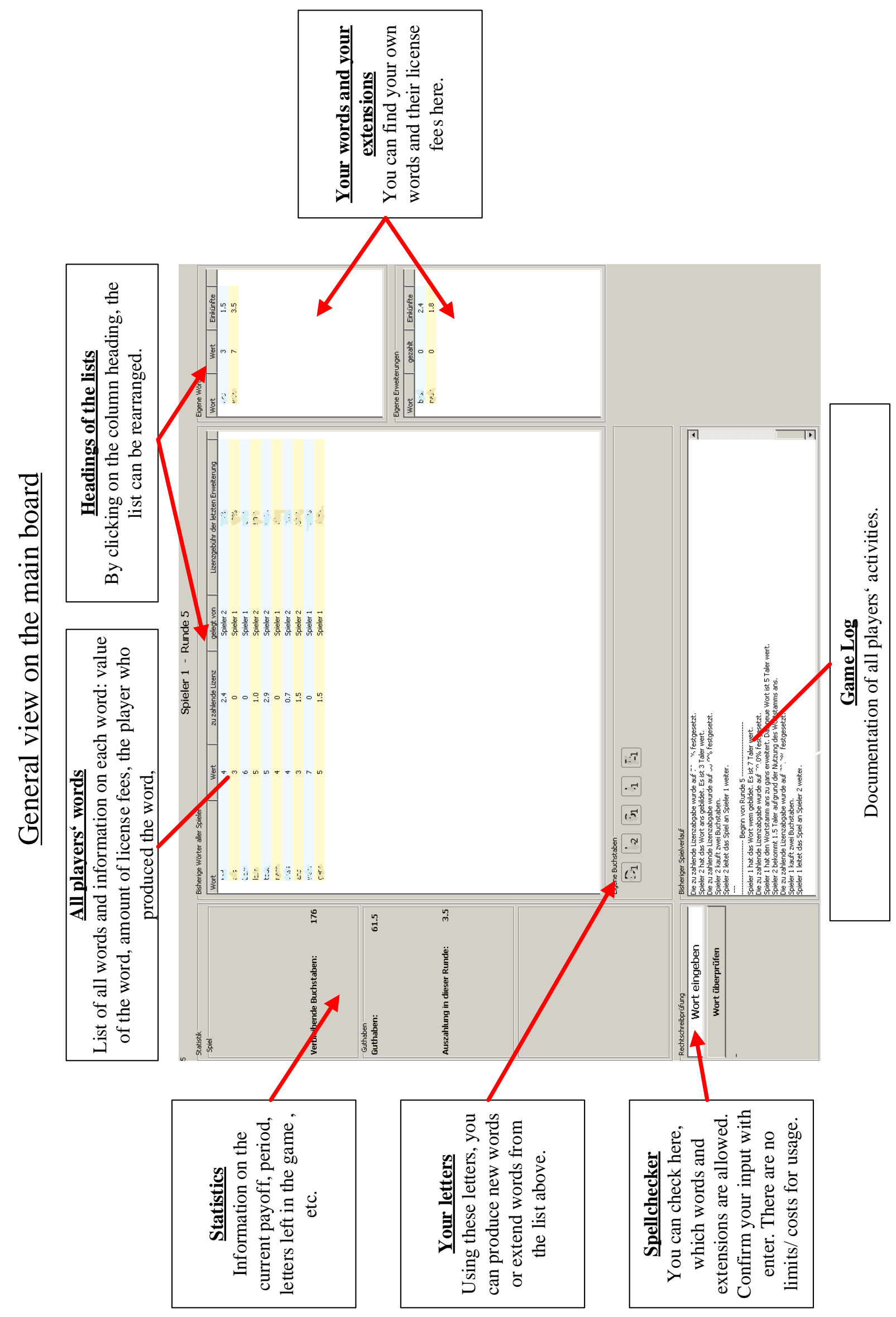




\section{Course of a Turn}

When it is your turn, a dialog pops up asking you for choices. You have 60 seconds for your decisions. You can see the remaining time at the top-left corner of the screen. If your time expires, you are subtracted 1 token from your endowment for every additional 10 seconds. Every turn comprises five phases:

\section{Word phase I}

\section{Your activity: Producing or extending words}

You can use German words, their conjugations and declinations and some names of places and persons. You can test if a word is correct using the spellchecker when it is not your turn. Each letter can only be used once: after producing or extending a word, the letter will be deleted from your list.

Correct words can be built as follows:

\section{Option 1: $\quad$ Producing a 3-letter word}

a) You can produce a word using exactly three of your letters by typing the letters on your keyboard.

The payoff that you earn for creating a word is given by the sum of the value of the letters (Example: 'pol': $\mathrm{p}=4, \mathrm{o}=2, \mathrm{l}=2$. This results in $4+2+2=8$ tokens).

Option 2:

Extending a word

b) You can extend an existing word by inserting one letter in any position in the word. For example, 'ast' can be extended into 'last', 'rast' and 'aste', and 'last' again into 'laust' and this into 'klaust'. It is not possible to rearrange existing words (e.g. to build from 'ast' the word 'star').

Your payoff results from the sum of the value of the letters of the newly-extended word. By extending e.g. 'last' into 'laust', you get $\mathrm{l}=2, \mathrm{a}=1, \mathrm{u}=1, \mathrm{~s}=1, \mathrm{t}=1$, so $2+1+1+1+1=6$ tokens. Every word can only be produced once but can subsequently be used for as many extensions as possible.

\section{Option 3: $\quad$ Passing}

c) In case you are unable to produce or extend any word, you can pass the turn to the next player. 


\section{Royalty phase I}

\section{Your activity: Setting a royalty fee}

After producing a word, you have to decide whether or not to set a royalty fee that other players are required to pay when creating extensions. If you set a royalty fee, you will have to choose between 10 and 100 percent of the value of the word.

Figure A4.1. Intellectual property choice

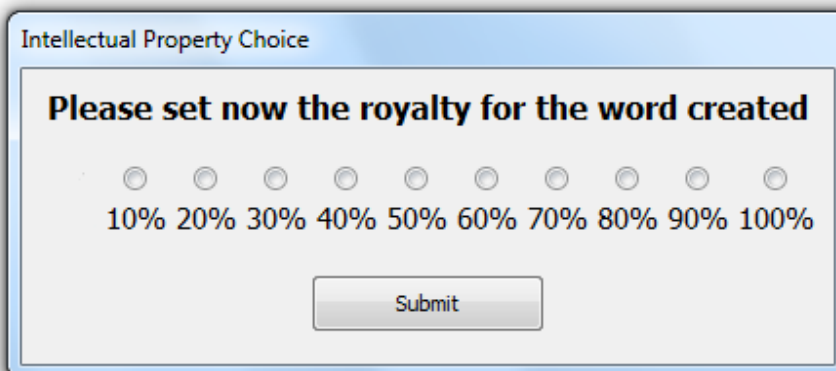

If another player extends your word, the fee is automatically transferred to you.

In the following, you can find three examples for others extending your word:

- If you choose no license fee, the word is entirely free to use for the other players. They will receive the entire value of the word.

- At 100 percent, you will receive the initial value of the word and the next player only receives the value of his added letter.

- The choice of 20 percent means that the respective player has to pay 20 percent of the value of the word to you. The other player will receive 80 percent plus the value of their added letter.

The word and the royalty fee remain fixed during the entire game. Both appear on the list of public words on the main board and can be used by all other players. However, other players are required to pay the respective royalty fee when extending the word.

Furthermore, you will have to decide whether to set a royalty fee if you extend a word with a single letter. In this case, you only decide on the fee for your added letter.

\section{Word phase II}

After the first license phase, a second word phase ensues, in which you can produce another word following the procedure described above.

\section{Royalty phase II}

If you have produced or extended a second word, you will have to decide once again whether to set a royalty fee or not and - if so - determine the level of the royalty fee as described above. 


\section{Buying phase}

\section{Your activity: Buying letters}

You can choose to buy no, one or two letters at the price of 4 tokens for each letter. The order of the letters has been randomly determined prior to the game by sampling without replacement from the list of letters shown on the table A4.1. At the beginning, you are provided four letters and 50 tokens

[extra letter, first: and in each turn one additional letter in the buying phase] [extra money, first: and in each turn four additional tokens in the buying phase] for free.

After that, your turn ends and it is the next player's turn. The game is played for 12 periods. Finally, some examples for the calculation of your payoff are provided:

Example 1: If player 1 sets a royalty fee of 90 percent for the word 'ast' (value of the word 3 tokens: $\mathrm{a}=1, \mathrm{~s}=1, \mathrm{t}=1$ ) and player 2 extends the word into 'hast' (value of $\mathrm{h}=2$ ), this results in the following payoffs:

Player 1: 90 percent of 3 tokens $=2.7$ tokens (royalty fee for player 1 )

Player 2: $3-2.7$ tokens (to player 1 ) +2 tokens for the letter ' $h$ ' $=0.3$ tokens +2 tokens $=$ 2.3 tokens

Example 2: If player 1 sets the royalty fee of 0 percent for 'ast', player 2 receives the sum of the value of all letters for extending it into 'hast':

Player 1: 0 percent of 3 tokens $=0$ token

Player 2: 100 percent of 5 tokens $=5$ tokens

Example 3: After extending a word, the player has to set a royalty fee for the added letter. Player 1 sets a royalty fee of 10 percent for 'ast' and player 2 sets a royalty fee of 50 percent for the letter ' $h$ ' in 'hast'. If player 3 then extends 'hast' into 'haust', this results in the following payoffs:

Player 1: 10 percent of 3 tokens $=0.3$ (royalty fee for player 1 )

Player 2: 50 percent of 2 tokens $=1$ (royalty fee for player 2 )

Player 3: 6 tokens for 'haust' -0.3 tokens (to player 1 ) -1 token (to player 2 ) $=4.7$ tokens

Once the participants of a session had finished the first part, they were handed out the second part of the instructions:

Hereafter, you will play the game again with the following changes:

- You receive again 50 tokens. Your payoffs will be aggregated at the end of the experiment.

- The groups are matched randomly.

- [control, first; extra letter, second: In the buying phase at the end of your turn, you receive a free letter in each turn and you can only buy one additional letter.] [control, first; extra money, second: At the end of each turn, 4 tokens are added to your endowment, which amounts to the cost of one letter.]

[extra letter, first; control, second: In the buying phase at the end of your turn, you no longer receive a free letter anymore; instead, you are now able to buy two, one or no letters.]

[extra money, first; control, second: In the buying phase at the end of your turn, it is no longer the case that 4 extra tokens are added to your endowment.]

Apart from these changes, all parameters of the game remain constant. 


\section{Appendix B}

Instructions for the control task

Note: The instructions for the word task were shown to participants on the screen.

In the next screen, you will see a string comprising 9 letters.

You will be asked to create as many German words as possible using these letters within 3 minutes.

You can type the words you create in the field beneath the string of 9 letters and submit them by pressing Enter.

You can use each letter only once per word and a word cannot be shorter than 3 letters.

Longer words generate more points.

3-letter word: $3+2+1=6$ points

4-letter word: $4+3+2+1=10$ points

etc.

After 3 minutes have expired, the test will end and you will be shown your results.

As soon as you enter the next screen, the timer will start ticking.

To proceed to the next screen, please press the letter ' $R$ ' on your keyboard. 
To test for individual task-specific knowledge, a control task is run prior to the experiment. Therefore, the word task by Eckartz et al. (2012) is implemented, in which subjects are asked to build as many words as possible out of the letterset accehhikllst within three minutes. The instructions for the control task are provided in appendix B. For every word that they create, subjects earn points, whereby the number of points increases disproportionally with the word length: a word with three letters generates 6 points, a four-letter word 10 points, a five-letter word 15 points, etc. Overall, given the letterset, 330 different words can be generated, which are worth 5,585 points. In each session, the five subjects scoring the most points were awarded an additional $1 €$ to their overall payoff. The distribution of the groups' performance across treatments - as measured by the points achieved - is provided in figure A4.2.

Figure A4.2. Performance in the control task by group and treatment

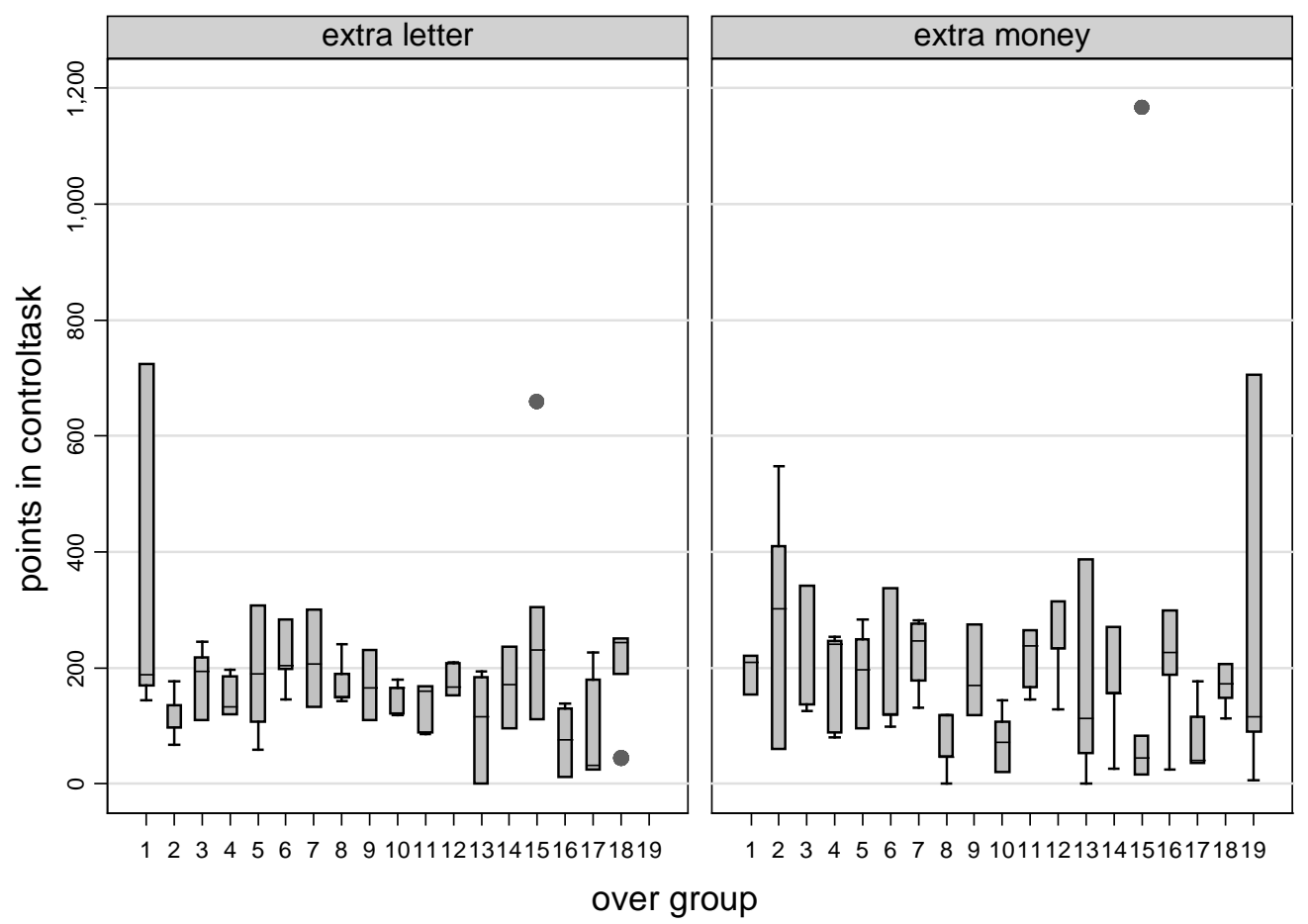

At the group level, there is some heterogeneity in the task-specific skills, yet no substantial differences when compared across experiments (MWU-test for extra letter vs. extra money $\mathrm{z}=-1.216$ and $\mathrm{p}=.2242$ ). Accordingly, it can be assumed that these results are not driven by subjects' systematically different abilities in creating words across the two experiments. 


\section{Experimental approaches to innovation research}

with Kilian Bizer 


\begin{abstract}
Innovation research has developed a broad set of methodological approaches in recent decades. In this paper, we propose laboratory experiments as a fruitful methodological addition to the existing methods in innovation research. We provide an overview of the existing methods, discuss the advantages and limitations of laboratory experiments and review examples of experimental studies dealing with different fields of innovation policy, namely intellectual property rights, financial instruments, payment schemes and $R \& D$ competition. Following recent methodological contributions, we propose a pragmatic use of laboratory experiments, whenever they can complement established methods of innovation research.
\end{abstract}

\title{
Keywords
}

innovation research, laboratory experiments, methodology

\section{JEL-Classification}

C90, L50, O38 


\subsection{Introduction}

Fostering research and innovativeness to support economic growth and increase competitiveness has become a central paradigm for policy makers worldwide in recent decades. The European Commission has recently reaffirmed this goal by committing to spend up to three percent of the European Union's GDP to support private innovation activity until 2020. By means of this and other policy instruments, the EU thus aims to become an “innovation union” $(\operatorname{COM}(2014)$ 339). This paradigmatic focus has been adopted by the scientific community, which similarly discusses the topics of innovation and industrial policy broadly, trying to obtain insights and provide advice to policy makers concerning the design of policy instruments that optimally foster innovation activity (Mazzucato et al. 2015).

Economic innovation research traditionally argues for government intervention in the case of market failure, which is characterized by the imperfect allocation of resources; for example, due to public goods, imperfect competition, negative externalities, information and coordination failures (Bator 1958). Given the political commitment to foster innovation activity, government interventions can provide remedies to market failures. For this purpose, several distinct methods of supporting private economic subjects in their innovation activities have been developed. Firstly, regulatory instruments such as rules, norms and standards have been introduced, such as patents and copyright law. These regulations are compulsory for all economic actors and thus shape the overall market conditions for innovative products and processes. Secondly, financial instruments have been introduced to promote innovative activity, with examples including subsidies, cash grants and reduced interest-loans, as well as disincentives like tariffs, taxes and charges. Thirdly, there are 'soft' instruments that include normative incentives such as moral appeals to economic actors and voluntary commitments like technical standards or public-private partnerships (Vedung 1998; Borrás and Edquist 2013).

To analyze and evaluate the effects and optimal design of these instruments, economic innovation research has established a large number of empirical research methods. Along with the overall expansion and professionalization of experimental economics, behavioral evidence collected in laboratory experiments have become a vital complement to economic innovation research in recent years. Following Sørensen et al. (2010) and Chetty (2015), we suggest that lab experiments constitute a promising addition to the methodological toolkit in innovation research, thus advancing novel insights and providing predictions and policy implications by incorporating behavioral factors. We thus argue that laboratory experiments should be used if they yield additional evidence unattainable by other methods in a particular field of study. 
This resonates with the arguments by Falk and Heckman (2009), Chetty (2015), Madrian (2014) and Weimann (2015), who propose a pragmatic approach concerning the use of evidence derived from experimental methods, arguing that all empirical methods should be viewed as complementary (Falk and Heckman 2009). In this paper, we aim to contribute to the growing field of experimental innovation research, firstly by outlining the advantages and limitations of different methodological approaches in innovation research and more specifically laboratory experiments. Secondly, we provide a literature review of the existing experimental approaches to the field of innovation policy with examples from four sub-fields in which lab experiments have been conducted. We conclude by emphasizing the further use of laboratory experiments to innovation research.

This paper is structured as follows: in chapter two, we outline the range of methods in economic innovation research, before discussing the scopes of the experimental method in detail in chapter three. Subsequently, we present a selection of laboratory experiments in the field of innovation policy, namely intellectual property rights, financial instruments, payment schemes and R\&D competition. A conclusion is finally provided in chapter four.

\subsection{Methodological approaches in innovation research}

A large number of research methods have been developed to analyze which policy instruments might best foster innovative activity. Weimann (2015, 247-48) categorizes the different methods of generating insight by their features regarding their ability to identify causal relations, their generalizability to other contexts (external validity) as well as their broad applicability; particularly, the trade-off between causality and external validity is emphasized. Thus, Weimann distinguishes between (1) neoclassical models pointing out causal relationships, (2) 'traditional' empirical research primarily showing correlations, (3) natural experiments attempting to substantiate causal relationships, (4) randomized field experiments that optimally offset the trade-off between causality and external validity and (5) laboratory experiments providing a strong causality, yet lacking external validity. Figure 5.1 provides an overview of these methodological approaches and their features. 
Figure 5.1. Methodological approaches and their features

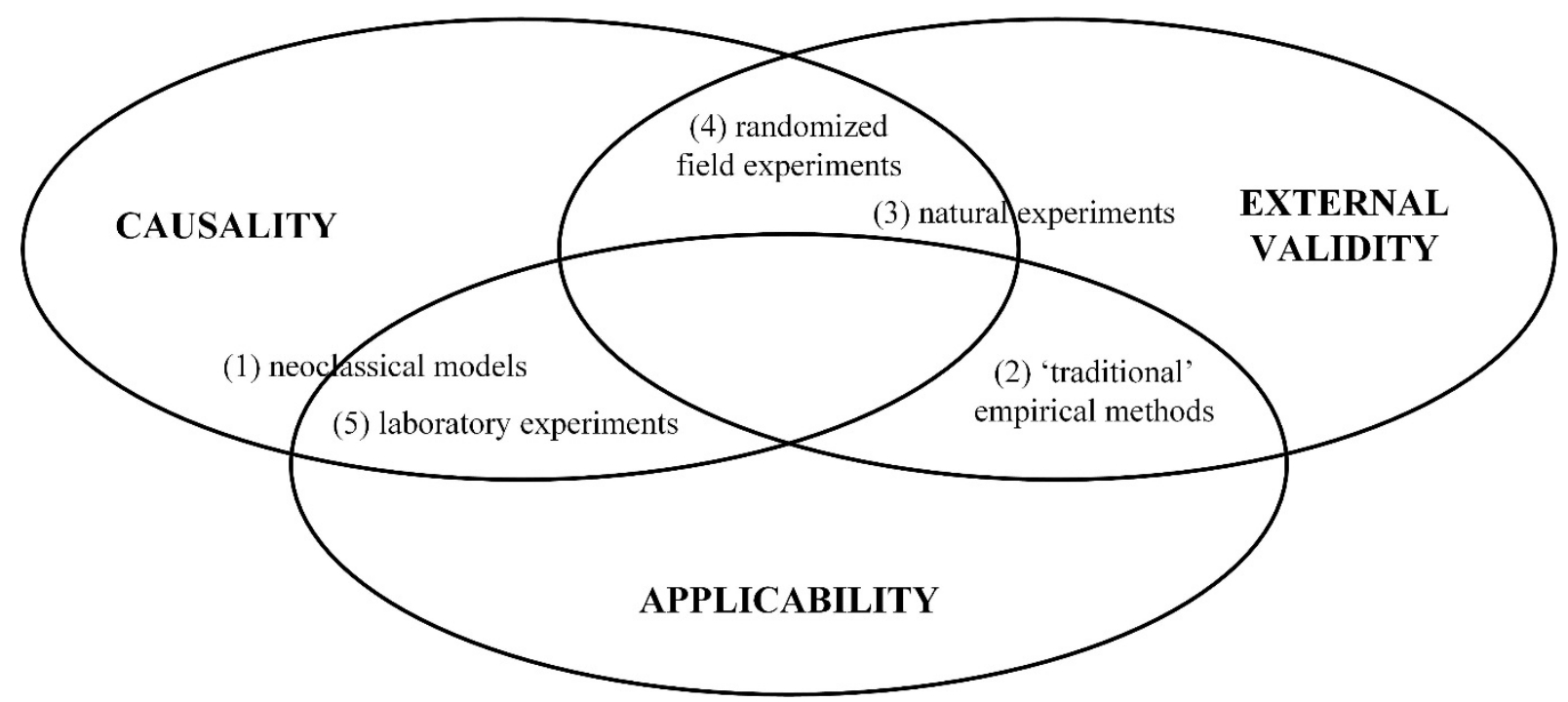

Note: The figure is based on the classification by Weimann (2015).

(1) Neoclassical models such as game theoretical or general equilibrium models have the advantages of enabling deriving causal relations and being easily applicable, yet they often lack external validity.

Empirical investigations in innovation economics most commonly use the methods of (2) 'traditional' empirical economic research, for instance official patent statistics or micro firmlevel data from surveys. For this, OLS estimations are considered appropriate to analyze and quantify observable variables of innovation processes; however, for dynamic effects, these methods often lead to problems of causality, endogeneity and selectivity. A further shortcoming of using this form of data is that innovation surveys necessarily rely on the entrepreneurs' willingness to voluntarily disclose information about their firm, which potentially biases the data. Furthermore, the extent to which government funding is actually used for research by the firms often remains unclear and the public funding decisions often lead to a selectivity bias, thus making public funding an endogenous variable, which establishes further dependencies between the respective variables (Busom 2000). Moreover, patents and patent pools are often used as an approximation for the innovation activity to estimate the firms' innovation output. This prompts a number of issues; for example, because small and medium enterprises use other forms of protecting their innovations and patent less than large firms, due to potentially expensive patent litigations and patent theft (Thomä and Bizer 2013). Nevertheless, this methodological approach to innovation research has strongly improved its data availability, methods and research designs in the past 25 years, implementing methods such as difference-in-difference estimators, sample selection models, instrumental variables and non-parametric matching methods (Angrist and Pischke 2010; 
Zúñiga-Vicente et al. 2014). Overall, this approach entails a high level of external validity and applicability, but often only a low level of causality.

Another empirical means of evaluating policy instruments is (3) natural experiments, which feature a high level of external validity. Furthermore, due to improved methodological approaches, causal relations have substantiated in recent years. However, the applicability is often low, since it is difficult to find appropriate control groups that could enable a clear comparison (Weimann 2015).

It has been argued that the issues involved with using the 'traditional' methods of empirical economic can best be solved by conducting (4) randomized field experiments in which reallife incidents are treated similar to experiments. They are considered the "gold standard" for evaluating new policy instruments as they enable identifying causality rather than mere correlations (Falck et al. 2013; Boockmann et al. 2014). As an example, Chatterji et al. (2013) suggest that the distribution of building sites in new industrial areas could be randomized, which would lead to better results in subsequent impact analyses of cluster policies. While optimally combining external validity and causality, randomized field experiments suffer from a lack of applicability as their adequate design is time-consuming, expensive and often highly impractical; consequently, other methods are regularly preferred (Angrist and Pischke 2010).

(5) Laboratory experiments can be considered an alternative to overly costly and impractical field experimentation, combining a high level of causality with a high level of applicability. Despite the lower level of external validity, laboratory studies can be a valuable substitute for randomized field experiments and provide insightful new angles to research topics inaccessible through 'traditional' empirical methods.

Since each method has its own strengths and weaknesses, the method used for a particular research question should be chosen depending on the object of research, the availability of data and the possibility for conducting field experimentation. Overall, a mix of complementary empirical methods might thus be the most promising approach (Weimann 2015). In the following, we focus on laboratory experiments, which are the most recent addition to the methodological toolbox of innovation research, including discussing their limitations and advantages.

\subsection{Limitations and advantages of experimental methods}

Although lab experiments can be transferred and used to derive relevant policy implications, there are systematic limitations to this approach. Critics of lab experiments such as Levitt and 
List (2007; 2008) emphasize the restrictions, while Falk and Heckman (2009) provide refutations:

Observation: Participants are observed and act in an artificial environment, which might influence their behavior due to expectancy effects and the experimenter demand bias. Barmettler et al. (2012) contradict this argument and show experimentally that complete anonymity between the experimenter and participants does not change the latter's behavior. Furthermore, it is argued that close social observation is not limited to the lab but rather is a feature common to all economic interactions.

Stakes: It can be argued that the stakes in experiments are too low to induce realistic behavior in participants. Experiments with varying stake sizes yield mixed results depending on the experimental situation (Camerer and Hogarth 1999). However, Falk and Heckman (2009) ask how often people take choices involving sums equal to their monthly incomes and how representative such high-stake experiments would actually be. Consequently, they suggest that the average level of stakes in laboratory experiments correspond to the most common choices that individuals take.

Sample size: The sample sizes of lab experiments are criticized as being too small, although this is refuted such that sample sizes are stated to adequately correspond to this method and thus yield valid assertions.

Participants: Student participant pools are considered unrepresentative of the overall population. While this might not be a problem when testing theories, in the case of innovation experiments, other populations such as researchers or entrepreneurs might be more appropriate experimental participants, depending on the research question.

Self-selection: There is a self-selection bias since students with particular traits sign up for participant pools. Nevertheless, student pools ensure that the selection can be controlled and provide information on participants' demographics, personal backgrounds and preferences. Thus, the disadvantages connected to selection biases - which are potentially prevalent in field experiments as well as other empirical research methods - can be somewhat controlled.

Learning: Participants often cannot learn in experiments and adjust their behavior accordingly, yet this is also a prevalent factor in many economic interactions outside of the 
lab, as real-world interactions can often be considered as one-shot games with no chance of learning in repeated decisions. Furthermore, a large number of repeated games have been considered in experimental settings to determine learning effects, for example Cooper et al. (1999) with regard to incentive systems.

External validity: Lab experiments are considered as lacking external validity, meaning that they produce unrealistic data without further relevance for understanding the "real world": a criticism that holds true both for lab experiments and theoretic models (Weimann 2015, 240 41). The challenge in designing experiments is to establish the best way of isolating the causal effect of interest and thus providing insights about universally prevalent effects that transfer to other economic situations outside of the lab. In a recent study, Herbst and Mas (2015) show how well-designed experiments can ensure that individual behavior outside the lab is captured adequately, thereby gaining a higher external validity than traditionally assumed for laboratory studies. Further studies comparing laboratory and field evidence will have to show whether this might change the general perception of the external validity of lab experiments (Charness and Fehr 2015). However, in some research contexts, it might not be possible to substantially increase the external validity. In such cases, lab experiments can serve as a starting point to isolate clear effects of specific innovation instruments. Subsequently, these effects have to be investigated with other methods involving a higher external validity, e.g. field experiments in a firm. These methods then have to show whether the initial results from the laboratory hold in contexts outside the lab.

Generalizability: The lack of generalizability of behavioral patterns resulting from lab experiments that refrain from testing a theoretical model is criticized. While the arguments mentioned above reduce this problem, it remains a considerable drawback to some experimental evidence. Nevertheless, every empirical method faces this issue due to the unavoidable dependency of data on a specific context.

Overall, lab experiments entail several distinct advantages as they provide researchers with the means of deriving causal relations from controlled manipulations of specific conditions, while controlling all surrounding factors. This ensures precise measurements and makes it possible to preclude confounding effects such as multiple incentives or repeated interactions. The experimenter thus retains almost complete control of the decision environment, namely the material payoffs, the information given to participants, the order of decisions, the duration 
and iterations of the experiment. Participants are assigned randomly, which reduces the selection bias. Moreover, they are incentivized monetarily for their decisions, whereby it can be assumed that decisions are taken seriously: "In this sense, behavior in the laboratory is reliable and real: Participants in the lab are human beings who perceive their behavior as relevant, experience real emotions, and take decisions with real economic consequences” (Falk and Heckman 2009, 536). The results are replicable and they allow investigating specific institutions at a relatively low cost. This can be particularly useful when considering exogenous changes like policy interventions and new regulations, where counterfactual situations can be created and their effects tested far more easily in lab rather than field experiments. With the possibility of altering only one factor - e.g. the patent regime - lab experiments allow analyzing the relevance of a particular factor without other factors confounding the observed behavior. Furthermore, lab experiments enable the researcher to examine different innovation types, effects of incentives and splitting up the innovation process to observe individual behavior at particular points of the process (Smith 1994, 2003; Falk and Heckman 2009).

In the following, we review examples of different fields of innovation research where lab experiments have been put forth to provide novel insights.

\subsection{Literature review}

By analyzing the effects of specific policy instruments via economic experiments, several of the advantages of lab experiments described above can be used fruitfully. In particular, it becomes possible to compare counterfactual data of decision situations with and without a particular instrument. Therefore, it is possible to analyze subjects' specific reactions to changes in the framework conditions, which is almost impossible when using "real-world" data. There are additional merits to the controlled lab environment, in which only one factor is changed; for instance, innovation behavior and its development can be observed and analyzed over several periods. Of course, the innovation process is necessarily stylized in lab experiments; nevertheless, a number of promising ideas concerning how to transfer the innovation process into the laboratory have been provided in recent years. Table 5.1 comprises the experiments reviewed in the following chapters and summarizes in brief the particular task subjects had to solve. 
Table 5.1. Overview on the experiments reviewed

\begin{tabular}{|c|c|c|c|}
\hline Field of research & Short title & Type of task & Subjects' task in the experiment \\
\hline \multirow{5}{*}{$\begin{array}{l}4.1 \\
\text { Intellectual } \\
\text { property rights }\end{array}$} & $\begin{array}{l}\text { Buchanan and Wilson } \\
2014\end{array}$ & $\begin{array}{l}\text { Real effort } \\
\text { search task }\end{array}$ & $\begin{array}{l}\text { Producing and trading rivalrous and non- } \\
\text { rivalrous goods composed of colors }\end{array}$ \\
\hline & Meloso et al. 2009 & $\begin{array}{l}\text { Real effort } \\
\text { search task }\end{array}$ & $\begin{array}{l}\text { Solving the knapsack problem and trading the } \\
\text { potential components }\end{array}$ \\
\hline & $\begin{array}{l}\text { Buccafusco and } \\
\text { Sprigman } 2010\end{array}$ & Creative task & Creating and trading poems \\
\hline & Crosetto 2010 & Creative task & $\begin{array}{l}\text { Creating and extending words and deciding } \\
\text { whether to use IP protection }\end{array}$ \\
\hline & $\begin{array}{l}\text { Brüggemann et al. } \\
2015\end{array}$ & Creative task & $\begin{array}{l}\text { Creating and extending words, setting license } \\
\text { fees }\end{array}$ \\
\hline \multirow{2}{*}{$\begin{array}{l}4.2 \\
\text { Financial } \\
\text { instruments }\end{array}$} & $\begin{array}{l}\text { Brüggemann and } \\
\text { Meub } 2015\end{array}$ & Creative task & $\begin{array}{l}\text { Creating and extending words, setting license } \\
\text { fees }\end{array}$ \\
\hline & Brüggemann 2015 & Creative task & $\begin{array}{l}\text { Creating and extending words, setting license } \\
\text { fees }\end{array}$ \\
\hline \multirow{4}{*}{$\begin{array}{l}4.3 \\
\text { Payment schemes }\end{array}$} & Eckartz et al. 2012 & $\begin{array}{l}\text { Real effort } \\
\text { search task }\end{array}$ & $\begin{array}{l}\text { Combining as many words as possible from } 12 \\
\text { given letters }\end{array}$ \\
\hline & $\begin{array}{l}\text { Ederer and Manso } \\
2012\end{array}$ & $\begin{array}{l}\text { Real effort } \\
\text { search task }\end{array}$ & Managing a virtual lemonade stand \\
\hline & $\begin{array}{l}\text { Erat and Gneezy } \\
2015\end{array}$ & Creative task & Solving rebus puzzles \\
\hline & Bradler 2015 & Creative task & Imagining unusual uses for items \\
\hline \multirow{7}{*}{$\begin{array}{l}4.4 \\
\text { R\&D competition }\end{array}$} & $\begin{array}{l}\text { Isaac and Reynolds } \\
1988\end{array}$ & Investment task & Taking investment choices under competition \\
\hline & $\begin{array}{l}\text { Isaac and Reynolds } \\
1992\end{array}$ & Investment task & $\begin{array}{l}\text { Taking investment choices including the game } \\
\text { bingo }\end{array}$ \\
\hline & $\begin{array}{l}\text { Sbriglia and Hey } \\
1994\end{array}$ & Search task & $\begin{array}{l}\text { Finding a letter combination by buying } \\
\text { different letter trails under competition }\end{array}$ \\
\hline & Zizzo 2002 & Investment task & Competing for a prize over several periods \\
\hline & Silipo 2005 & Investment task & $\begin{array}{l}\text { Accumulating “knowledge units” under risk } \\
\text { and competition }\end{array}$ \\
\hline & Cantner et al. 2009 & Search task & $\begin{array}{l}\text { Searching for product specifications of a car } \\
\text { including investment and competition }\end{array}$ \\
\hline & Aghion et al. 2014 & Investment task & $\begin{array}{l}\text { Competing for finding an innovation including } \\
\text { investment and risk }\end{array}$ \\
\hline
\end{tabular}




\subsubsection{Intellectual property rights}

For instance, there are several experiments implementing (real effort) search tasks to simulate the innovation process. Buchanan and Wilson (2014) design an experimental environment with subjects producing, trading and consuming rivalrous and non-rivalrous goods. Rivalrous goods are produced out of two complements and can be sold. By contrast, producing nonrivalrous goods is possible by participating in a search task in order to find the "favorite good" of the specific period, which is more valuable than the rivalrous good and - in opposition to rivalrous goods - can be sold several times. The authors implement one treatment with intellectual property, in which selling and transferring the non-rivalrous good is restricted to the respective owner, as well as one treatment without intellectual property, where non-rivalrous goods can be created several times. The authors find no differences in the value of produced non-rivalrous goods and the average money earned regardless of intellectual property protection. Overall, Buchanan and Wilson suggest that intellectual property protection does not spur innovativeness. However, the protection only serves as an additional incentive, whereas the existence of entrepreneurial individuals is more important. The respective entrepreneurs subsequently profit substantially from the protection, as well as generating wealth without intellectual property protection.

Meloso et al. (2009) use another kind of search task - namely the knapsack problem - to simulate intellectual discovery in a patent and a non-patent market system, in which components of potential discoveries are traded. The goal of the knapsack problem is to combine inputs of a particular value and realize an optimal weighing of the components. In sum, the number of subjects who were able to find the correct solution to the knapsack task was higher in the markets system, which has the advantages that no scope of intellectual property rights has to be defined beforehand and that it entails no monopoly rights. Therefore, the authors state that markets do not necessarily fail - as theoretical contributions suggest for non-excludable and non-rival goods.

Buccafusco and Sprigman (2010) let subjects write poems and implement a market for the poems. Depending on the initial distribution of intellectual property rights, they find different preferences of the innovators, owners and buyers. There is a robust endowment effect that manifests itself in the high offers of innovators and a significantly lower willingness to pay among the buyers. This experiment has the advantage of simulating the innovation activity most closely on an individual level, yet it is not possible to further evaluate the particular poems and determine a ranking for the quality of the innovations. 
Including further features of the innovation process - namely creativity, ownership and investment choices - Crosetto (2010) developed a task to simulate innovative activity based upon the board game Scrabble. He uses his setting to analyze the individual behavior when subjects have to create and extend words and are able to select between the intellectual property schemes of open source and fixed license fees. He finds that subjects' propensity to provide their innovations open source is more likely when the level of license fees is high. Brüggemann et al. (2015) extend this experimental setting to test for the effect of different regulatory incentive schemes on the individual innovativeness. They compare a treatment with the possibility to choose the amount of license fees to a system without license fees and further implement the ability to communicate. They find that communication does not change the innovative behavior and that welfare is higher in the no-license-fee system than in the license-fee system. However, when given the possibility to license innovations, subjects display a high demand for being rewarded monetarily rather than providing innovations to other participants free of charge.

\subsubsection{Financial instruments}

There is broad literature about the difficulties in analyzing the effect of subsidies and other public programs to foster innovativeness due to endogeneity and selection bias problems. Although the methods used have advanced substantially in past years, lab experiments can contribute to this sub-field of innovation research (Blundell and Costa Dias 2009). In some cases, experiments might be the only way to provide insights about new - and potentially costly - policy instruments before they are implemented in the "real world". This approach might thus be a particularly promising methodological choice when new institutional framework conditions are tested, which aim at fostering the innovative activity. Nevertheless, there is only a limited number of studies dealing with financial instruments to date.

Using the Scrabble-based word creation task introduced by Crosetto (2010), Brüggemann and Meub (2015) analyze the individual behavior in two types of innovation contests by awarding subjects with a bonus for the best innovation in one treatment and for the largest innovation effort in another, comparing individual performance to a benchmark treatment without a prize. They find that the willingness to cooperate decreases when innovation contests are introduced, while the overall welfare remains constant across treatments. Furthermore, using the same word task, Brüggemann (2015) analyzes the effects of two distinct forms of subsidies on innovativeness; first, by supplying resources determined for innovative activities; and second, by providing additional financial resources not restricted to the use in innovative activities. She finds that both forms of subsidy lead to a crowding-out of 
private investment and negative welfare effects when the costs for the subsidy are included. Furthermore, subsidies fail to induce a positive effect on the individual innovation behavior.

\subsubsection{Payment schemes}

Another class of experiments focuses on the creative element of innovation and the effects of different payment schemes. Eckartz et al. (2012) test the effects of different payment schemes on creativity using a word-based real effort task, where subjects have to combine as many words as possible out of twelve prescribed letters within a certain time. They examine a flat fee, a linear payment and a tournament and find no substantial differences between the three incentive schemes. Similarly analyzing different payment schemes, Ederer and Manso (2012) compare the innovative activity when offering a fixed wage, a wage based upon pay-forperformance and a split wage, which is fixed at the beginning and based upon performance later on. In a search task, subjects have to manage a lemonade stand, whereby they have to decide upon several variables such as the location, content, and price to find the most profitable solution. The authors find that the split wage with tolerance for early failure and compensation for long-term success leads to more innovative effort and higher overall welfare.

Erat and Gneezy (2015) compare three payment schemes, namely a pay-for-performance scheme, a competitive scheme and a benchmark without incentives. Unlike Ederer and Manso (2012), they use rebus puzzles as a creative task and find that competition reduces creativity and a pay-for-performance scheme does not change creativity in comparison to a situation without incentives. Comparing the two financial incentives, creativity is higher in a pay-forperformance scheme.

Bradler (2015) used the "unusual uses task" - an established creativity test - to compare accomplishment, self-reporting and risk behavior. In the task, subjects have to imagine as many uses for a particular object as possible in a certain time, choosing their preferred payment scheme prior to the task, i.e. a tournament or a fixed payment. She finds that the different payment schemes appeal to different types of subjects: risk-loving subjects with a high self-assessment tend to choose the tournament; however, in contrast to previous studies, creative subjects do not tend to choose the tournament more often than the fixed payment.

\subsubsection{R\&D competition}

Finally, in the experiments on R\&D competition, the authors focus on different investment task to analyze the individual behavior in competitive and innovative environments. Experiments on patent races and R\&D competition were first established by Isaac and 
Reynolds (1988) to simulate a one-stage stochastic invention model and subsequently a twostaged model (Isaac and Reynolds 1992). This class of experiments aims to test the findings of models with empirical evidence, whereby - in contrast to the experiments described before - they do not analyze specific policy instruments. Sbriglia and Hey (1994) develop a costly combinatorial task representing research competition for a patentable innovation to analyze three behavioral problems of patent races, namely how subjects select their search procedures, which investment strategies they use and how information is processed. The authors identify different types of innovators: the "winners", who search successfully, do not act randomly and invest more in comparison to the "losers", who are unable to establish a strategic search procedure. Furthermore, stronger competition accelerates the rate of investment and with a higher number of periods, successful players more commonly adapt their searching behavior.

Zizzo (2002) tests the multi-stage patent race model by Harris and Vickers (1987) with an investment task where subjects compete for a monetary prize over several periods. Their results disconfirm the theoretical assertions, as leaders of a patent race do not invest more than their followers. Furthermore, the authors find no virtual monopoly and investments do not change as predicted by the model. Silipo (2005) analyze the cooperation and break-up behavior in joint ventures in a dynamic patent race model theoretically and experimentally. In the model, they find that the starting positions of the competitors are crucial for being cooperative or not: if the innovators start at different points of the research process, the probability of joint ventures decreases, while in joint ventures the pace of the process slows down. The results of their experiment correspond to the model, aside from some races in which subjects perform worse than anticipated.

Cantner et al. (2009) test a patent race model limited to a duopoly market without price competition by implementing a multi-dimensional search task with uncertainty. They find that different strategies solve the task, namely risky innovative investment and risk-free imitations. On average, subjects choose the risky innovative investment based upon the risk of an investment failure, their anticipated revenue and their relative success in the experiment. Furthermore, the gap in subjects' earnings has a positive impact on their investment in the next periods. Finally, Aghion et al. (2014) analyze the effects of competition on a step-by-step innovation by means of a risky investment task with different levels of competition and time horizons. The results show an increase in investment for neck-and-neck firms, yet a decrease in investment for firms lagging behind. 


\subsection{Conclusion}

In this paper, we present the limitations and advantages of using laboratory experiments for innovation research and review 18 examples from four specific fields in which lab experiments already have been conducted. As the experimental method yields promising results in testing intellectual property rights, financial instruments, payment schemes and R\&D competition, we suggest that laboratory experiments can serve as a useful additional tool to innovation economists and represent a source of promising new insights for innovation research.

In particular, we argue that lab experiments should be used to target specific policy questions and thus provide measures for the effectiveness of specific instruments prior to their introduction. This approach has - in marked contrast to all other methods - the advantages of yielding evidence from counterfactual situations and a strong control of the setting; for example, when testing external incentives for innovative activity or changing parameters of the institutional framework. Therefore, we follow Chetty (2015) and Weimann (2015), who suggest a pragmatic perspective on behavioral economics, thus adding experimental evidence to the existing methods whenever its particular advantages outweigh its limitations. Within this pragmatic perspective on laboratory experiments, Chetty (2015) characterizes three ways in which this field of research can contribute to public policy: by presenting new policy instruments, developing better predictions regarding the effects of existing policies and more accurately measuring welfare implications.

We hope that this overview encourages other researchers to use lab experiments in innovation research, which could be further developed in several domains of innovation research: as the existing laboratory studies on financial instruments measure effectiveness, future studies might focus on measuring efficiency, which would reflect promising progress in evaluating new means of public policy. Furthermore, lab experiments might be helpful as a methodological starting point for developing new policy instruments. 


\section{Acknowledgments}

Financial support from the German Federal Ministry of Education and Research via the HansBöckler-Stiftung is gratefully acknowledged. Further, we would like to thank Till Proeger for his very helpful comments.

\section{References}

Aghion, Philippe, Stefan Bechtold, Lea Cassar, and Holger Herz. 2014. "The causal effects of competition on innovation. Experimental evidence.” NBER Working Paper 19987.

Angrist, Joshua D. and Jörn-Steffen Pischke. 2010. "The credibility revolution in empirical economics. How better research design is taking the con out of econometrics.” Journal of Economic Perspectives, 24(2): 3-30.

Barmettler, Franziska, Ernst Fehr, and Christian Zehnder. 2012. "Big experimenter is watching you! Anonymity and prosocial behavior in the laboratory." Games and Economic Behavior, 75(1): 17-34.

Bator, Francis M. 1958. "The anatomy of market failure." The Quarterly Journal of Economics, 72(3): 351-79.

Blundell, Richard and Monica Costa Dias. 2009. "Alternative approaches to evaluation in empirical microeconomics.” The Journal of Human Resources, 44(3): 565-640.

Boockmann, Bernhard, Claudia M. Buch, and Monika Schnitzer. 2014. "Evidenzbasierte Wirtschaftspolitik in Deutschland. Defizite und Potentiale." Perspektiven der Wirtschaftspolitik, 15(4): 307-232.

Borrás, Susana and Charles Edquist. 2013. “The choice of innovation policy instruments." Technological Forecasting and Social Change, 80(8): 1513-22.

Bradler, Christiane. 2015. "How creative are you? An experimental study on self-selection in a competitive incentive scheme for creative performance.” ZEW Discussion Paper 15021.

Brüggemann, Julia. 2015. "The effectiveness of public subsidies for private innovations. An experimental approach.” cege Discussion Paper 266.

Brüggemann, Julia, Paolo Crosetto, Lukas Meub, and Kilian Bizer. 2015. "Intellectual property rights hinder sequential innovation. Experimental evidence.” cege Discussion Paper 227.

Brüggemann, Julia and Lukas Meub. 2015. "Experimental evidence on the effects of innovation contests.” cege Discussion Paper 251.

Buccafusco, Christopher and Christopher Sprigman. 2010. "Valuing intellectual property. An experiment." Cornell Law Review, 96(1): 1-46.

Buchanan, Joy A. and Bart J. Wilson. 2014. "An experiment on protecting intellectual property.” Experimental Economics, 17(4): 691-716.

Busom, Isabel. 2000. “An empirical evaluation of the effects of R\&D subsidies.” Economics of Innovation and New Technology, 9(2): 111-48.

Camerer, Colin F. and Robin M. Hogarth. 1999. "The effects of financial incentives in experiments. A review and capital-labor-production framework." Journal of Risk and Uncertainty, 19(1-3): 7-42. 
Cantner, Uwe, Werner Güth, Andreas Nicklisch, and Torsten Weiland. 2009. "Competition in product design. An experiment exploring innovation behavior." Metroeconomica, 60(4): 724-52.

Charness, Gary and Ernst Fehr. 2015. "From the lab to the real world." Science, 350(6260): 512-13.

Chatterji, Aaron K., Edward Glaeser, and William Kerr. 2013. "Clusters of entrepreneurship and innovation.” NBER Working Paper 19013.

Chetty, Raj. 2015. "Behavioral economics and public policy. A pragmatic perspective." American Economic Review: Papers and Proceedings, 105(5): 1-33.

COM (2014) 339. "Research and innovation as sources of renewed growth." (https://ec.europa.eu/research/innovation-union/pdf/state-of-the-union/2013/research-andinnovation-as-sources-of-renewed-growth-com-2014-339-final.pdf) last accessed on $14^{\text {th }}$ Dec. 2015.

Cooper, David J., John H. Kagel, Wei Lo, and Qing L. Gu. 1999. "Gaming against managers in incentive systems. Experimental results with Chinese students and Chinese managers.” The American Economic Review, 89(4): 781-804.

Crosetto, Paolo. 2010. “To patent or not to patent. A pilot experiment on incentives to copyright in a sequential innovation setting." In IFIP advances in information and communication technology, Open source software. New horizons. $6^{\text {th }}$ International IFIP WG 2.13 Conference on Open Source Systems, ed. Pär J. Ågerfalk, C. Boldyreff, J.M González-Barahona, G.R Madey, and J. Noll. Berlin, New York: Springer, 53-72.

Eckartz, Katharina, Oliver Kirchkamp, and Daniel Schunk. 2012. "How do incentives affect creativity?” CESifo Working Paper 4049.

Ederer, Florian and Gustavo Manso. 2012. "Is pay-for-performance detrimental to innovation?” Management Science, 59(7): 1496-513.

Erat, Sanjiv and Uri Gneezy. 2015. "Incentives for creativity." Experimental Economics: first published online.

Falck, Oliver, Simon Wiederhold, and Ludger Wößmann. 2013. "Innovationspolitik muss auf überzeugender Evidenz basieren.” ifo Schnelldienst, 66(5): 14-19.

Falk, Armin and James J. Heckman. 2009. "Lab experiments are a major source of knowledge in the social sciences.” Science, 326(5952): 535-38.

Harris, Christopher and John Vickers. 1987. "Racing with uncertainty." The Review of Economic Studies, 54(1): 1-21.

Herbst, Daniel and Alexander Mas. 2015. "Peer effects on worker output in the laboratory generalize to the field.” Science, 350(6260): 545-49.

Isaac, R. M. and Stanley S. Reynolds. 1988. "Appropriability and market structure in a stochastic invention model.” The Quarterly Journal of Economics, 103(4): 647-71.

Isaac, R. M. and Stanley S. Reynolds. 1992. "Schumpeterian competition in experimental markets.” Journal of Economic Behavior \& Organization, 17(1): 59-100.

Levitt, Steven D. and John A. List. 2007. "What do laboratory experiments measuring social preferences reveal about the real world?” Journal of Economic Perspectives, 21(2): 153-74.

Levitt, Steven D. and John A. List. 2008. "Homo economicus evolves." Science, 319(5865): 909-10. 
Madrian, Brigitte C. 2014. “Applying insights from behavioral economics to policy design.” Annual review of economics, 6: 663-88.

Mazzucato, Mariana, Mario Cimoli, Giovanni Dosi, Joseph E. Stiglitz, Michael A. Landesmann, Mario Pianta, Rainer Walz, and Tim Page. 2015. "Which industrial policy does Europe need?” Intereconomics, 50(3): 120-55.

Meloso, Debrah, Jernej Copic, and Peter Bossaerts. 2009. "Promoting intellectual discovery. Patents versus markets.” Science, 323(5919): 1335-39.

Sbriglia, Patrizia and John D. Hey. 1994. "Experiments in multi-stage R\&D competition.” Empirical Economics, 19(2): 291-316.

Silipo, Damiano B. 2005. "The evolution of cooperation in patent races. Theory and experimental evidence.” Journal of Economics, 85(1): 1-38.

Smith, Vernon L. 1994. "Economics in the laboratory.” Journal of Economic Perspectives, 8(1): 113-31.

Smith, Vernon L. 2003. "Constructivist and ecological rationality in economics." The American Economic Review, 93(3): 465-508.

Sørensen, Flemming, Jan Mattson, and Jon Sundbo. 2010. "Experimental methods in innovation research.” Research Policy, 39(3): 313-23.

Thomä, Jörg and Kilian Bizer. 2013. "To protect or not to protect? Modes of appropriability in the small enterprise sector.” Research Policy, 42(1): 35-49.

Vedung, Evert. 1998. "Policy instruments. Typologies and theories.” In Carrots, sticks \& sermons. Policy instruments \& their evaluation, ed. Marie-Louise Bemelmans-Videc, Ray C. Rist, and Evert Vedung. New Brunswick, NJ: Transaction Publishers, 21-58.

Weimann, Joachim. 2015. "Die Rolle von Verhaltensökonomik und experimenteller Forschung in Wirtschaftswissenschaft und Politikberatung." Perspektiven der Wirtschaftspolitik, 16(3): 231-52.

Zizzo, Daniel John. 2002. "Racing with uncertainty. A patent race experiment." International Journal of Industrial Organization, 20(6): 877-902.

Zúñiga-Vicente, José Á., César Alonso-Borrego, Francisco J. Forcadell, and José I. Galán. 2014. "Assessing the effect of public subsidies on firm R\&D investment. A survey.” Journal of Economic Surveys, 28(1): 36-67. 


\section{Danksagung}

Diese letzten Zeilen meiner Dissertation möchte ich nutzen, um denjenigen zu danken, die mich in den letzten drei Jahren begleitet, unterstützt und gefördert haben. Zuerst gilt mein Dank für die Betreuung Prof. Dr. Kilian Bizer, der mir viele Freiheiten ließ, mir jedoch wenn notwendig mit Rat und Tat zur Seite stand und mich dabei mit jeglicher Infrastruktur unterstützte. Auch danke ich Prof. Dr. Markus Spiwoks und Prof. Dr. Margarete Boos für ihre Betreuung der Arbeit. Verfasst habe ich diese Arbeit auf Basis eines Stipendiums, das mir von der Hans-Böckler-Stiftung und dem Bundesministerium für Bildung und Forschung im Rahmen des Promotionskollegs „Qualifikatorisches Upgrading in KMU“ gewährt wurde.

Allen Kollegen am Lehrstuhl für Wirtschaftspolitik und Mittelstandsforschung danke ich für ihre Kommentare bei den Doktorandenseminaren, abwechslungsreiche Mittagspausen und die kooperative Atmosphäre. Danken möchte ich auch Dennis Kotte und Sven Orzel für die nicht ganz einfache Programmierung meiner Experimente. Sowohl ihnen als auch den übrigen studentischen Hilfskräften vom Lehrstuhl für Wirtschaftspolitik und Mittelstandsforschung möchte ich für ihre Unterstützung bei der Durchführung der Experimente danken.

Bedanken möchte ich mich auch bei meinen Freunden, im Besonderen bei Johanna Kuhlmann, Wiebke Glässer und Miriam Bader-Gassner für die Gespräche über den Stand der Promotion. Mein Dank gilt auch meinen Freunden aus Holsten-Mündrup und der Umgebung, insbesondere den Lorbassen, die mich immer wieder das Unileben für eine Weile haben vergessen lassen.

Besonders bedanken möchte ich mich bei Paolo Crosetto, der mir so bereitwillig seine Experiment-Idee zur Verfügung gestellt hat. Durch die gemeinsame Arbeit habe ich in regelmäßigen Skype-Gesprächen und regen E-Mail Diskussionen viel gelernt und genauso viel gelacht. Des Weiteren möchte ich mich bei Lukas Meub für seine Stata-Expertise, die Zusammenarbeit und die Aufnahme in „sein“ Büro bedanken. Vor allem möchte ich mich bei Till Proeger für all das bedanken, was er zum Gelingen dieser Arbeit von Anfang an beigetragen hat. Dazu zählen neben des Zuspruchs das Diskutieren der Designs, Fragen zur Durchführung und schlussendlich die Korrektur und Verbesserung meiner Texte.

Abschließend möchte ich meinen Eltern Maria und Mathias und meinen beiden Brüdern Tobias und Michael von ganzem Herzen für ihren Rückhalt und ihr langjähriges Vertrauen in mich danken.

Göttingen, März 2016 